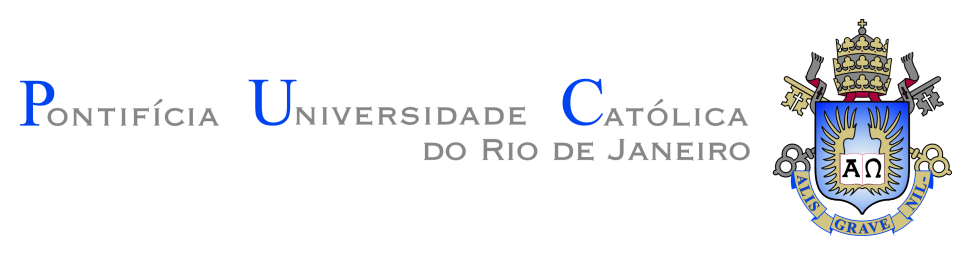

Renata Lorenzoni

\title{
Uso da microtomografia computadorizada para avaliação de danos na microestrutura de pasta de cimento submetida a carregamento cíclico e a temperaturas elevadas
}

Dissertação apresentada como requisito parcial para obtenção do grau de Mestre pelo Programa de Pós-graduação em Engenharia de Materiais e de Processos Químicos e Metalúrgicos do Departamento de Engenharia Química e de Materiais do Centro Técnico Científico da PUC-Rio.

Orientador

Prof. Sidnei Paciornik

Co-orientador: Prof. Flávio de Andrade Silva 
Renata Lorenzoni

\begin{abstract}
Uso da microtomografia computadorizada para avaliação de danos na microestrutura de pasta de cimento submetida a carregamento cíclico e

a temperaturas elevadas
\end{abstract}

Dissertação apresentada como requisito parcial para obtenção do grau de Mestre pelo Programa de Pós-graduação em Engenharia de Materiais e de Processos Químicos e Metalúrgicos do Departamento de Engenharia Química e de Materiais do Centro Técnico Científico da PUC-Rio. Aprovada pela Comissão Examinadora abaixo assinada.

Prof. Sidnei Paciornik

Orientador

Departamento de Engenharia Química e de Materiais PUC-Rio

Prof. Flávio de Andrade Silva

Co-orientador Departamento de Engenharia Civil - PUC-Rio

Dr. Marcos Henrique de Pinho Mauricio

Pontificia Universidade Católica do Rio de Janeiro - PUC-Rio

Prof. Otávio Gomes

Centro de Tecnologia Mineral - CETEM

Prof. Márcio da Silveira Carvalho

Cordenador Setorial de Pós Graduação - CTC - PUC-Rio

Rio de Janeiro, 09 de Agosto de 2017 
Todos os direitos reservados. É proibida a reprodução total ou parcial do trabalho sem autorização da universidade, do autor e do orientador.

\section{Renata Lorenzoni}

Formada em Engenharia Civil pela Universidade Feedral do Espírito Santo em 2013. Especializando-se nas áreas de: Ciência dos Materiais, Microscopia Digital e Processamento e Análise de Imagens.

Ficha Catalográfica

Lorenzoni, Renata

Uso da microtomografia computadorizada para avaliação de danos na microestrutura de pasta de cimento submetida a carregamento cíclico e a temperaturas elevadas / Renata Lorenzoni; orientador: Sidnei Paciornik; co-orientador: Flávio de Andrade Silva. - Rio de janeiro: PUC-Rio, Departamento de Engenharia Química e de Materiais , 2017.

v., 97 f: il. color. ; $30 \mathrm{~cm}$

Dissertação (mestrado) - Pontifícia Universidade Católica do Rio de Janeiro, Departamento de Engenharia Química e de Materiais .

Inclui bibliografia

1. Engenharia Química - Teses. 2. Engenharia de Materiais - Teses. 3. Durabilidade;. 4. Carregamento cíclico;. 5. Temperaturas elevadas;. 6. Microtomografia Computadorizada.. I. Paciornik, Sidnei. II. de Andrade Silva, Flávio . III. Pontifícia Universidade Católica do Rio de Janeiro. Departamento de Engenharia Química e de Materiais. IV. Título. 


\section{Agradecimentos}

Agradeço primeiramente a Deus por todas as bênçãos.

Aos meus pais por serem exemplos em minha vida e que com todo amor e carinho não mediram esforços para que eu chegasse até aqui. Aos familiares e amigos que sempre presentes incentivaram minhas escolhas, compreendendo as ausências, falta de tempo e cansaço.

Ao meu orientador Prof. Dr. Sidnei Paciornik, por me acolher em sua equipe e me ensinar, além dos inúmeros conhecimentos acadêmicos, a importância das relações pessoais na vida profissional.

Ao meu coorientador Prof. Dr. Flávio de Andrade Silva, por acreditar na ideia do projeto e se empenhar para que esse desse certo, sempre disponível para me ajudar nas dificuldades.

Ao Dr. Marcos Henrique de Pinho Mauricio pela ajuda nas microCT, passando seus conhecimentos sobre a técnica e indicando sugestões para o melhor uso dessa.

Ao Dr. Otávio Gomes por disponibilizar o laboratório do CETEM para a realização do ensaio de DRX e me orientar na análise dos dados. Ao técnico Josimar pela ajuda na preparação da amostra para esse ensaio.

Ao Prof. Dr. Bojan Marinkovic pela realização dos ensaios de DSC e TGA.

Aos técnicos de Laboratório de Estruturas e Materiais da PUC-Rio Euclides Neto, José Nilson de Melo e Rogério Daniel que, sempre muito dedicados, me ajudaram na realização dos ensaios.

Ao grupo de Microscopia Digital e Análise de Imagem pela ótima companhia diária e pelo trabalho em equipe, sempre solícitos um aos outros. Aos professores do mestrado que ministraram suas aulas com muita dedicação contribuindo para minha formação.

Ao CNPq, pelo apoio financeiro, e à PUC-Rio, pela bolsa de isenção de mensalidades do Mestrado. 


\section{Resumo}

Lorenzoni, Renata; Paciornik, Sidnei; de Andrade Silva, Flávio . Uso da microtomografia computadorizada para avaliação de danos na microestrutura de pasta de cimento submetida a carregamento cíclico e a temperaturas elevadas. Rio de Janeiro, 2017. 97p. Dissertação de Mestrado - Departamento de Engenharia Química e de Materiais , Pontifícia Universidade Católica do Rio de Janeiro.

A pasta de cimento classe $\mathrm{G}$ é muito utilizada nas operações de cimentação de poços de petróleo, sendo submetida a várias formas de deterioração, afetando sua durabilidade. Duas dessas formas de deterioração que ocorrem nos poços são por carregamento cíclico e temperaturas elevadas. Neste estudo, corpos de prova foram submetidos a ensaios de carregamento cíclicos de $30 \%, 50 \%$ e $70 \%$ das tensões de ruptura e a temperaturas elevadas de $100^{\circ} \mathrm{C}, 200^{\circ} \mathrm{C}, 450^{\circ} \mathrm{C}$ e $650^{\circ} \mathrm{C}$. A microtomografia computadorizada (microCT) foi utilizada para gerar imagens tridimensionais para observar a estrutura interna do material e, através de uma rotina computacional desenvolvida, avaliar qualitativa e quantitativamente a evolução de poros e fissuras após os ensaios. Primeiramente foi utilizado o software Fiji para aplicação de filtro de redução de ruído, em seguida as imagens de antes e depois dos ensaios são alinhadas com auxílio do software DataViewer. No software Dragonfly os vazios (poros e fissuras) das imagens são segmentadas e quantificados, apresentando o volume e esfericidade dos vazios de interesse. Os resultados dos ensaios de carregamento cíclico mostraram que submeter a $30 \%$ da tensão de ruptura quase não influencia na estrutura interna mas $50 \%$ e $70 \%$ causam danos significativos no material. Os corpos de prova submetidos a $100^{\circ} \mathrm{C}$ e $200^{\circ} \mathrm{C}$ apresentaram pequenas fissuras, mas a estrutura dos poros não mudou. No corpo de prova submetido a $450^{\circ} \mathrm{C}$ muitas fissuras foram observadas. Já no submetido a $650^{\circ} \mathrm{C}$ apresentou um elevado nível de degradação, impossibilitando a realização da microCT após o ensaio. Como conclusão, a pasta de cimento classe $G$ pode ser utilizada para operações com carregamentos cíclicos inferior a $30 \%$ da tensão de ruptura e inferior a temperaturas de $200^{\circ} \mathrm{C}$. Finalmente, a correlação de resultados de testes de DRX, DSC e TGA com as imagens obtidas das microCT mostraram que a desidroxilação do $\mathrm{Ca}(\mathrm{OH})_{2}$ e a degradação do $\mathrm{CaCO}_{3}$ causam alta deterioração para o material em estudo.

\section{Palavras-chave}

Durabilidade; Carregamento cíclico; Temperaturas elevadas; Microtomografia Computadorizada. 


\section{Abstract}

Lorenzoni, Renata; Paciornik, Sidnei (Advisor); de Andrade Silva, Flávio (Co-Advisor). Demage analysis in cement paste submitted to cyclic loading and elevated temperatures by $\mathrm{Mi}$ crocomputed Tomography. Rio de Janeiro, 2017. 97p. Dissertação de mestrado - Departamento de Engenharia Química e de Materiais , Pontifícia Universidade Católica do Rio de Janeiro.

Class G oil well cement is frequently used a in oil well cementing operation, which is subjected to various forms of deterioration, affecting its durability. Two of these forms of deterioration is due to cyclic loading and elevated temperatures. In the present study, cylindrical specimens were subjected to cyclic loading of 30,50 and $70 \%$ of the materials ultimate strength and to temperatures of $100^{\circ} \mathrm{C}, 200^{\circ} \mathrm{C}, 450^{\circ}$ and $650^{\circ} \mathrm{C}$ for one hour. Microcomputed tomography (microCT) was used to generate threedimensional images to visualize the internal structure of the material before and after the tests, and to quantitatively assess the evolution of pore structures and cracking by a computational routine developed. First, the FIJI software was used to reduce noises of images, then the images generated before and after the tests was aligned using the DataViewer software. In the Dragonfly software the voids (pores and fissures) of the images are segmented and quantified, showing the volume and sphericity of the voids of interest. The results of the cyclic load test showed that when the specimen was submitted to $30 \%$ of its ultimate strength almost no influence in the internal structure was observed. When the cyclic load was increased to $50 \%$ and $70 \%$ significant damage to the specimens was noticed. The results of the qualitative and quantitative analysis of the specimen submitted to $100^{\circ} \mathrm{C}$ and $200^{\circ} \mathrm{C}$ showed the appearance of small cracks, however, the pore structures did not change. In the specimen subjected to $450^{\circ} \mathrm{C}$ the appearance of several cracks was visualized. For the sample submitted to $650^{\circ} \mathrm{C}$ specimen was imposed to the material, making it impossible to visualize in the microCT. As a conclusion, the Class G Oil Well Cement Paste may be used for operations with cyclic loading up to $30 \%$ of the ultimate strength with service temperatures up to $200^{\circ} \mathrm{C}$. Finally, the dehydroxylation of $\mathrm{Ca}(\mathrm{OH})_{2}$ and degradation of $\mathrm{CaCO}_{3}$ led to high deterioration in this cement paste.

\section{Keywords}

Durability; Cyclic Load; Elevated Temperature; Microcomputed tomography. 


\section{Sumário}

1 Introdução $\quad 15$

2 Revisão da Literatura $\quad 17$

2.1 Motivação e Histórico 17

2.2 Durabilidade em Materiais Cimentícios 19

2.2.1 Carregamento Cíclico 22

2.2.2 Temperaturas Elevadas $\quad 27$

2.3 Uso da Tomografia para a Análise de Durabilidade em Material Cimentício 30

3 Materiais e Métodos 33

3.1 Moldagem do Corpo de Prova 33

3.2 Ensaio de Carregamento Cíclico 35

3.3 Ensaio de Temperaturas Elevadas 40

3.3.1 DRX 41

$\begin{array}{ll}\text { 3.3.2 DSC e TGA } & 42\end{array}$

3.4 MicroCT 43

3.4.1 Parâmetros de Aquisição das Imagens 45

3.4.2 Reconstrução das Imagens 46

3.5 Processamento e Análise Digital das Imagens 47

3.5.1 Pré-processamento e Processamento Digital das Imagens 47

3.5.2 Análise Digital das Imagens 54

4 Resultados e Discussões $\quad 55$

4.1 Ensaio de Carregamento Cíclico 55

4.1.1 Ensaio de Compressão em Corpos de Prova com Diferentes Idades 55

4.1.2 Ensaio de Compressão na máquina RTR-1500 Rapid Triaxial Rock 56

4.1.3 Análise de dano, microestrutura e correlação com propriedades mecânicas

4.1.3.1 CP $1-500.000$ ciclos a $30 \%$ da tensão de ruptura $\quad 58$

4.1.3.2 CP $2-1.000 .000$ ciclos a $30 \%$ da tensão de ruptura 64

4.1.3.3 CP 3 - 100.000 ciclos a $50 \%$ da tensão de ruptura 67

4.1.3.4 CP $4-500.000$ ciclos a $50 \%$ da tensão de ruptura $\quad 73$

4.1.3.5 CP 5 - 100.000 ciclos a $70 \%$ da tensão de ruptura 74

4.1.3.6 CP 6 - 500.000 ciclos a $70 \%$ da tensão de ruptura 78

4.2 Ensaio de Temperaturas Elevadas $\quad 79$

4.2.1 Ensaio de compressão em corpos de prova submetidos a diferentes temperaturas $\quad 79$

$\begin{array}{lll}\text { 4.2.2 DRX } & 82 \\ 4.2 .3 & \text { DSC e TGA }\end{array}$

4.2.3 DSC e TGA 83

4.2.4 Análise de dano, microestrutura e correlação com propriedades mecânicas

$\begin{array}{lll}4.2 .4 .1 & \mathrm{CP} 7-100^{\circ} \mathrm{C} & 84\end{array}$

4.2.4.2 CP $8-200^{\circ} \mathrm{C} \quad 86$ 
$\begin{array}{lll}\text { 4.2.4.3 CP } 9-450^{\circ} \mathrm{C} & 89\end{array}$

$\begin{array}{lll}4.2 .4 .4 \mathrm{CP} 10-650^{\circ} \mathrm{C} & 92\end{array}$

5 Conclusões $\quad 93$

6 Sugestão para Trabalhos Futuros $\quad 94$

$\begin{array}{ll}\text { Referências bibliográficas } & 95\end{array}$ 


\section{Lista de figuras}

Figura 2.1 Deterioração do concreto causada por esforços físicos, adaptado de Metha e Monteiro (5)

Figura 2.2 Comportamento típico do concreto submetido a carregamento cíclico, conforme Metha e Monteiro (5)

Figura 2.3 Curva S-N obtida experimentalmente e por ajuste linear, de acordo com Pang et al. (1)

Figura 2.4 Curva S-N de um concreto de agregado reciclado (RAC) com um concreto convencional (NAC) sob carregamento cíclico uniaxial de compressão, de acordo com Xiao et al. (15)

Figura 2.5 Curva S-N de um concreto de agregado reciclado (RAC) com um concreto convencional (NAC) sob carregamento cíclico de flexão, de acordo com Xiao et al. (15)

Figura 2.6 Imagens obtidas da MicoCT: (a) 0 e 650 ciclos; (b) 0 e 1365 ciclos e (c) 0 e 3065 ciclos para 40\%, 30\% e 20\% da tensão estática de ruptura, respectivamente, de acordo com Braz et al. (17)

Figura 2.7 Resposta térmica da pastas de cimento classe G conforme Zhu et al. (3)

Figura 2.8 Curva da DRX de acordo com Zhu et al. (3)

Figura 2.9 Imagens obtidas da microCT. Fissuras desenvolvidas a partir dos poros em pesquisa de Kim et al. (18)

Figura 2.10 Imagem original com seu respectivo histograma e imagem binária após segmentação, de acordo com Lu et al. (19)

Figura 2.11 Curva tensão-deformação conforme Jung et al. (21)

Figura 2.12 Vazios em 3D: (a) antes do carregamento, (b) após o carregamento de $90 \%$, conforme Jung et al. (21)

Figura 3.1 Procedimento de mistura da pasta de cimento: (a) misturador; (b) recipiente da mistura; (c) forma de PVC.

Figura 3.2 Ensaio de compressão uni-axial: (a) máquina MTS 810; (b) extensômetro; (c) corpo de prova instrumentado na máquina MTS 810.

Figura 3.3 (a) máquina RTR-1500 Rapid Triaxial Rock da GCTS Testing System; (b) corpo de prova instrumentado na máquina RTR-1500.

Figura 3.4 Gráfico Tensão x Tempo do ensaio de carregamento cíclico do corpo de prova 1.

Figura 3.5 Mufla utilizada no ensaio de temperaturas elevadas.

Figura 3.6 Preparação de amostra: (a) moinho de bolas; (b) amostrador rotativo; (c) DRX.

Figura 3.7 MicroCT XRadia 510 Versa.

Figura 3.8 MicroCT: fonte de raios X, porta amostras, detector e conjunto de lentes ópticas.

Figura 3.9 Imagens do corpo de prova antes da eliminação das partes inferior e superior. 
Figura 3.10 Imagens antes e depois da aplicação do filtro Non-local Mean no software Fiji.

Figura 3.11 Parâmetros DataViewer.

Figura 3.12 Imagens sobrepostas antes e depois do alinhamento no DataViewer.

Figura 3.13 Segmentação da pasta cimentícia com o "Threshold"de 140.

Figura 3.14 Segmentação antes e depois do ensaio com o mesmo valor de corte.

Figura 3.15 Seleção da pasta de cimento: (a) antes do ensaio com o valor de corte de 145; (b) depois do ensaio com o valor de corte de 145; (c) depois do ensaio com o valor de corte de 180.

Figura 3.16 Seleção da pasta de cimento e vazios: (a) aplicação do comando "fill inner areas"; (b) aplicação do comando "fill inner areas"e "close".

Figura 3.17 Segmentação de poros e fissuras.

Figura 3.18 Poros com os dados de esfericidade e volume.

Figura 4.1 Curva Tensão x Deformação dos CP A e B e as respectivas retas tangente à zona elástica.

Figura 4.2 Comparação de curvas Tensão x Deformação de ensaios realizados: (a) na máquina Material Test System (MTS) 810 e; (b) na máquina RTR-1500 Rapid Triaxial Rock.

Figura 4.3 Ajuste linear das curvas Tensão x Deformação dos corpos de prova A e B.

Figura 4.4 Seção do corpo de prova: (a) antes do ensaio cíclico de 500.000 ciclos a $30 \%$ da tensão de ruptura; (b) depois do ensaio com detalhe em zoom.

Figura 4.5 Poros em 3D: (a) antes do ensaio de 500.000 ciclos a 30\% da tensão de ruptura; (b) depois do ensaio; (c) sobreposição de (a) e (b).

Figura 4.6 Esfericidade dos Poros em 3D: (a) antes do ensaio de 500.000 ciclos a 30\% da tensão de ruptura; (b) depois do ensaio.

Figura 4.7 Curva de histerese do ensaio cíclico de 500.000 ciclos a

$30 \%$ da tensão de ruptura.
Figura 4.8 Seção do corpo de prova: (a) antes do ensaio cíclico de 1.000.000 ciclos a 30\% da tensão de ruptura; (b) depois do ensaio. 64

Figura 4.9 Poros em 3D: (a) antes do ensaio de 1.000.000 ciclos a $30 \%$ da tensão de ruptura; (b) depois do ensaio; (c) sobreposição de (a) e (b).

Figura 4.10 Esfericidade dos Poros em 3D depois do ensaio de 1.000 .000 ciclos a $30 \%$ da tensão de ruptura.

Figura 4.11 Curva de histerese do ensaio cíclico de 1.000 .000 ciclos a $30 \%$.

Figura 4.12 (a) Poros em 3D antes do ensaio de 100.000 ciclos a 50\% da tensão de ruptura; (b) Poros e fissura em 3D depois do ensaio; (c) Poros em 3D depois do ensaio; (d) Fissura em 3D depois do ensaio. 
Figura 4.13 Histograma dos tons das imagens de antes e depois do ensaio de 100.000 ciclos a $50 \%$ da tensão de ruptura.

Figura 4.14 Esfericidade dos Poros e Fissura em 3D: (a) antes do ensaio de 100.000 ciclos a $50 \%$ da tensão de ruptura; (b) depois do ensaio.

Figura 4.15 Poros que se conectaram a fissura que surgiu no ensaio de 100.000 ciclos a $50 \%$ da tensão de ruptura.

Figura 4.16 Curva de histerese do ensaio cíclico de 100.000 ciclos a $50 \%$.

Figura 4.17 Curva de histerese do ensaio cíclico a 50\%.

Figura 4.18 Seção do corpo de prova: (a) antes do ensaio cíclico de 100.000 ciclos a $70 \%$ da tensão de ruptura; (b) depois do ensaio. 74

Figura 4.19 (a) Poros e fissura em 3D antes do ensaio de 100.000 ciclos a $70 \%$ da tensão de ruptura; (b) Poros e fissura em 3D depois do ensaio; (c) Poros em 3D depois do ensaio; (d) Fissura em 3D depois do ensaio.

Figura 4.20 Histograma dos tons das imagens de antes e depois do ensaio de 100.000 ciclos a $70 \%$ da tensão de ruptura.

Figura 4.21 Esfericidade dos Poros e Fissura em 3D: (a) antes do ensaio de 100.000 ciclos a $70 \%$ da tensão de ruptura.; (b) depois do ensaio.

$\begin{array}{ll}\text { Figura 4.22 Curva de histerese do ensaio cíclico a } 70 \% \text {. } & 77\end{array}$

$\begin{array}{ll}\text { Figura 4.23 Curva de histerese do ensaio cíclico a } 70 \% . & 79\end{array}$

Figura 4.24 Variação de $\sigma_{r}$ com o aumento de temperatura. $\quad 80$

Figura 4.25 Curva Tensão x Deformação com o aumento de temperatura.

Figura 4.26 Resultado do ensaio de DRX.

Figura 4.27 Resultado das análises térmicas.

Figura 4.28 Superfície do corpo de prova: (a) antes do ensaio de temperatura elevada de $100^{\circ} \mathrm{C}$; (b) depois do ensaio.

Figura 4.29 Seção do corpo de prova: (a) antes do ensaio de temperatura elevada de $100^{\circ} \mathrm{C}$; (b) depois do ensaio.

Figura 4.30 Sobreposição dos poros em 3D de antes e depois do ensaio de temperatura elevada de $100^{\circ} \mathrm{C}$.

Figura 4.31 Esfericidade dos Poros em 3D depois do ensaio de temperatura elevada de $100^{\circ} \mathrm{C}$.

Figura 4.32 Superfície do corpo de prova: (a) antes do ensaio de temperatura elevada de $200^{\circ} \mathrm{C}$; (b) depois do ensaio.

Figura 4.33 Seção do corpo de prova: (a) antes do ensaio de temperatura elevada de $200^{\circ} \mathrm{C}$; (b) depois do ensaio.

Figura 4.34 Sobreposição dos poros em 3D de antes e depois do ensaio de temperatura elevada de $200^{\circ} \mathrm{C}$.

Figura 4.35 Esfericidade dos Poros em 3D depois do ensaio de temperatura elevada de $200^{\circ} \mathrm{C}$.

Figura 4.36 Superfície do corpo de prova: (a) antes do ensaio de temperatura elevada de $450^{\circ} \mathrm{C}$; (b) depois do ensaio. 
Figura 4.37 (a) Poros em 3D antes do ensaio de temperatura elevada de $450^{\circ} \mathrm{C}$; (b) Poros e fissura em 3D depois do ensaio; (c) Poros em 3D depois do ensaio; (d) Fissura em 3D depois do ensaio.

Figura 4.38 Histograma dos tons das imagens de antes e depois do ensaio de temperatura elevada de $450^{\circ} \mathrm{C}$.

Figura 4.39 Corpo de prova após ser submetido a $650^{\circ} \mathrm{C}$. 


\section{Lista de tabelas}

Tabela 2.1 Porosidade para diferentes tensões de carregamentos cíclicos.(16)

Tabela 3.1 Composição química do cimento classe G. (22)

Tabela 3.2 Idade dos corpos de prova utilizados nos ensaios de compressão uni-axial estático e de carregamento cíclico (Dias). $\quad 37$

Tabela 3.3 Ensaio de Carregamento Cíclico. 38

Tabela 3.4 Ensaio de Temperaturas Elevadas. 40

Tabela 3.5 Procedimento da captura da imagem no microCT 44

Tabela 3.6 Parâmetros de aquisição. $\quad 45$

Tabela 3.7 Parâmetro tempo de exposição(s) . 45

Tabela 3.8 Parâmetros da Reconstrução das Imagens. 46

Tabela 4.1 Resultados de tensão de ruptura (MPa) dos ensaios de compressão em corpos de prova diferentes idades. $\quad 55$

Tabela 4.2 Inclinações (GPa) das curvas Tensão x Deformação dos corpos de prova A e B.

Tabela 4.3 Tensões de ruptura (MPa) dos corpos de prova de referência para os CP 1 e 2.

Tabela 4.4 Número e volume de poros antes e depois do ensaio de 500.000 ciclos a $30 \%$.

Tabela 4.5 Número e volume de poros antes e depois do ensaio de 500.000 ciclos a $30 \%$ eliminando poros de até 9 voxels.

Tabela 4.6 Porosidade antes e depois do ensaio de 500.000 ciclos a $30 \%$.

Tabela 4.7 Resultado quantitativo do ensaio de 1.000 .000 ciclos a $30 \%$.

Tabela 4.8 Tensões de ruptura (MPa) dos corpos de prova de referência para os CP 3 e 4 .

Tabela 4.9 Resultado quantitativo do ensaio de 100.000 ciclos a $50 \%$.

Tabela 4.10 Tensões de ruptura (MPa) dos corpos de prova de referência para os CP 5 .

Tabela 4.11 Resultado quantitativo do ensaio de 100.000 ciclos a $70 \%$.

Tabela 4.12 Tensões de ruptura (MPa) dos corpos de prova de referência para os CP 6 .

Tabela 4.13 Resultados das tensões de ruptura $\left(\sigma_{r}\right)$ dos ensaios de compressão para diferentes temperaturas.

Tabela 4.14 Módulo de elasticidade (GPa) com o aumento da temperatura.

Tabela 4.15 Resultado quantitativo do corpo de prova submetido a $100^{\circ} \mathrm{C}$.

Tabela 4.16 Resultado quantitativo do corpo de prova submetido a $200^{\circ} \mathrm{C}$. 
Lista de tabelas

Tabela 4.17 Resultado quantitativo do corpo de prova submetido a $450^{\circ} \mathrm{C}$. 


\section{Introdução}

As propriedades de um material variam ao longo de sua vida útil devido à interação com o meio ambiente. Essas variações dizem sobre a sua durabilidade. Diversas são as formas de interação do material com o meio que comprometem suas propriedades e causam sua degradação. Submeter o material a carregamento cíclico ou temperaturas elevadas são maneiras de afetar a durabilidade do material.

O cimento classe $G$, também conhecido na norma brasileira (NBR 9831) como cimento para poços petrolíferos (CPP), é utilizado no Brasil exclusivamente para cimentação de poços de petróleo. Na etapa de cimentação, a pasta preenche o espaço anular do poço entre os tubos e a parede da formação, com o objetivo de suportar as altas pressões presentes na formação, além de sustentar a tubulação. Os poços de petróleo são normalmente mantidos durante muitos anos, por isso é de suma importância o estudo, além das suas propriedades mecânicas, da durabilidade dessa pasta de cimento.

Nas fases de perfuração e produção do poço de petróleo, a pasta de cimento é submetida à vibrações das operações rotineiras e das mudanças de pressão e temperatura que ocorrem frequentemente, causando danos por esforços de carregamento cíclico no material. Também estão constantemente submetidas as altas temperaturas em que se encontram os poços de petróleo.

O método de caracterização não destrutivo de microtomografia computadorizada (microCT - microcomputed tomography) vem sendo muito utilizado para estudo da durabilidade de materiais. O princípio básico da microCT é a atenuação de um feixe de raios X quando atravessa a amostra. Como a atenuação dos raios X está relacionada com a densidade e com o número atômico do material, diferentes materiais irão gerar diferentes tons na imagem. No caso de uma amostra de pasta de cimento, duas fases são identificadas: a pasta e os vazios. Desta forma, é possível obter informações sobre o posicionamento e a forma tridimensional (3D) de alguma característica do objeto inspecionado. No caso do presente estudo o foco é a durabilidade e a característica de interesse é a evolução ou aparecimento de poros e fissuras. 
O objetivo geral deste trabalho foi de desenvolver uma rotina computacional para a caracterização de um material cimentício submetido a ensaios que simulem esforços que afetam sua durabilidade. As propriedades mecânicas desse material quando submetido a carregamento cíclico e a temperaturas elevadas foram analisadas como objetivos específicos.

O trabalho foi dividido em revisão bibliográfica, materiais e métodos, resultados e conclusões e sugestões de trabalhos futuros. A revisão bibliográfica apresenta trabalhos anteriores sobre a durabilidade de materiais cimentícios, enfatizando quando submetido a carregamentos cíclicos e temperaturas elevadas, e sobre a utilização da microCT para caracterização desse material. No capítulo seguinte os materiais utilizados e metodologia desenvolvida foram apresentados, seguido dos resultados dos ensaios mostrados na metodologia. Por fim, a conclusão da eficácia ou não da rotina desenvolvida é comentada, sugerindo melhorias para trabalhos futuros. 


\section{2}

\section{Revisão da Literatura}

\section{1}

\section{Motivação e Histórico}

Esta pesquisa tem como objetivo geral elaborar um padrão de investigação da microestrutura de um material cimentício submetido a um ensaio de carregamento cíclico e a temperaturas elevadas. Este ensaio causa deterioração no concreto, afetando a sua durabilidade. A durabilidade é a capacidade do material de resistir à ação das intempéries conservando sua forma original, qualidade e capacidade de utilização. As formas mais comuns de analisar a durabilidade são expor o concreto a altas ou baixas temperaturas, carregamento cíclico ou ataque químico. Assim, ensaios que simulam estes esforços são realizados em corpos de prova de materiais cimentícios com o objetivo de estudar sua durabilidade.

Muitas estruturas de material cimentício são projetadas para suportar esforços de carregamento cíclico. As pontes, por exemplo, estão submetidas à passagem de veículos constantemente, causando carregamento e descarregamento inúmeras vezes ao longo de sua vida útil. A pasta de cimento utilizada entre os pré-moldados e a rocha na construção de túneis também está submetida a esforços cíclicos, uma vez que a tuneladora provoca vibrações durante a escavação. Outro exemplo foi estudado por Pang et al. (1) em uma pesquisa da fadiga em cimentos destinados para poços de petróleo. Para eles, esta pesquisa tem importância pois a pasta de cimento, que preenche o espaço anular do poço entre os tubos e a parede da formação, está submetida a vibrações provocadas pelas operações rotineiras nas fases de perfuração e produção do poço, além das mudanças de pressão e temperatura que ocorrem frequentemente, que também são responsáveis por danos por fadiga.

Pesquisas sobre carregamento cíclico em pasta de cimento são menos comuns quando comparadas com pesquisas do mesmo tipo em concreto. Raju (2) elabora uma pesquisa comparando a fadiga em um concreto, uma argamassa e uma pasta de cimento e conclui que, para carregamentos abaixo de $80 \%$ da carga de ensaio de carregamento estático, o desempenho da pasta 
de cimento é melhor que a da argamassa e que a da argamassa é melhor que a do concreto. Ou seja, que materiais mais homogêneos são mais resistentes à fadiga.

Apesar disso, neste estudo queremos entender como ocorre a fissuração no elemento fundamental do concreto, que é a pasta de cimento. Além do mais, é o ideal para casos em que a estrutura é de fato uma pasta de cimento, como em construções de túneis e cimentação de poços de petróleo. Outra razão para a escolha da pasta de cimento e não do concreto é a da facilidade de utilizar a microCT em amostras menores obtendo melhores resoluções. Para confecção de amostras pequenas, a utilização de agregado graúdo se torna inviável.

Algumas estruturas cimentícias estão submetidas, além de carregamento cíclico, a altas temperaturas. É o caso de pesquisas como as de Zhu et al. (3) e Jingfua et al. (4) cujo objetivo principal foi observar o decaimento da tensão de ruptura com o incremento da temperatura de amostras de pastas de cimento classe $\mathrm{G}$, utilizadas em poços de petróleo. Isso mostra que a exposição da pasta de cimento a temperaturas elevadas é corriqueira quando utilizadas para cimentação de poços de petróleo.

O padrão para uma análise desse tipo é caracterizar o material antes e depois de submetido ao ensaio, e para isso será utilizado o método de caracterização não destrutiva da microtomografia computadorizada. A tomografia computadorizada é utilizada na medicina desde o início da década de 70, mas para caracterização de materiais só veio ser utilizada na década de 80, já como microCT, e por isso é considerada uma ferramenta relativamente nova. Seu princípio básico é a atenuação de um feixe de raios $\mathrm{X}$ quando atravessa a amostra. Como a atenuação dos raios X está relacionada com a densidade e com o número atômico do material, diferentes materiais irão gerar diferentes tons na imagem. No caso de uma amostra de pasta de cimento, duas fases de interesse são identificadas: a pasta e os vazios.

Dessa forma, a microCT possibilita obter informações sobre o posicionamento e a forma tridimensional (3D) de alguma característica do objeto inspecionado. No caso do estudo da durabilidade, a característica de interesse é a evolução ou aparecimento de poros e fissuras. 


\section{2 \\ Durabilidade em Materiais Cimentícios}

"De acordo com a ACI Commitee 201, a durabilidade do concreto de cimento Portland é definida como a habilidade que este tem de resistir a ação do tempo, ataque químico, abrasão, ou qualquer outro processo de deterioração. Em outras palavras, o concreto durável irá manter sua forma original, qualidade e capacidade de utilização quando exposto ao ambiente”. (5)

Para Hewlett (6) o concreto é utilizado para muitos propósitos e, por isso, existem situações em que devem ser tomadas precauções para fornecer proteção contra agentes potencialmente destrutivos. Devido a essa versatilidade de utilizações do concreto, muitas pesquisas de campo e de laboratórios foram feitas no último século com o intuito de analisar o seu desempenho quando exposto a agentes agressivos. Os resultados dessas pesquisas mostraram que a qualidade do concreto está prioritariamente relacionada com a capacidade deste resistir aos agentes, ou seja, com a sua durabilidade, e não necessariamente com a capacidade de resistência aos esforços mecânicos. Para um determinado concreto, quanto menor sua permeabilidade maior será sua durabilidade. Além disso, como os fatores que influenciam na diminuição da permeabilidade também apresentam efeitos positivos na resistência a esforços mecânicos, é provável que, para um mesmo concreto, a durabilidade esteja diretamente relacionada com a resistência mecânica.

Um exemplo desses estudos foi a pesquisa feita por Lécolier et al. (7), que analisaram a durabilidade de uma pasta de cimento utilizada em poços de petróleo. Como foi visto, a pasta de cimento destinada a esta estrutura sofre com alguns esforços que afetam sua durabilidade. Nessa pesquisa em específico foram levados em consideração apenas os esforços estáticos de exposição da pasta a temperaturas e pressões elevadas e a água do mar. Para isso, foi estabelecido um protocolo de envelhecimento das amostras simulando condições a que esta pasta estaria submetida. A resistência à compressão, a permeabilidade e a porosidade foram acompanhadas durante o experimento a fim de analisar a sua durabilidade. Eles concluíram que, após um ano de ensaio, as propriedades mecânicas diminuíram cerca de $20 \%$. Mas, não foi observada nenhuma dissolução ou precipitação que poderiam ter levado à degradação macroscópica das propriedades da pasta. Apesar das dificuldades de simular uma situação similar às condições reais no fundo do poço, pôde-se concluir que sua durabilidade foi afetada, uma vez que a perda de resistência mecânica está diretamente relacionada com a durabilidade. 
É comum encontrar pesquisas sobre a durabilidade de concreto destinado à utilização em redes de esgoto, que estão constantemente expostos a microorganismos que causam reações químicas no concreto e, por consequência, levam a sua deterioração. Fisher et al. (8) compararam a durabilidade de um concreto reforçado com fibra de celulose e um concreto armado convencionalmente utilizado em tubulações de esgoto. Frustradas as expectativas, eles concluíram que o concreto armado tradicionalmente utilizado apresentou melhor desempenho. Binici at al. (9) investigaram a influência da adição de escória de alto forno e utilização de basalto como agregado fino na durabilidade do concreto destinado para tubulação de esgoto. De um modo geral, a adição desses materiais contribuiu positivamente para a durabilidade do concreto.

Há muitos outros ambientes em que o concreto pode estar exposto a ataques químicos e, por isso, são corriqueiras as pesquisas relacionadas a ataques de sulfatos ou outros elementos químicos sem especificar a destinação do concreto. Roziere et al. (10) analisaram a durabilidade do concreto exposto a lixiviação e a ataque por sulfatos, e concluíram que a resistência do concreto é afetada quando exposto a esses dois tipos de ambientes agressivos. Merida et al. (11) estudaram o uso de pozolanas em concretos expostos a ataques por sulfatos e confirmaram que a substituição parcial do cimento por pozolanas contribui positivamente para a durabilidade de um material cimentício.

Os países em que ocorrem temperaturas extremamente baixas durante alguma época do ano enfrentam problemas causados pelos ciclos de gelo e degelo dentro do concreto, afetando sua durabilidade. Em 1999, Sun et al. (12) avaliaram a resistência a deterioração de um concreto de alta resistência submetido a ciclos de gelo e degelo, concluindo que o incremento do número de ciclos de gelo e degelo acarretam em perda de módulo de elasticidade e de resistência e aceleração no processo de deterioração. Os autores mostraram que a adição de fibras de aço ou incorporação de ar melhora a capacidade do concreto de resistir à deterioração.

Estudos sobre durabilidade do concreto envolvendo mais de um meio deteriorante são comuns, uma vez que é comum encontrar na prática estruturas de concreto expostas a um ambiente com diversos fatores agressivos. Por exemplo, Jiang et al. (13) estudaram a durabilidade do concreto submetido a ataques de sulfatos e a ciclos de gelo e degelo, conjuntamente. Essa pesquisa se justificou pelo fato do noroeste da China possuir muitos locais com o solo rico em sulfato e diversos lagos salgados, e ser um local frio. 
Pela diversidade de pesquisas feitas a fim de estudar a durabilidade de um material cimentício, podemos observar que existem diversas maneiras de deteriorar o concreto com o objetivo de analisar essa durabilidade. De acordo com Metha e Monteiro (5) a deterioração do concreto pode ser causada por reações químicas ou por esforços físicos. Na presente pesquisa a durabilidade da pasta de cimento será analisada pela deterioração por esforços físicos através do carregamento cíclico e exposição a altas temperaturas, conforme apresentado na figura 2.1.

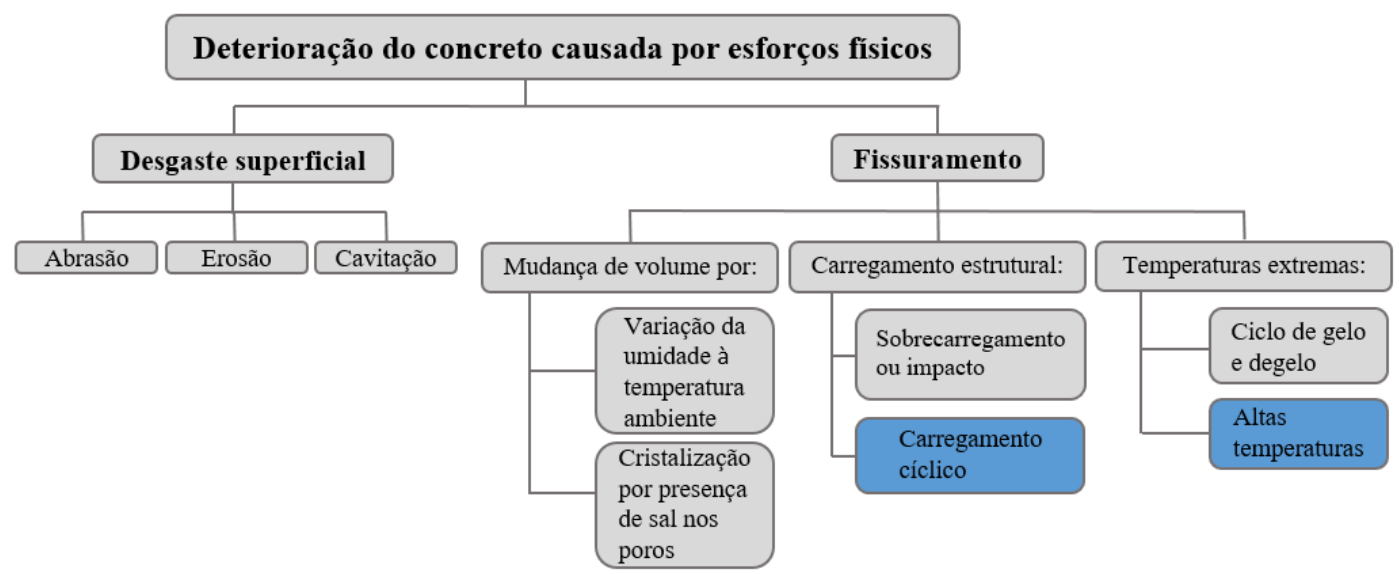

Figura 2.1: Deterioração do concreto causada por esforços físicos, adaptado de Metha e Monteiro (5)

As pesquisas até agora citadas neste tópico utilizaram métodos de determinação de permeabilidade, porosidade e/ou resistência mecânica para a análise da durabilidade do material cimentício. Existem outras maneiras de se analisar a deterioração de um material cimentício, como, por exemplo, analisar o aparecimento de fissuras ou o crescimento das fissuras existentes. Zijl et al. (14) dizem que para caracterizar a formação de fissuras e, consequentemente, sua durabilidade, pode-se medir fissuras através de processamento digital de imagem ou correlação digital de imagens e que esses dois métodos têm resultado em medidas precisas das fissuras. Eles analisaram o desenvolvimento de fissuras de um compósito à base de cimento com o intuito de obter uma formulação para a concepção da durabilidade desse material cimentício. Para isso, utilizaram imagens de uma câmera fotográfica. Outros equipamentos podem ser utilizados para gerar imagens, como, por exemplo, microscópios ou microCT. 


\subsection{1}

\section{Carregamento Cíclico}

Uma estrutura submetida a carregamento cíclico pode ser simulada, para fins de pesquisa, através de ensaio uniaxial com carregamento cíclico. O ensaio de carregamento cíclico é um ensaio no qual o corpo de prova é submetido a um carregamento máximo e mínimo, completando um ciclo, em uma determinada frequência.

Segundo Metha e Monteiro (5) o incremento do número de ciclos em uma estrutura causa uma microfissuração progressiva na zona de transição interfacial e na matriz, levando à falha do material a uma tensão menor do que a tensão de ruptura do ensaio estático. Ensaios de carregamento cíclico com tensão entre $50 \%$ e $75 \%$ da tensão de ruptura causam uma degradação gradual no módulo de elasticidade. Por isso, a curva de descarregamento apresenta uma não-linearidade e um ciclo de histerese é formado. Assim, o comportamento típico do concreto submetido a carregamento cíclico é aquele conforme mostrado na figura 2.2. Metha e Monteiro (5) também dizem que a curva de tensão-deformação do ensaio de carregamento estático serve razoavelmente como um envelope para os valores de pico de tensão do ensaio cíclico.

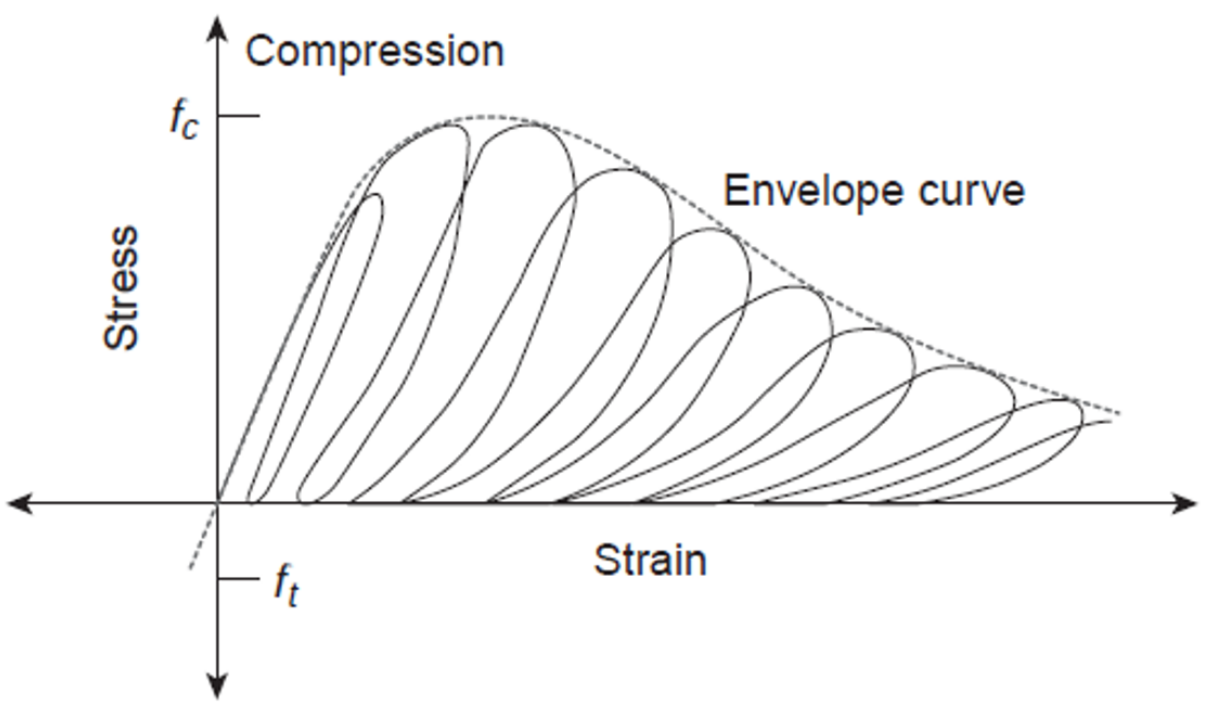

Figura 2.2: Comportamento típico do concreto submetido a carregamento cíclico, conforme Metha e Monteiro (5) 
Pelo fato de muitas estruturas de material cimentício serem projetadas para suportar esforços de carregamento cíclico, muitos estudos sobre a durabilidade do concreto analisada através da deterioração por carregamento cíclico são encontrados. Uma maneira de fazer essa análise é submeter o concreto ao ensaio de fadiga, que nada mais é que o ensaio de carregamento cíclico até a ruptura do material. A partir desse ensaio uma curva S-N é obtida, que apresenta a tensão máxima aplicada no ensaio versus o números de ciclos até a fadiga. A curva $\mathrm{S}-\mathrm{N}$ pode ser utilizada para comparar diferentes tipos ou formulações de concreto. Aquele que apresentar maior números de ciclos até a fadiga para uma mesma porcentagem da carga de ruptura de ensaio estático, terá uma maior resistência a fadiga e, consequentemente, maior durabilidade.

$\mathrm{Na}$ pesquisa de Pang et al. (1), sobre fadiga em pastas de cimentos destinados para poços de petróleo, dez diferentes formulações de amostras foram preparadas, variando fatores como a relação água/cimento, inclusão de aditivos como sílica, cinza volante e fibras de vidro. Os ensaios de fadiga foram realizados utilizando uma frequência de $1 \mathrm{~Hz}$ e gráficos da curva S$\mathrm{N}$ foram gerados. Na figura 2.3 está representado um desses gráficos obtido para uma das formulações. Foi feito o ajuste considerando todas as amostras ensaiadas e também desconsiderando as que tiveram valores discrepantes. Estes gráficos foram utilizados para comparar as diferentes formulações. Os autores mostram que, apesar de indícios que a resistência a fadiga aumenta com a homogeneidade e densidade, o incremento dessa resistência foi muito pequena. O que eles puderam afirmar com essa pesquisa foi que nenhum dos fatores estudados têm influência significativa na resistência à fadiga da pasta de cimento de poço de petróleo.

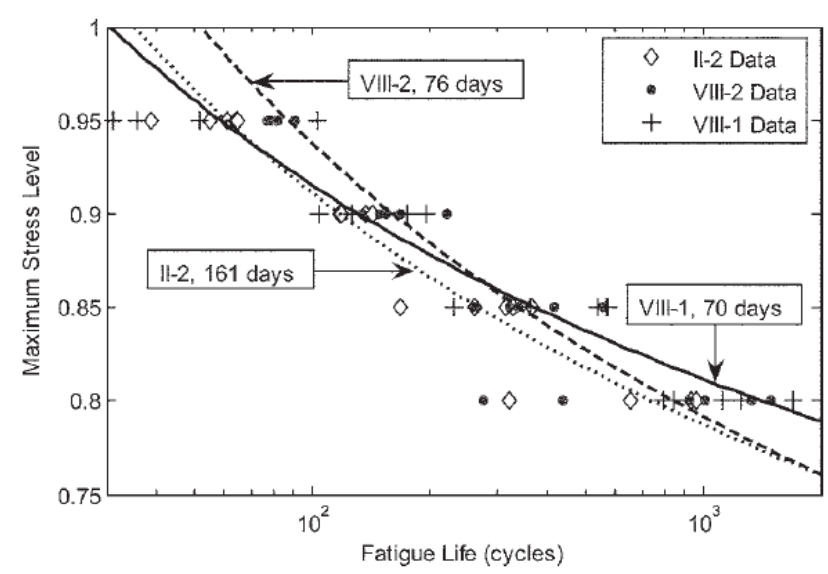

Figura 2.3: Curva S-N obtida experimentalmente e por ajuste linear, de acordo com Pang et al. (1) 
Xiao et al. (15) compararam um concreto de agregado reciclado com um concreto convencional, ambos submetidos a ensaios de fadiga sob carga cíclica de compressão e de flexão. Nos ensaios cíclicos de carregamento uniaxial de compressão, fixaram a carga mínima em $10 \%$ da carga da tensão estática de ruptura e variaram a carga máxima em 85\%, 80\%,75\%,70\% e 65\%, todos os ensaios a uma frequência de $10 \mathrm{~Hz}$. As amostras submetidas a $65 \%$ da carga de ruptura não romperam após três milhões de ciclos e os ensaios foram interrompidos. A curva S-N obtidas estão apresentados na figura 2.4, e observase que a vida de fadiga do concreto de agregado reciclado é maior que a do concreto convencional. Já no ensaio cíclico de flexão os resultados foram o contrário, como é observado na curva S-N da figura 2.5. Esses resultados podem ser explicados pela maior facilidade de iniciar ou desenvolver um poro ou uma fissura sob tensão de flexão do que sob tensão de compressão. Novas pesquisas precisariam ser feitas para explicar melhor o porquê do resultado do teste de fadiga sob carga de compressão.

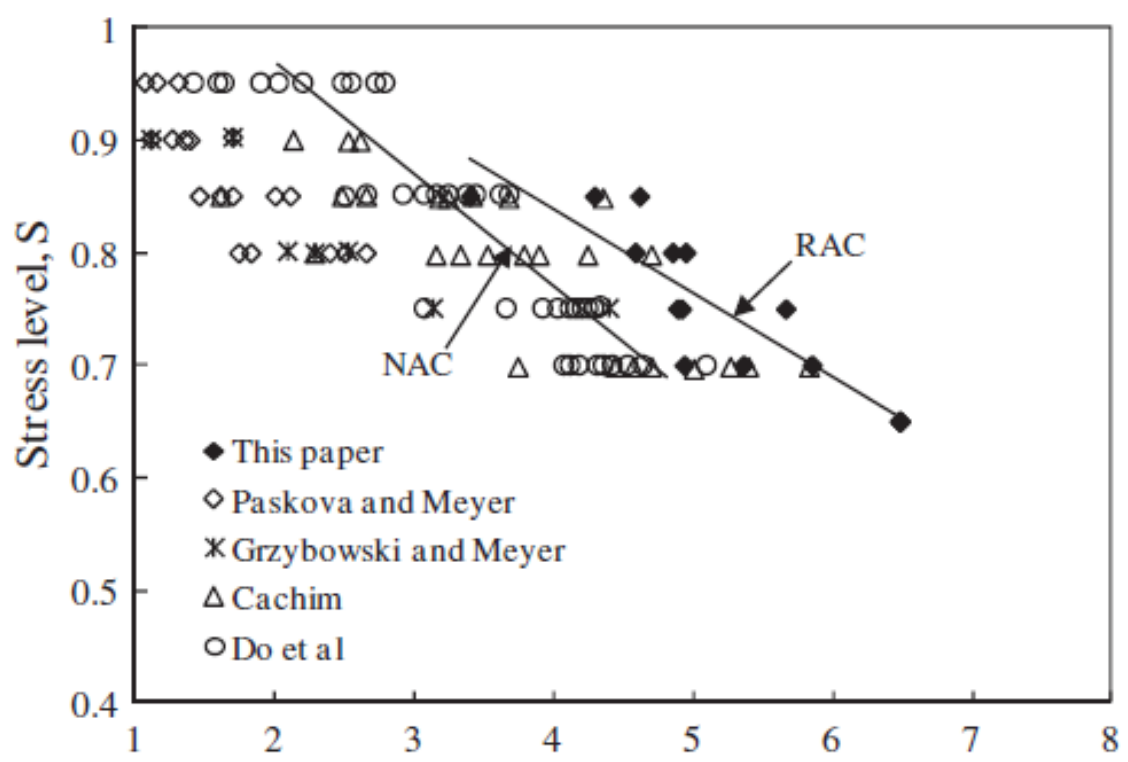

Fatigue life, $\lg \mathrm{N}_{\mathrm{f}}$

Figura 2.4: Curva S-N de um concreto de agregado reciclado (RAC) com um concreto convencional (NAC) sob carregamento cíclico uniaxial de compressão, de acordo com Xiao et al. (15) 


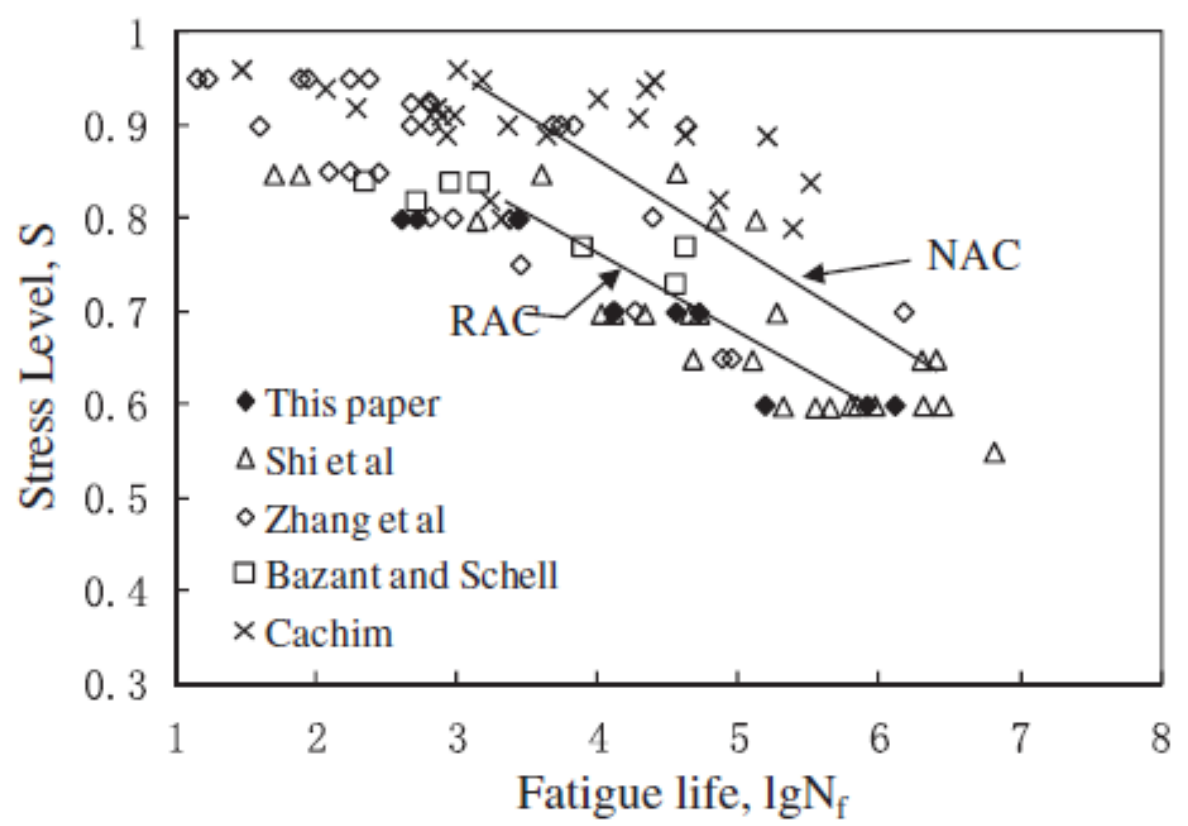

Figura 2.5: Curva S-N de um concreto de agregado reciclado (RAC) com um concreto convencional (NAC) sob carregamento cíclico de flexão, de acordo com Xiao et al. (15)

JIANG et al. (16) realizaram uma pesquisa na qual analisaram a influência do carregamento cíclico na porosidade de um concreto de alto desempenho. Nesta pesquisa foi feito o ensaio cíclico progressivo em três amostras, com a carga mínima fixada em 10\% da carga da tensão estática de ruptura, e a carga máxima foi variada de $65 \%, 75 \%$ e $85 \%$. De acordo com pesquisas anteriores, eles afirmaram que a frequência dos ciclos utilizada no ensaio não é significante se esta estiver entre 5 e $15 \mathrm{~Hz}$. Por aquilo, a frequência foi variada da seguinte maneira: $15 \mathrm{~Hz}$ para o ensaio de $65 \%, 10 \mathrm{~Hz}$ para o ensaio de $75 \%$ e $5 \mathrm{~Hz}$ para o ensaio de $85 \%$. A porosidade foi determinada através de uma simples equação que envolve a massa da amostra seca e saturada. Os resultados foram conforme o esperado (tabela 2.1): a porosidade aumenta com o aumento do número de ciclos e com o aumento da carga máxima aplicada. Desses resultados espera-se que ocorra um aumento na porosidade da amostra, mas, pelo método de caracterização utilizado, não se pode ter certeza se houve aumento dos poros ou fissuras existentes, ou se houve aparecimento de novos poros ou fissuras. 
Tabela 2.1: Porosidade para diferentes tensões de carregamentos cíclicos.(16)

\begin{tabular}{|c|c|c|c|c|c|}
\hline Carga & $\mathbf{0}$ & Carga Estática & $\mathbf{2 0 . 0 0 0}$ & $\mathbf{5 0 . 0 0 0}$ & $\mathbf{1 0 0 . 0 0 0}$ \\
\hline $65 \%$ & \multirow{3}{*}{5,69} & 7,77 & 7,84 & 8,14 & 8,34 \\
$75 \%$ & 8,29 & 8,17 & 8,68 & 9,45 \\
$85 \%$ & & 8,82 & 8,37 & & \\
\hline
\end{tabular}

Outras técnicas também são utilizadas para a análise da deterioração do material cimentício por carregamento cíclico. Por exemplo, Braz et al.(17) utilizaram a microCT para avaliar o crescimento de fissuras em um concreto asfáltico submetido a ensaio cíclico. Eles disseram que, de acordo com observações experimentais anteriores, o crescimento das fissuras está relacionado com as condições nos extremos dessas. Essas condições, por sua vez, podem ser caracterizadas pela variação de intensidade da tensão aplicada $(\Delta K)$, que é dado pela diferença entre as tensões máxima e mínima aplicadas durante o ensaio cíclico. Os autores variaram os valores de carga máxima aplicada em: $40 \%, 30 \%$ e $20 \%$ da tensão estática de ruptura, mantendo o valor da carga mínima fixo. Os resultados foram que, como esperado, quanto maior a carga máxima de ruptura, maior o crescimento das fissuras, e para uma mesma carga máxima, quanto maior a variação $\Delta K$, maior o crescimento das fissuras. A microCT foi utilizada para observação do crescimento de fissuras, como mostra a figura 2.6. Foram obtidas imagens antes do ensaio e após a aplicação de um certo número de ciclos, até a ruptura. A conclusão da utilização dessa técnica foi que o aparecimento das primeiras fissuras se deu no centro do corpo de prova e que essas se propagam de forma aleatória.
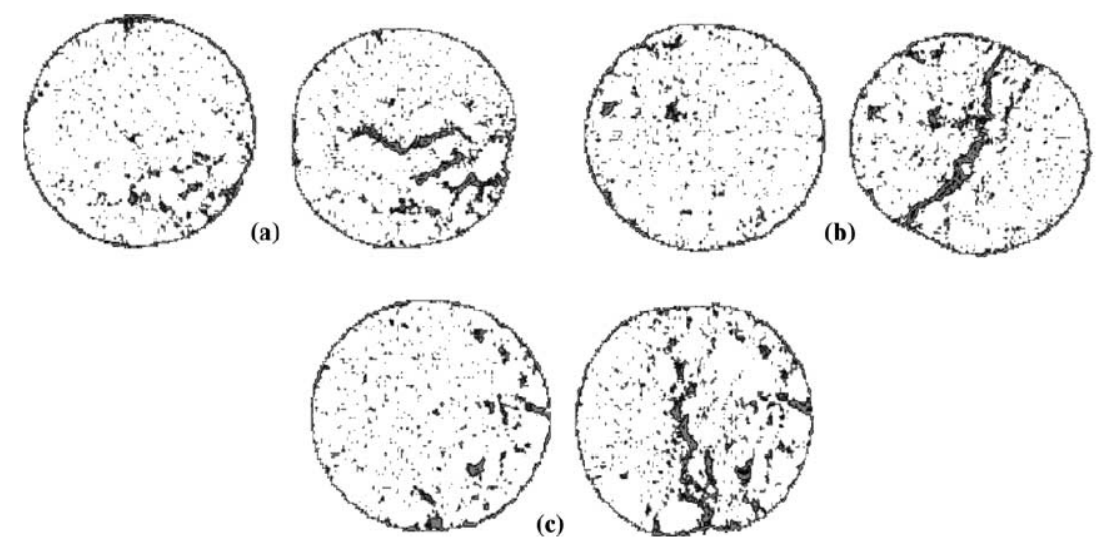

Figura 2.6: Imagens obtidas da MicoCT: (a) 0 e 650 ciclos; (b) 0 e 1365 ciclos e (c) 0 e 3065 ciclos para 40\%, 30\% e 20\% da tensão estática de ruptura, respectivamente, de acordo com Braz et al. (17) 


\subsection{2}

\section{Temperaturas Elevadas}

A importância do estudo do concreto submetido a temperaturas elevadas é, além de ter estruturas destinadas a suportar ambientes com essa característica, como o cimento utilizado na etapa de cimentação de poços de petróleo, a questão de segurança humana em caso de incêndio. Para Metha e Monteiro (5), a composição do concreto, a permeabilidade, o tamanho dos grãos e a taxa de aumento de temperatura são fatores que influenciam a resposta do concreto a temperaturas elevadas.

Muitas são as técnicas utilizadas para analisar o comportamento de um material cimentício exposto a temperaturas elevadas, e muitas vezes algumas delas são utilizadas em conjunto com o objetivo de obter resultados complementares. Zhu et al. (3) utilizaram as técnicas de análise térmica diferencial (DSC), análise termogravimétrica (TGA) e difração de raios $\mathrm{x}$ (DRX) para a caracterização de uma pasta de cimento classe G exposta a altas temperaturas. As análises térmicas DSC e TGA levaram a amostra até $1000^{\circ} \mathrm{C}$ a uma taxa de aquecimento de $10^{\circ} \mathrm{C} /$ minuto e uma atmosfera de $N_{2}$. O resultado dessa análise é mostrado na figura 2.7, na qual podem ser observados quatro picos endotérmicos: $110^{\circ} \mathrm{C}$, em que ocorre a evaporação da água livre e a eliminação da água interlamelar do silicato de cálcio hidratado (C-S-H ou $\mathrm{CaO} . \mathrm{SiO}_{2} \cdot \mathrm{H}_{2} \mathrm{O}$ ) e etringita (C-A-S-H ou $\left.\mathrm{Ca}_{6} \mathrm{Al}_{12}(\mathrm{OH})_{2}\left(\mathrm{SO}_{4}\right)_{3}\right) ; 440^{\circ} \mathrm{C}$, que está associado a desidroxilação do $\mathrm{Ca}(\mathrm{OH})_{2}$ em $\mathrm{CaO}$ e $\mathrm{H}_{2} \mathrm{O} ; 650^{\circ} \mathrm{C}$ e $850^{\circ} \mathrm{C}$.

O DRX foi feito em amostras submetidas a $80^{\circ} \mathrm{C}, 200^{\circ} \mathrm{C}, 400^{\circ} \mathrm{C}, 600^{\circ} \mathrm{C}$, $800^{\circ} \mathrm{C}$ e $1000^{\circ} \mathrm{C}$, e seus resultados estão apresentados na figura 2.8. Foi observado que nas amostras até $400^{\circ} \mathrm{C}$ há uma certa quantidade de $\mathrm{Ca}(\mathrm{OH})_{2}$ que, a partir de $600^{\circ} \mathrm{C}$ não é mais encontrada. Em $600^{\circ} \mathrm{C}$, ocorre o aparecimento de $\mathrm{CaO}$, e portanto pode-se concluir que ocorreu uma desidroxilação do $\mathrm{Ca}(\mathrm{OH})_{2}$ em $\mathrm{CaO}$ e $\mathrm{H}_{2} \mathrm{O}$. A $800^{\circ} \mathrm{C}$ e $1000^{\circ} \mathrm{C}$ há o aparecimento da $\mathrm{C}_{2} \mathrm{~S}$ $\left((\mathrm{CaO})_{2} \cdot \mathrm{SiO}_{2}\right)$, proveniente da decomposição do $\mathrm{C}-\mathrm{S}-\mathrm{H}$ e em $1000^{\circ} \mathrm{C}$ não é mais encontrado o $\mathrm{CaCO}_{3}$.

Esses resultados estão de acordo com os resultados das análises térmicas DSC e TGA. A pesquisa em questão também analisou a resistência à compressão das amostras após serem submetidas a temperaturas elevadas. A conclusão geral de Zhu et al. (3) foi que é provável que a pasta de cimento classe $\mathrm{G}$ pode ser utilizada para poços de petróleo com temperatura de serviço abaixo de $200^{\circ} \mathrm{C}$. 


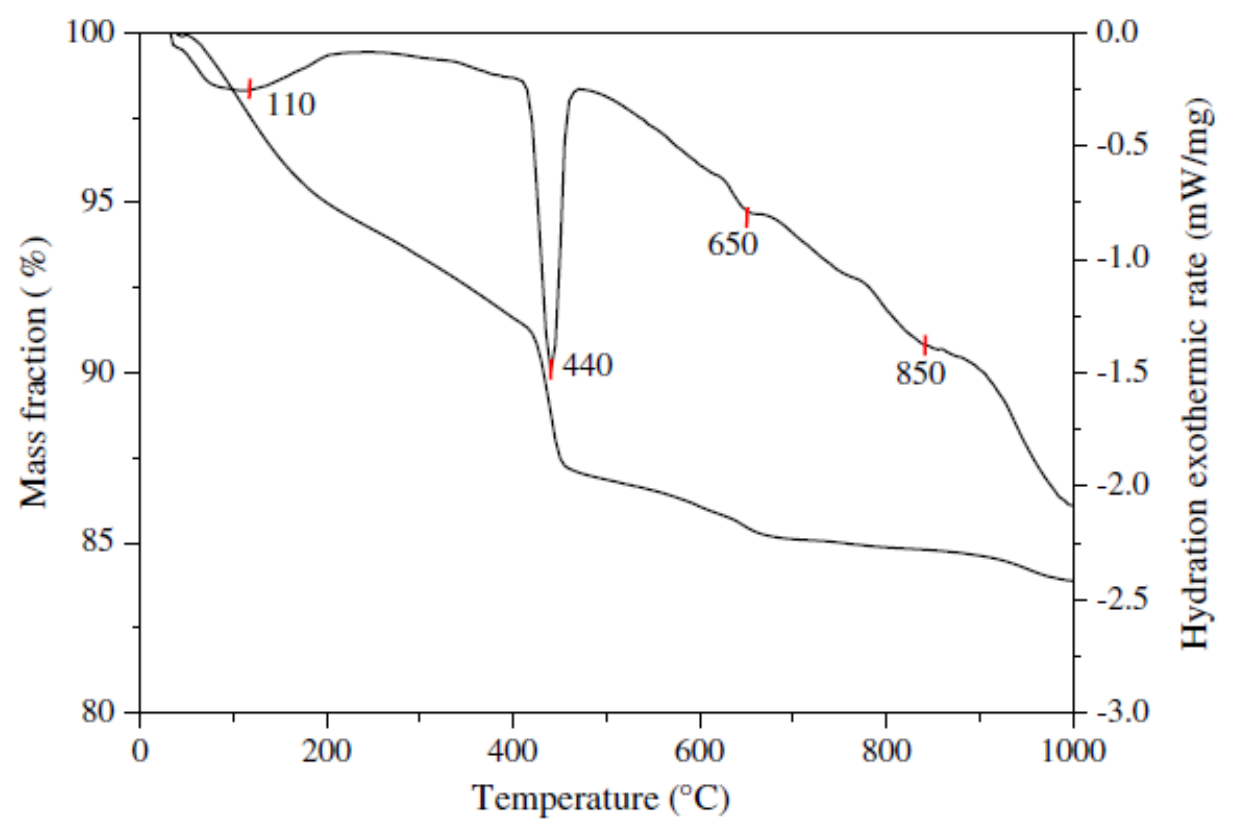

Figura 2.7: Resposta térmica da pastas de cimento classe G conforme Zhu et al. (3)

Jingas et al. (4) também estudaram o efeito do aumento de temperatura em pasta de cimento classe G, mas com o objetivo de estudar apenas as alterações da resistência à compressão. Para isso, os autores realizaram a cura em uma câmara de alta pressão em amostras com e sem adição de sílica. A conclusão foi que a adição de $30 \%$ a $40 \%$ de sílica na pasta leva a uma menor queda da resistência à compressão a temperaturas elevadas.

Kim et al. (18) utilizaram a microCT para avaliar as mudanças físicas na estrutura interna de uma pasta de cimento quando exposta a altas temperaturas. Também foram utilizados os métodos de DRX e o microscópio eletrônico de varredura (MEV) para análise dos compostos presentes nas amostras. Corpos de provas cúbicos foram moldados e levados a temperaturas variando de temperatura ambiente até $1000^{\circ} \mathrm{C}$. Os resultados da DRX e do MEV apontaram que de $25^{\circ} \mathrm{C}$ até $300^{\circ} \mathrm{C}$ os produtos de hidratação $\mathrm{Ca}(\mathrm{OH})_{2}$ e C-S-H já foram formados. A partir de $500^{\circ} \mathrm{C}$ esses começam a diminuir e a aparecer o composto $\mathrm{CaO}$ e a partir de $700^{\circ} \mathrm{C}$ a maioria dos produtos de hidratação se decompõem. 


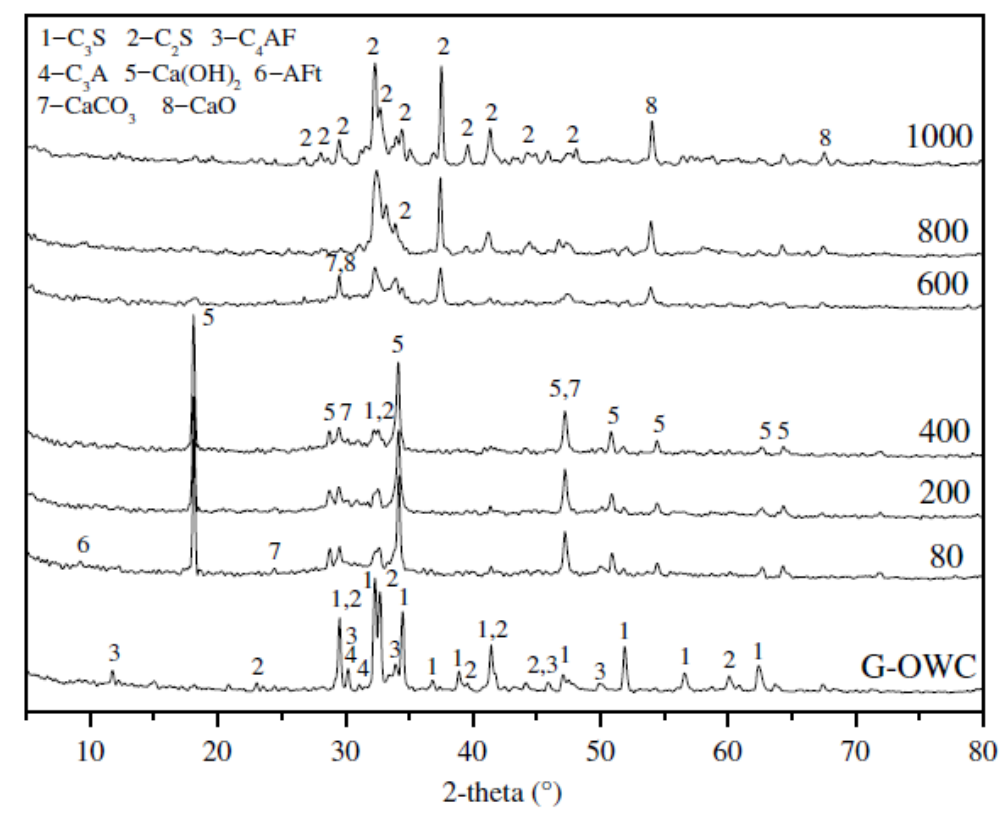

Figura 2.8: Curva da DRX de acordo com Zhu et al. (3)

Estes resultados corroboraram com a análise das imagens obtidas na microCT (figura 2.9) , uma vez que as fissuras começaram a ser observadas a partir de $700^{\circ} \mathrm{C}$, que é o que se espera com a decomposição dos produtos de hidratação. Porém, a microtomografia mostrou que as configurações morfológicas das fissuras desenvolvidas se propagam através dos poros macros, que são aqueles onde encontra-se bolhas de ar aprisionadas. Isso significa que a fratura é formada principalmente pelo aumento da pressão do ar aprisionado. A dessecação da argamassa sólida também contribui para a formação das fraturas, mas em menor proporção. (18)

(a) $600{ }^{\circ} \mathrm{C}$

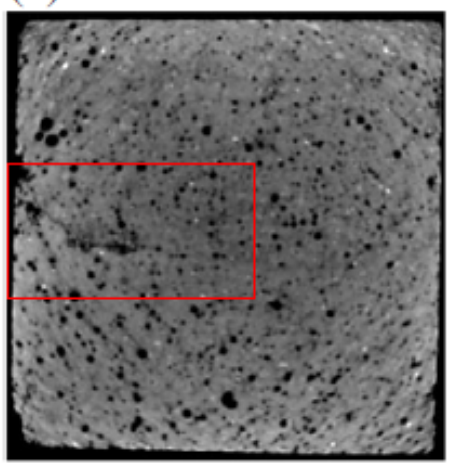

(b) $700{ }^{\circ} \mathrm{C}$

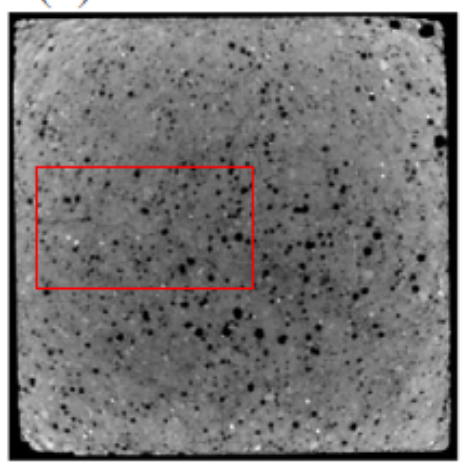

(c) $800^{\circ} \mathrm{C}$

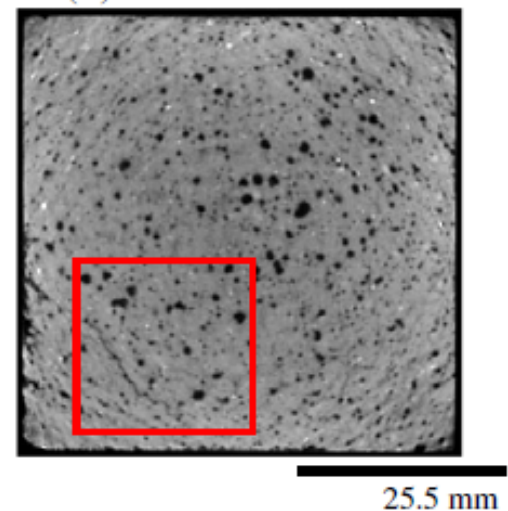

Figura 2.9: Imagens obtidas da microCT. Fissuras desenvolvidas a partir dos poros em pesquisa de Kim et al. (18) 


\section{3}

\section{Uso da Tomografia para a Análise de Durabilidade em Material Cimentício}

O princípio básico da microCT é a atenuação de um feixe de raios $\mathrm{X}$ por uma amostra. Como esta atenuação está relacionada com a densidade e com o número atômico do material, diferentes materiais irão gerar diferentes tons de pixels na imagem. Na prática, a técnica é idêntica a da tomografia axial computadorizada (CAT), utilizada na área médica, exceto pelo fato da microCT atingir resolução espacial muito maior, em escala micrométrica. (19)

Estudos anteriores trazem resultados positivos referente à utilização da microCT para qualificação e quantificação de porosidade e defeitos em materiais cimentícios. Lu et al. (19) utilizaram a microCT para estudar a estrutura dos poros de um concreto de cimento Portland. A motivação para esta pesquisa foi o fato de a porosidade estar diretamente relacionada com a resistência do concreto, assim como a permeabilidade está relacionada com a durabilidade. A pesquisa foi basicamente comparar a porosidade e a permeabilidade de quatro diferentes tipos de concreto de cimento Portland, um de referência e outros três com adição de cinza volante, sílica ativa e escória. Para isso, as imagens geradas da microCT foram processadas e segmentadas. Na etapa de segmentação, os voxels referentes a vazios (pixels escuros) são diferenciados do voxels referente à parte sólida (pixels claros) na imagem original, a partir do histograma da imagem, gerando uma imagem binária (figura 2.10). A análise é feita de maneira que se dois voxels pretos adjacentes compartilharem uma mesma face, borda ou canto, serão considerados um mesmo vazio, e aquilo poderá informar sobre a permeabilidade do material (conectividade dos poros).
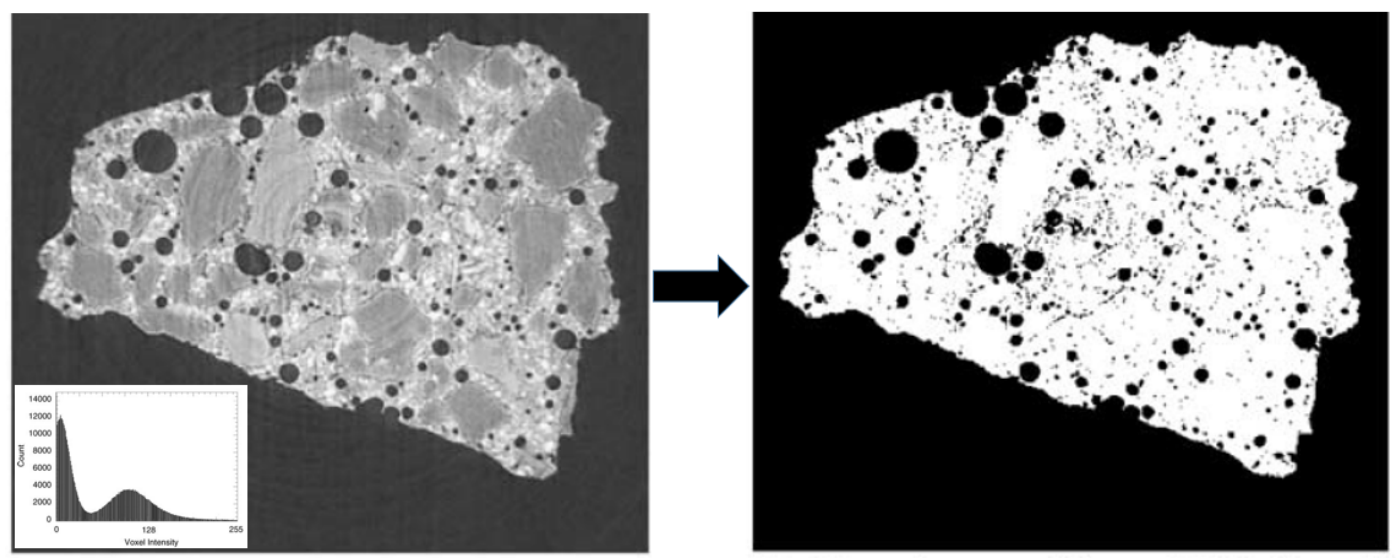

Figura 2.10: Imagem original com seu respectivo histograma e imagem binária após segmentação, de acordo com Lu et al. (19) 
Além da análise por imagens do microCT, foram feitos ensaios de permeabilidade, que mostraram que a permeabilidade no concreto de referência era maior que nos que tiveram adicionada cinza volante, sílica ativa ou escória.Todas as amostras foram tomografadas em resolução de $4 \mu \mathrm{m}$ e $1 \mu \mathrm{m}$ por pixel. O resultado para a de $4 \mu \mathrm{m}$ foi que as amostras de referência e a com cinza volante possuem maior quantidade de poros conectados, quando comparadas com as amostras de sílica ativa e escória. Já na resolução de $1 \mu \mathrm{m}$ o corpo de prova de referência mostrou uma quantidade de poros conectados muito maior do que os outros. Apesar da diferença dos resultados obtidos a partir das imagem de $4 \mu \mathrm{m}$ e $1 \mu \mathrm{m}$, as duas corroboraram com o resultado obtido do ensaio de permeabilidade. (19)

Naik et al. (20) utilizaram a microCT para caracterizar a influência do tipo de cimento, do fator água-cimento e da presença ou não de agregados em um concreto submetido a ataques de sulfato de sódio. Para isso, foram moldados corpos de prova variando esses parâmetros. Dois tipos de cimentos foram utilizados, o tipo I e V, assim como dois fatores água-cimento, 0,485 e 0,435, e a inclusão ou não de agregado. Os corpos de prova foram tomografados periodicamente e uma análise qualitativa foi feita com objetivo de observar a evolução dos defeitos com o tempo para cada parâmetro. As conclusões desta pesquisa foram que o concreto com cimento do tipo $\mathrm{V}$ tem maior resistência a ataque de sulfato, a deterioração foi maior nos corpos de prova com menor fator água-cimento e que com presença de agregado a degradação por ataque químico ocorreu mais rapidamente.

Jung et al. (21) estudaram a deterioração de um concreto submetido a um carregamento cíclico uniaxial através de técnicas de análise das imagens obtidas da microCT. Tomografou-se a amostra antes do carregamento e depois dessa submetida a um ciclo de $60 \%, 70 \%, 80 \%$ e $90 \%$ da carga de ruptura em um ensaio de compressão simples. A curva tensão-deformação obtidas desses ensaios está apresentada na figura 2.11. As imagens foram segmentadas e o resultado para antes do carregamento e depois de um ciclo de $90 \%$ esta mostrado na figura 2.12, confirmando o aparecimento de defeitos. 


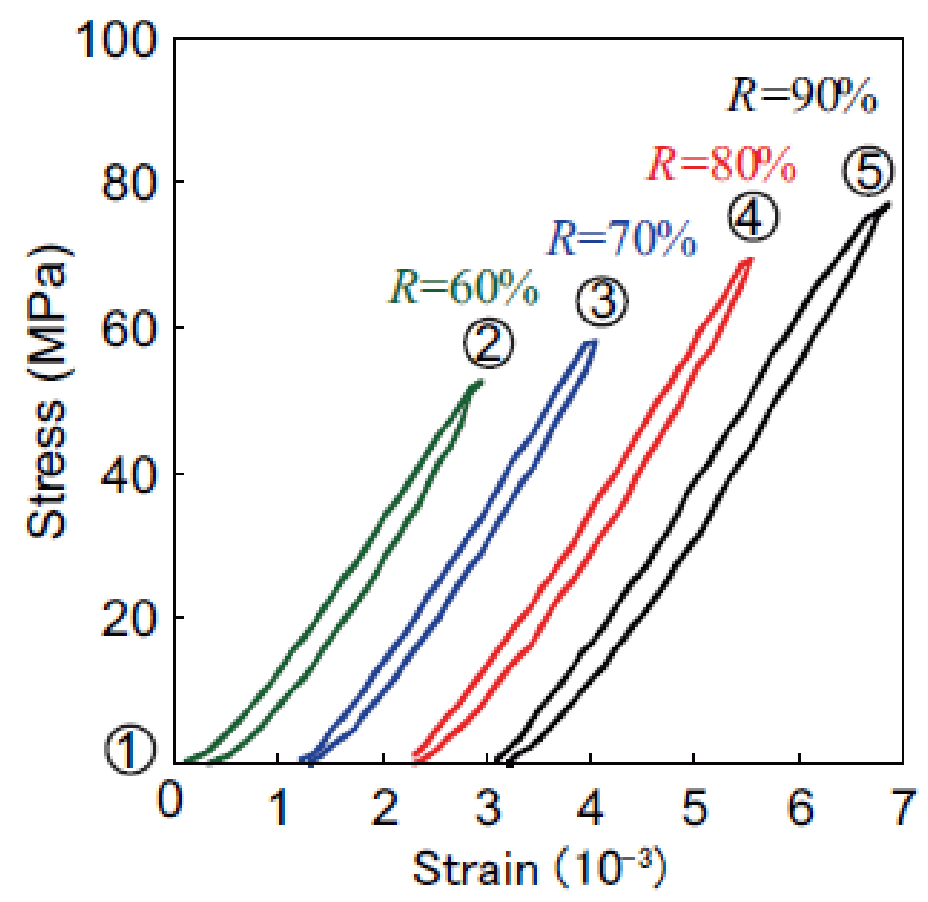

Figura 2.11: Curva tensão-deformação conforme Jung et al. (21)

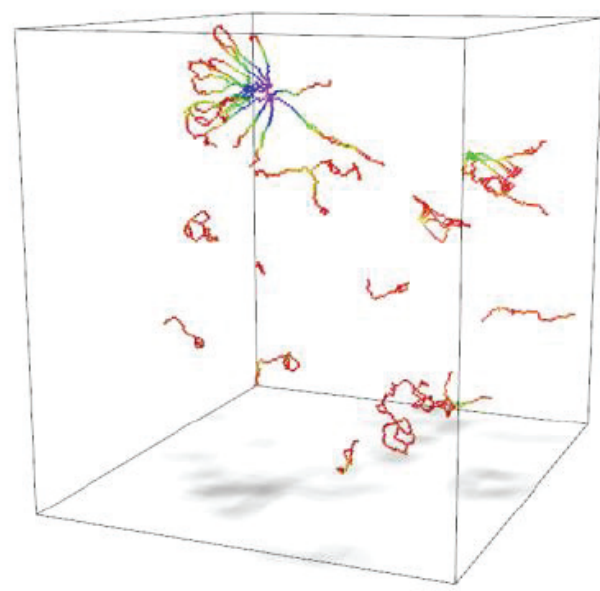

(a)

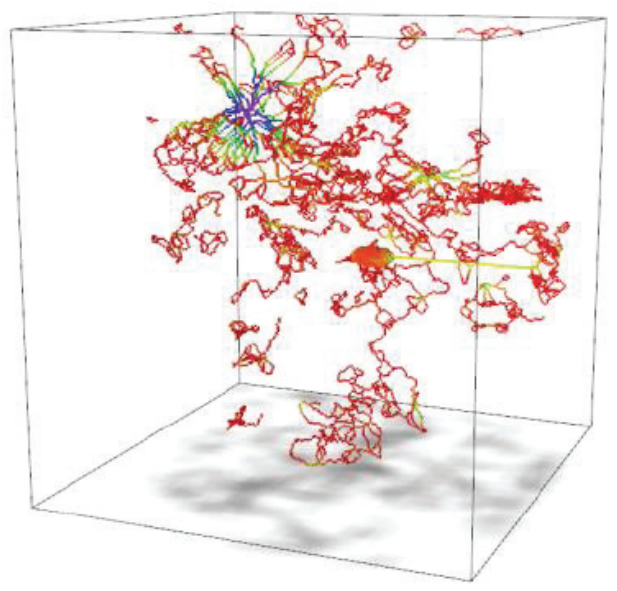

(b)

Figura 2.12: Vazios em 3D: (a) antes do carregamento, (b) após o carregamento de $90 \%$, conforme Jung et al. (21) 


\section{3}

\section{Materiais e Métodos}

\section{1}

\section{Moldagem do Corpo de Prova}

A pasta de cimento foi preparada utilizando apenas água e cimento classe G, ou, como conhecido no Brasil, cimento para poços petrolíferos (CPP). A massa específica desse cimento é de $3,17 \mathrm{~g} / \mathrm{cm}^{3}$ e sua composição química está descrita na tabela 3.1, de acordo com Silva (22).

Tabela 3.1: Composição química do cimento classe G. (22)

\begin{tabular}{lr} 
Fase/ Composto & $\%$ \\
\hline $\mathrm{SiO}_{2}$ & 20,94 \\
$\mathrm{Al}_{2} \mathrm{O}_{3}$ & 4,00 \\
$\mathrm{Fe}_{2} \mathrm{O}_{3}$ & 4,63 \\
$\mathrm{CaO}$ & 63,90 \\
$\mathrm{MgO}$ & 1,89 \\
$\mathrm{SO}_{3}$ & 2,48 \\
$\mathrm{Na}_{2} \mathrm{O}$ & 0,31 \\
$\mathrm{~K}_{2} \mathrm{O}$ & 0,40 \\
$(\mathrm{CaO})_{3} \cdot \mathrm{SiO}_{2}\left(\mathrm{C}_{3} \mathrm{~S}\right)$ & 52,71 \\
$(\mathrm{CaO})_{2} \cdot \mathrm{SiO}_{2}\left(\mathrm{C}_{2} \mathrm{~S}\right)$ & 20,57 \\
$(\mathrm{CaO})_{3} \cdot \mathrm{Al}_{2} \mathrm{O}_{3}\left(\mathrm{C}_{3} \mathrm{~A}\right)$ & 2,78 \\
$(\mathrm{CaO})_{4} \cdot \mathrm{Al}_{2} \mathrm{O}_{3} \cdot \mathrm{Fe}_{2} \mathrm{O}_{3}\left(\mathrm{C}_{4} \mathrm{AF}\right)$ & 14,08 \\
$2 \mathrm{C}$ & $\mathrm{A}+\mathrm{C}_{4} \mathrm{AF}$ \\
& 19,63
\end{tabular}

Foram moldados corpos de prova (CP) cilíndricos de 25,4 mm de diâmetro e 50,8 mm de altura. Essas dimensões foram escolhidas de maneira a respeitar a proporção da altura ser igual ao dobro do diâmetro, proposta na "NBR 5738 - Concreto - Procedimento para moldagem e cura de corpos de prova" (23). 
A dimensão determinada foi menor do que essa norma especifica, por motivo de facilidade da utilização de peças menores na realização da microCT. Para uma determinada resolução, a microCT de um corpo de prova menor será, obviamente, mais rápida. Um CP de maior dimensão poderia tornar a pesquisa inviável em relação ao tempo. Além do fato da escolha de um corpo de prova menor não causar prejuízo algum para a pesquisa, uma vez que o objetivo é analisar o aparecimento e o crescimento de fissuras, e isso não está relacionado com a dimensão do corpo de prova.

A relação em massa de água/cimento foi de 0,45. A mistura da água e do cimento seguiu o seguinte procedimento: toda a água foi colocada em um recipiente (Figura 3.1(b)) e um misturador (Figura 3.1(a)) foi ligado com uma velocidade angular de $1.100 \mathrm{rpm}$. Nos primeiros $30 \mathrm{~s}$ todo o cimento foi adicionado no recipiente mantido a esta frequência. Em seguida a velocidade foi aumentada para $2.000 \mathrm{rpm}$ por mais $30 \mathrm{~s}$ e então o misturador foi desligado. Com uma espátula mexeu-se a mistura de maneira a retirar acúmulos de cimento da parede do recipiente. Por fim, o misturador foi ligado a $2.000 \mathrm{rpm}$ por mais $30 \mathrm{~s}$.

Após a mistura, a pasta foi colocada em uma forma produzida a partir de um tubo de PVC de 25,4 milímetros de diâmetro. Este tubo foi cortado com altura de 50,8 milímetros e em sua lateral para facilitar a desforma. Por causa do corte lateral, abraçadeiras foram posicionadas envolvendo o tubo para que o seu diâmetro fosse mantido. Os tubos de PVC foram apoiados em uma plataforma de vidro, que funcionou como o fundo da forma. Nas paredes do tubo foi passado um desmoldante com auxílio de um pincel. Enfim, a pasta foi despejada no interior do tubo, conforme a figura 3.1 (c). A desforma é feita no dia seguinte (em aproximadamente $24 \mathrm{~h}$ ), de maneira que a abraçadeira é retirada e o tubo levemente aberto, liberando o corpo de prova facilmente do PVC. Por fim, os corpos de prova foram curados em um recipiente com água por 28 dias. 

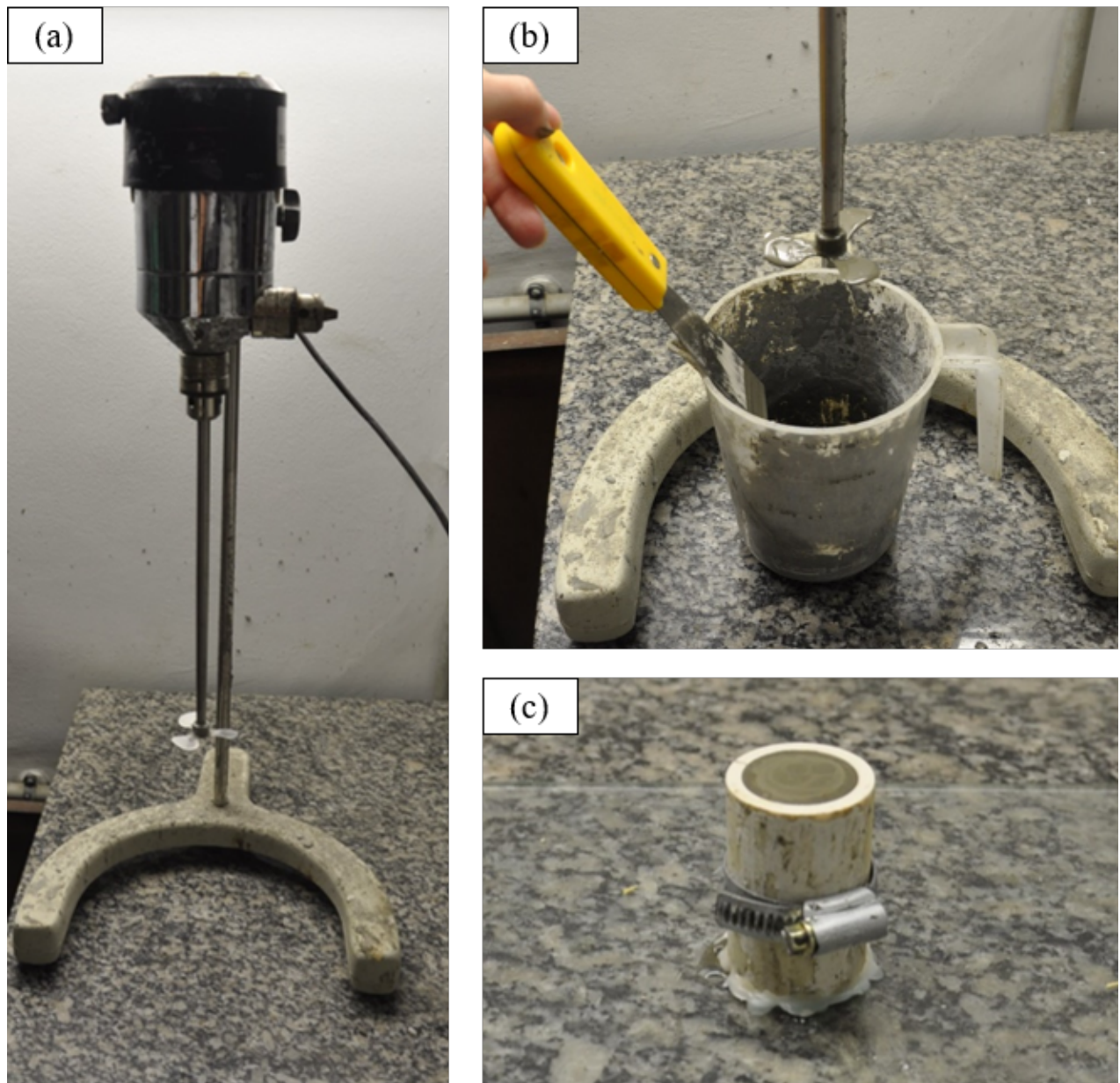

Figura 3.1: Procedimento de mistura da pasta de cimento: (a) misturador; (b) recipiente da mistura; (c) forma de PVC.

\section{2}

\section{Ensaio de Carregamento Cíclico}

Com o objetivo de determinar o comportamento mecânico estático da pasta de cimento, foram realizados testes de compressão uni-axial. O ensaio foi instrumentado utilizando um extensômetro resistivo (strain gage) (Figura 3.2 (b)). O teste foi realizado em uma máquina de ensaio mecânico servocontrolada modelo MTS 810 (Figura 3.2 (a)). O controle foi feito pelo deslocamento do atuador hidráulico com um taxa de $0,5 \mathrm{~mm} / \mathrm{min}$. 

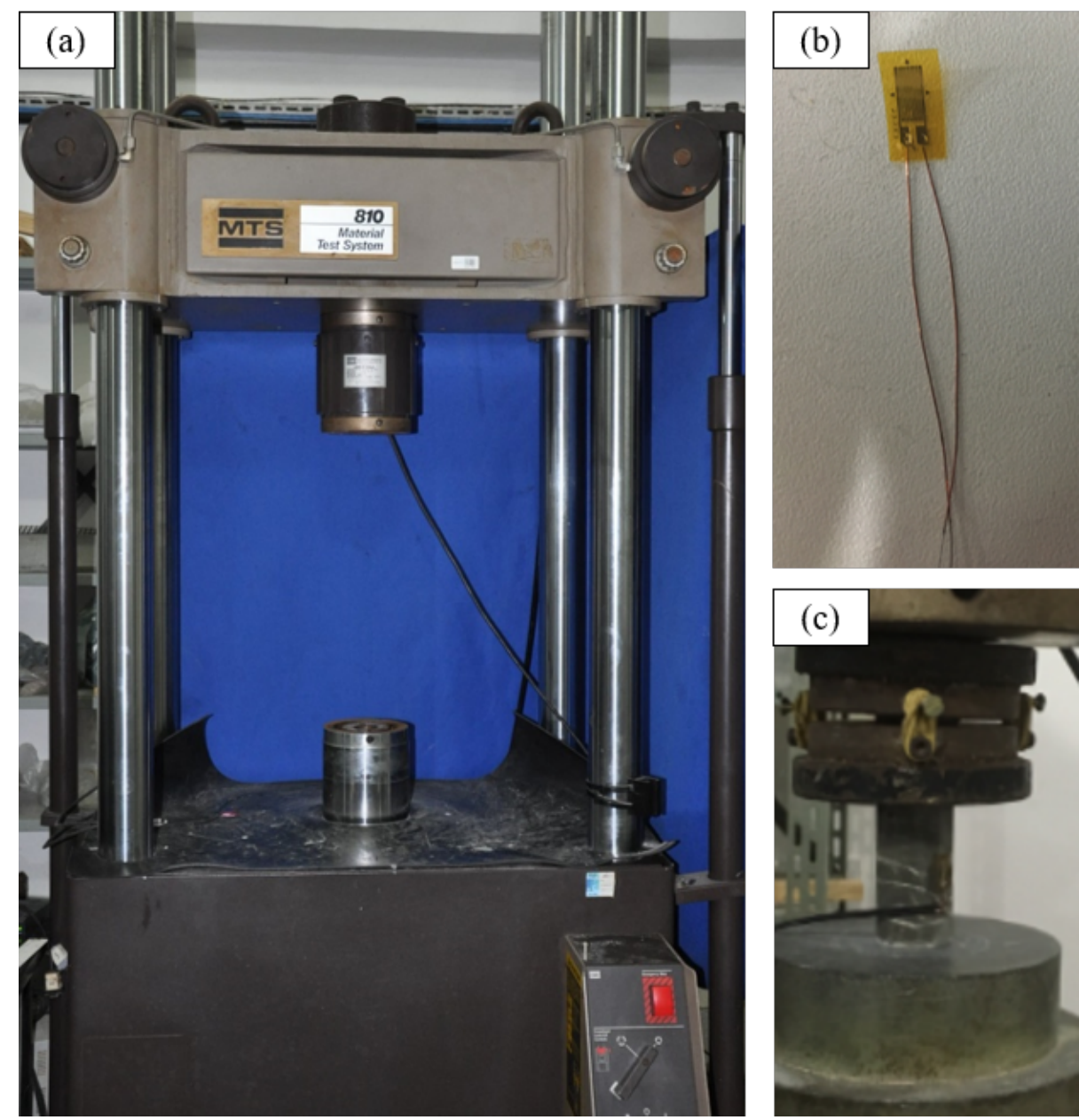

Figura 3.2: Ensaio de compressão uni-axial: (a) máquina MTS 810; (b) extensômetro; (c) corpo de prova instrumentado na máquina MTS 810.

Pang et al. (1) concluíram em sua pesquisa, que a idade do corpo de prova endurecido pouco influencia sobre o comportamento de fadiga da pasta cimento para poços de petróleo. Com base nisso, esses ensaios de compressão foram realizados em corpos de prova com diferentes idades, com o intuito de identificar a influência ou não da idade na tensão de ruptura $\left(\sigma_{r}\right)$. Os ensaios foram feitos nas seguintes idades: 30, 49 e 107 dias. Para cada idade foi calculada a média $(\bar{X})$ da $\sigma_{r}$ de três a quatro corpos de prova e o seu respectivo desvio padrão (dp).

Os resultados dos ensaios de compressão em corpos de prova com diferentes idades mostraram uma variação considerável nas $\sigma_{r}$. Esse resultado levou a decisão de utilizar como base da tensão máxima e mínima no ensaio de carregamento cíclico a média da $\sigma_{r}$ de corpos de prova moldados no mesmo momento (mesma leva) da amostra a ser ensaiada. 
Isso porque, além da influência da idade, a grande variação de valores de $\sigma_{r}$ apresentado pelos materiais cerâmicos está relacionada com a probabilidade do material apresentar um defeito crítico, que por sua vez, é influenciado pelo processo de moldagem. A idade de realização do ensaio de compressão e do ensaio cíclico está apresentado na tabela 3.2, a intenção foi que a diferença de idade entre esses ensaio não fosse expressiva, o que não aconteceu apenas com o corpo de prova 2 , por motivo de disponibilidade do equipamento.

Tabela 3.2: Idade dos corpos de prova utilizados nos ensaios de compressão uni-axial estático e de carregamento cíclico (Dias).

\section{Compressão Cíclico}

\begin{tabular}{lll}
\hline CP 1 & 32 & 32 \\
CP 2 & 32 & 60 \\
CP 3 & 30 & 30 \\
CP 4 & 30 & 31 \\
CP 5 & 28 & 28 \\
CP 6 & 35 & 35
\end{tabular}

Para determinar qual a porcentagem da $\sigma_{r}$ seria a tensão máxima a ser utilizada no ensaio cíclico, foi feito um ensaio de compressão na máquina RTR1500 Rapid Triaxial Rock da GCTS Testing System (figura 3.3) . O corpo de prova utilizado neste ensaio foi de $50 \mathrm{~mm}$ de diâmetro por $100 \mathrm{~mm}$ de altura. Esse equipamento possui instrumentação radial e axial no corpo de prova sendo capaz de controlar a deformação deste. Quando feito de forma lenta (no ensaio em questão foi utilizada uma taxa de 0,005 mm/min), a deformação acumulada durante o ensaio causa uma perda de rigidez no material levando a um aumento na inclinação da curva tensão x deformação, o que não aparece nos resultados de ensaios convencionais de compressão de materiais frágeis. Do gráfico tensão x deformação obtido deste ensaio foram medidas as inclinações de $30 \%$ até $50 \%$ da tensão de ruptura, de $50 \%$ até $70 \%$ e de $70 \%$ até $90 \%$ e comparadas com a inclinação da zona elástica do material. 

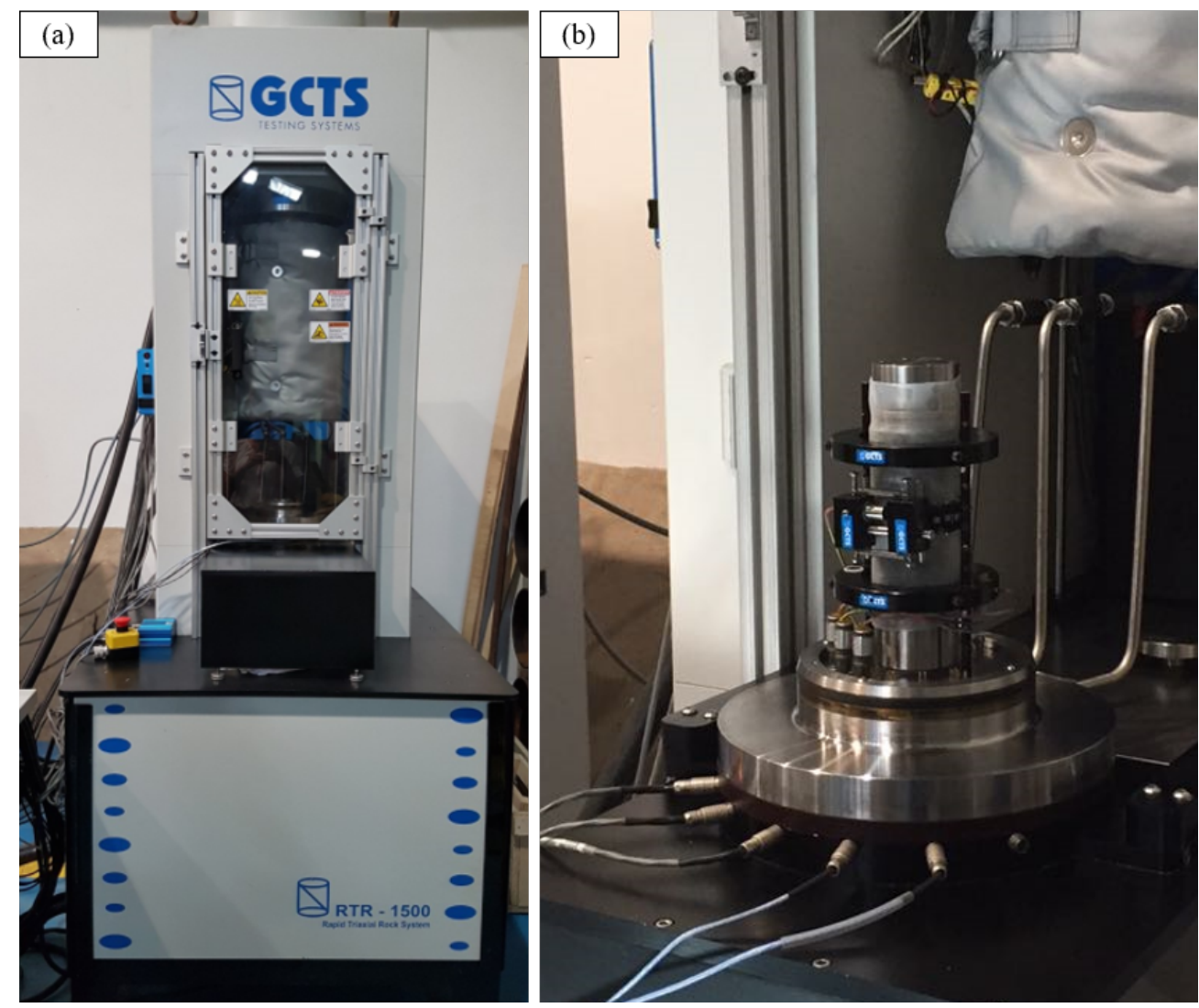

Figura 3.3: (a) máquina RTR-1500 Rapid Triaxial Rock da GCTS Testing System; (b) corpo de prova instrumentado na máquina RTR-1500.

A partir do ensaio de compressão lento, foi definido que as tensões máximas utilizadas nos ensaios cíclicos $\left(\sigma_{\text {máx }}\right)$ seriam de $30 \%, 50 \%$ e $70 \%$ das médias das tensões estáticas de ruptura. A tensão mínima $\left(\sigma_{\min }\right)$ foi determinada de maneira que $\sigma_{\min } / \sigma_{\text {máx }}=0,2$. A relação dos $\mathrm{CP}$ com suas respectivas porcentagens da $\sigma_{r}$, suas $\sigma_{m a ́ x}$ e $\sigma_{\text {min }}$ e números de ciclos que foram ensaiadas está apresentada na tabela 3.3. A frequência utilizada nos ensaios foi padronizada em $3 \mathrm{~Hz}$. A figura 3.4 mostra o gráfico $\sigma \mathrm{x}$ tempo do ensaio do CP 1, no qual três ciclos são completados em 1 segundo.

Tabela 3.3: Ensaio de Carregamento Cíclico.

\begin{tabular}{lcccc} 
& $\% \sigma_{r}$ & $\sigma_{\operatorname{máx}}$ & $\sigma_{\min }$ & № de ciclos \\
\hline CP 1 & $30 \%$ & 14,92 & 2,98 & 500.000 \\
CP 2 & $30 \%$ & 14,92 & 2,98 & 1.000 .000 \\
CP 3 & $50 \%$ & 24,73 & 4,95 & 100.000 \\
CP 4 & $50 \%$ & 24,73 & 4,95 & 500.000 \\
CP 5 & $70 \%$ & 24,25 & 4,85 & 100.000 \\
CP 6 & $70 \%$ & 33,23 & 6,65 & 500.000
\end{tabular}




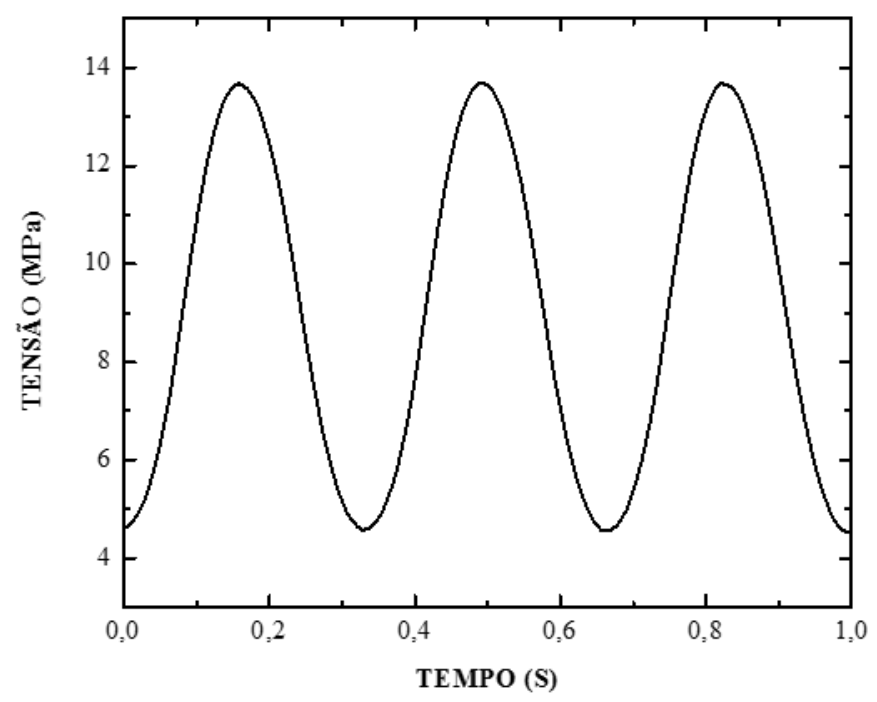

Figura 3.4: Gráfico Tensão x Tempo do ensaio de carregamento cíclico do corpo de prova 1.

Assim como o ensaio estático de compressão, o ensaio cíclico também é controlado pelo software, que informa os dados de força e deslocamento. A quantidade de pontos é um parâmetro determinado anteriormente ao início do ensaio e, no caso, foi escolhido um número de cinquenta pontos por ciclo. Dos valores de força $(F)$ e de deslocamento $(d)$ são obtidos a tensão $(\sigma)$ e a deformação $(\varepsilon)$ do corpo de prova, pelas equações:

$$
\begin{aligned}
& \sigma=\frac{F}{A} \\
& \varepsilon=\frac{d}{L_{0}}
\end{aligned}
$$

onde A é a área e $L_{0}$ é a o comprimento do corpo de prova.

A partir $\sigma$ e $\varepsilon$, é gerada uma curva de histerese, similar à curva da figura 2.11 obtida na pesquisa de Jung et al. (21). Sendo que foi plotada uma curva no início do ensaio e uma do final, com o intuito de visualizar uma possível mudança na inclinação devido à variação da rigidez do material. 


\section{3 \\ Ensaio de Temperaturas Elevadas}

O ensaio de temperaturas elevadas consistiu em levar os corpos de prova a uma mufla pré aquecida em uma determinada temperatura e deixá-los nessa temperatura por uma hora. A mufla utilizada no ensaio está apresentada na figura 3.5 .

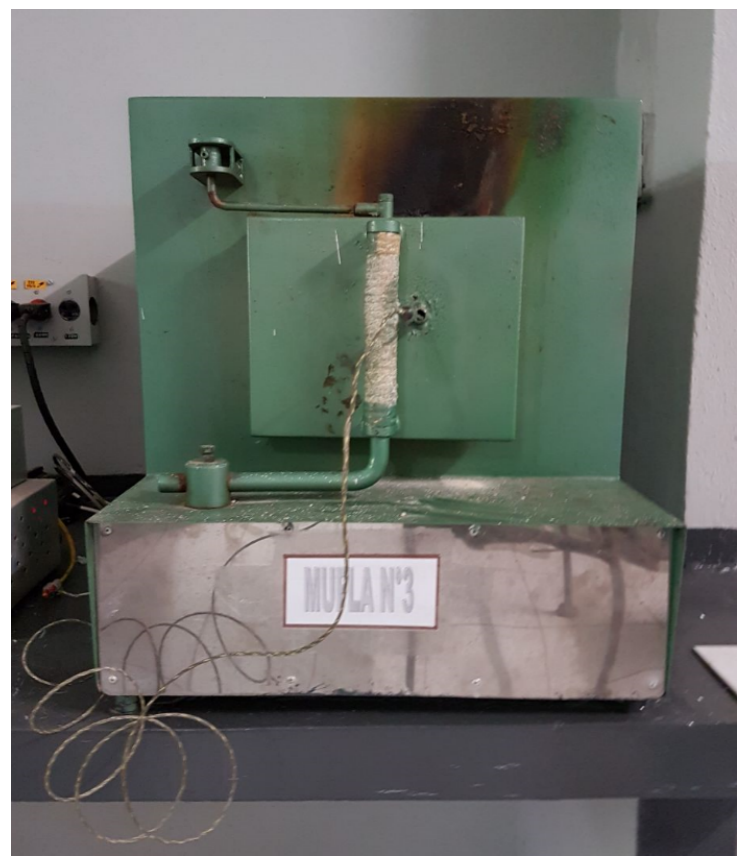

Figura 3.5: Mufla utilizada no ensaio de temperaturas elevadas.

A mufla é aquecida até a temperatura de ensaio e só então o corpo de prova é colocado dentro dela. Após 1 h a mufla é desligada. O corpo de prova é deixado dentro da mufla até que a temperatura ambiente seja atingida e, apenas após isso, o corpo de prova pode ser retirado. As temperaturas utilizadas nos ensaios para esta pesquisa foram de $100^{\circ} \mathrm{C}, 200^{\circ} \mathrm{C}, 450^{\circ}$ e $650^{\circ} \mathrm{C}$. A relação dos CP e das temperaturas é apresentada na tabela 3.4.

Tabela 3.4: Ensaio de Temperaturas Elevadas.

\section{Temperatura}

\begin{tabular}{ll}
\hline CP 7 & $100^{\circ} \mathrm{C}$ \\
CP 8 & $200^{\circ} \mathrm{C}$ \\
CP 9 & $450^{\circ} \mathrm{C}$ \\
CP 10 & $650^{\circ} \mathrm{C}$
\end{tabular}


As temperaturas de $100^{\circ} \mathrm{C}$ e $200^{\circ} \mathrm{C}$ foram escolhidas por razão de serem temperaturas de serviço quando se trata do cimento utilizado em poços de petróleo. Zhu et al. (3) concluíram em sua pesquisa que é provável que a pasta de cimento classe $\mathrm{G}$ possa ser utilizada para poços de petróleo com temperatura de serviço abaixo de $200^{\circ} \mathrm{C}$.

Já as temperaturas de $450^{\circ} \mathrm{C}$ e $650^{\circ} \mathrm{C}$ foram estabelecidas de acordo com o resultado das análises térmicas DSC e TGA (figura 2.8) da pesquisa Zhu et al. (3). A primeira temperatura corresponde aproximadamente o pico em que ocorre a desidroxilação do $\mathrm{Ca}(\mathrm{OH})_{2}$ e a segunda ao pico que indica o início da degradação do $\mathrm{CaCO}_{3}$.

Com o intuito de relacionar a exposição das temperaturas com o aparecimento de defeitos e com a resistência do material, foram realizados ensaios de compressão em corpos de prova submetidos a essas mesmas temperaturas. Com esses CPs foram feitos os ensaio de DRX, DSC e TGA, podendo relacionar os resultados destes ensaios também com as reações químicas que acontecem durante o aquecimento.

\subsection{1 \\ DRX}

Para a realização dos ensaios de DRX foi necessária uma preparação nas amostras de maneira que essa passasse pela peneira de $106 \mu \mathrm{m}$. Foram 5 amostras: a referência, que não foi levada a mufla e as que estiveram na mufla por $1 \mathrm{~h}$ a $100^{\circ} \mathrm{C}, 200^{\circ} \mathrm{C}, 450^{\circ} \mathrm{C}$ e $650^{\circ} \mathrm{C}$. Com objetivo de obter $3 \mathrm{~g}$ bem representativas de cada amostra, todo o corpo de prova passou por todos os processos. Primeiro o corpo de prova foi triturado com o auxílio de um soquete até passar pela peneira de 1,4 cm. Em seguida o material foi levado para um moinho de bolas (figura 3.6) a $350 \mathrm{rpm}$ até passar pela peneira de $106 \mu \mathrm{m}$. Para selecionar uma amostra representativa, esta é amostrada em um amostrador rotativo (figura 3.6), até obtenção de aproximadamente 3 g. Enfim, essa amostra é compactada no porta amostra com auxílio de uma lâmina de vidro e levada ao DRX. O equipamento utilizado foi o difratômetro Bruker modelo Focus D4 Advance (figura 3.6), com radiação Co-K $\alpha, \lambda=1,78897 \AA$. A varredura foi realizada entre os ângulos de Bragg $(2 \Theta)$ de $5^{\circ}$ e $80^{\circ}$, com velocidade angular de $0,02^{\circ} / \mathrm{s}$. 

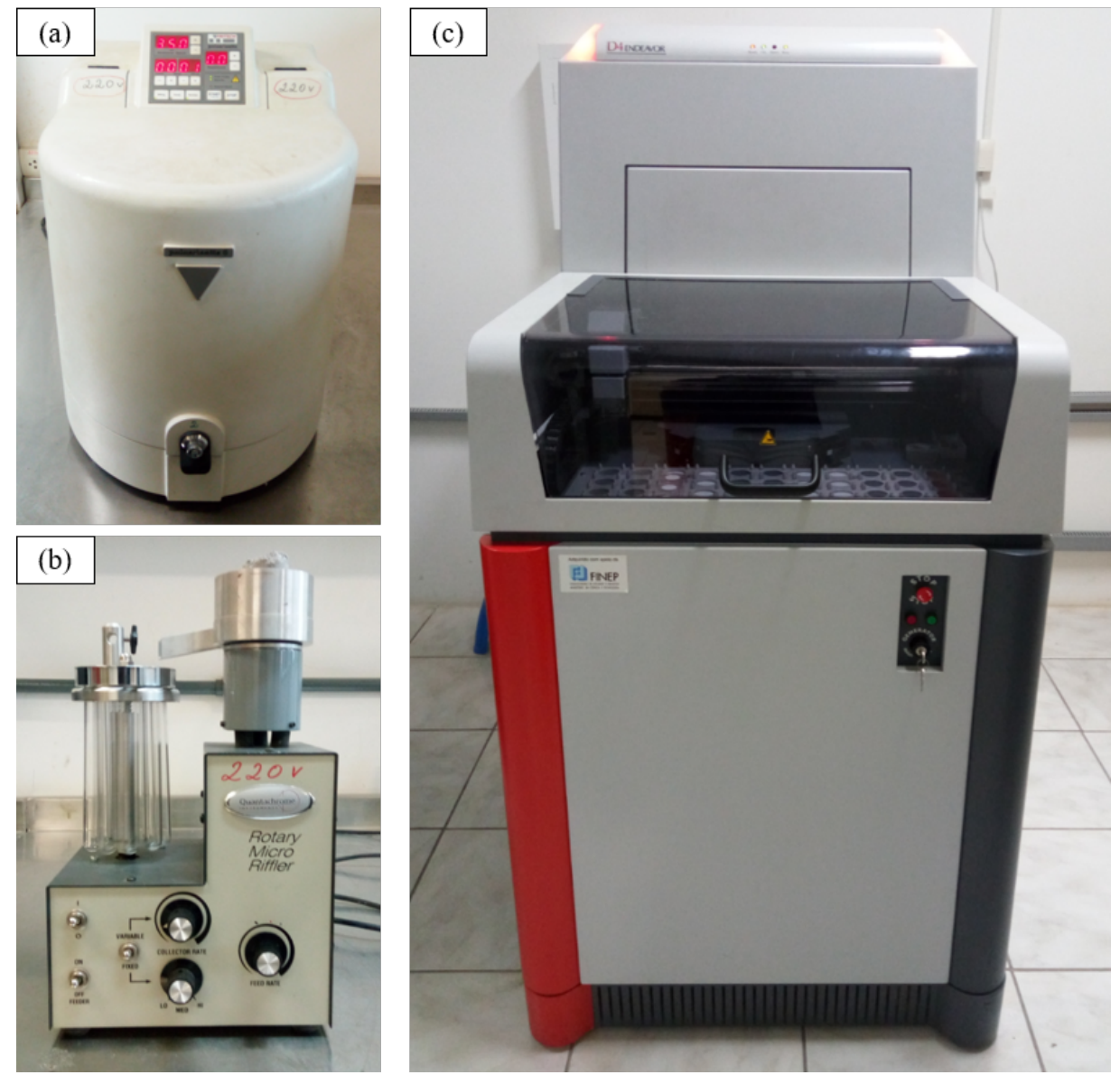

Figura 3.6: Preparação de amostra: (a) moinho de bolas; (b) amostrador rotativo; (c) DRX.

\subsection{2 \\ DSC e TGA}

Foi realizada a análise térmica diferencial (DSC) com o intuito de verificar os picos de variação de energia, nos quais estaria ocorrendo uma possível reação. Já a análise termogravimétrica (TGA) foi feita com o objetivo de verificar a perda de massa durante o aumento de temperatura. As amostra foram preparadas conforme o ensaio de DRX e o equipamento utilizado para a realização desses ensaios de DSC e TGA foi o Perkin-Elmer Simultaneous Thermal Analyzer (STA-6000). A taxa de aquecimento para a realização dessa análise foi de $10^{\circ} \mathrm{C} / \mathrm{min}$, iniciando a temperatura ambiente e finalizando a $990^{\circ} \mathrm{C}$. A atmosfera utilizada foi o nitrogênio $\left(N_{2}\right)$. 


\section{4 MicroCT}

Para a análise dos danos na microestrutura causados pelos ensaios de carregamento cíclico e de temperaturas elevadas, foi utilizado o método de caracterização não destrutivo de microCT. Para isso, foi usado o microtomógrafo de raios X modelo XRadia 510 Versa, do fabricante ZEISS, do Departamento de Engenharia Química e de Materiais da PUC-Rio (figura 3.7). De acordo com o manual do equipamento (24), esse atinge uma resolução espacial de 0,7 $\mu \mathrm{m}$, uma tensão variável entre $30-160 \mathrm{kV}$, uma potência máxima de 10W.

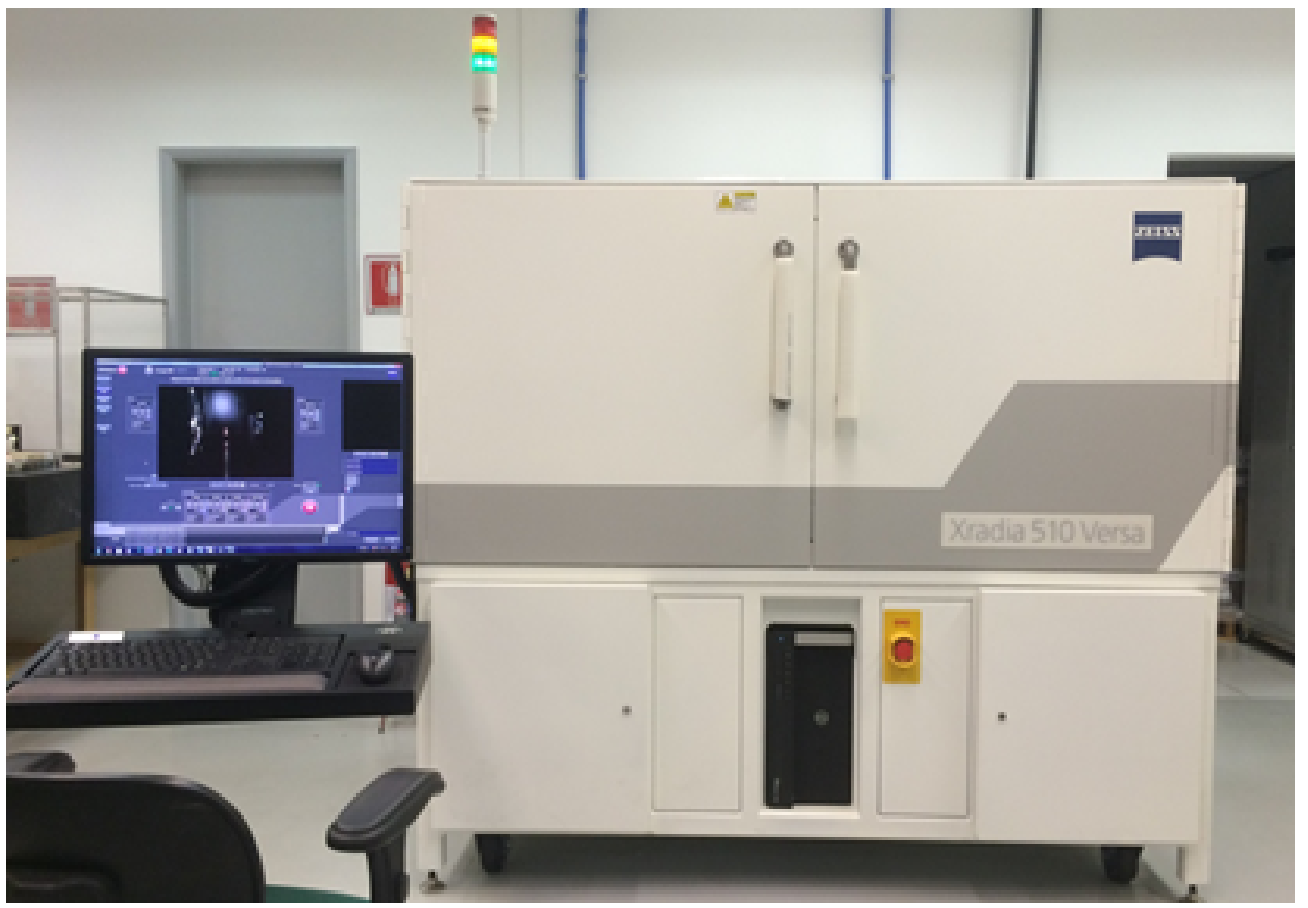

Figura 3.7: MicroCT XRadia 510 Versa.

O equipamento dispõe de uma fonte de raios X; um porta amostras, que está sobre uma mesa giratória; um detector acoplado a uma câmara CCD e um conjunto de lentes óticas de 0,4X, 4X, 20X e 40X (figura 3.8).

Para a realização do ensaio, o corpo de prova é colocado no porta amostra e a radiação atravessa o material cimentício. A intensidade da radiação é medida pelo detector e armazenada digitalmente como uma projeção 2D. Essa projeção é magnificada em duas etapas: primeiramente em uma magnificação geométrica e em seguida um cintilador converte os raios $\mathrm{X}$ em luz visível que é então ampliada oticamente. Neste momento, a imagem é capturada através do software Scout and Scan Control System, cujo procedimento está descrito na tabela 3.5. 


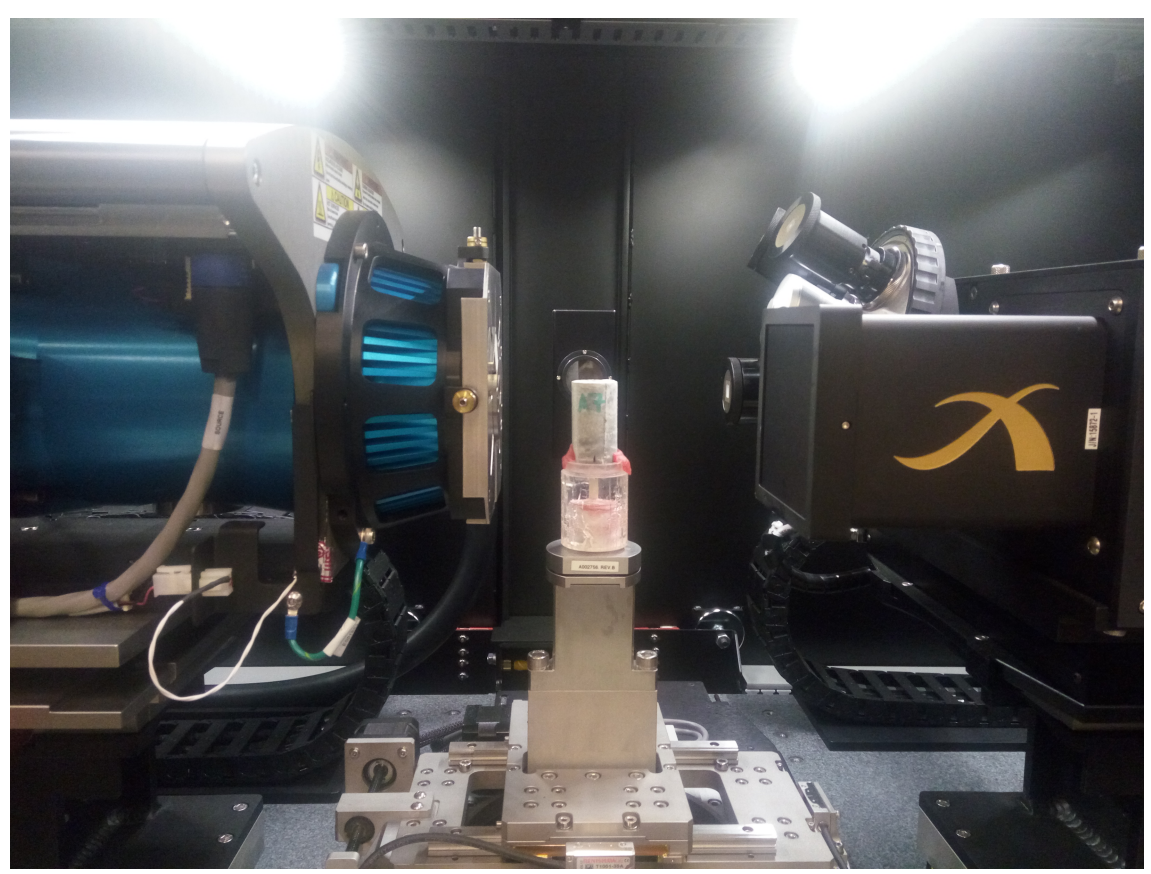

Figura 3.8: MicroCT: fonte de raios X, porta amostras, detector e conjunto de lentes ópticas.

Tabela 3.5: Procedimento da captura da imagem no microCT

\begin{tabular}{|c|c|}
\hline Etapa & Descrição \\
\hline Início da microCT & Criação de um novo arquivo. \\
\hline Alinhamento aproximado da amostra & $\begin{array}{l}\text { A amostra é colocada sobre o porta-amostra, } \\
\text { que é controlado mecanicamente pelo software } \\
\text { com a intenção de centralizá-la nos eixos x, y, } \\
\text { z. Nessa etapa deve-se ter o cuidado de que a } \\
\text { amostra não bata no detector. }\end{array}$ \\
\hline Escolha dos parâmetros & $\begin{array}{l}\text { Nessa etapa são escolhidos os parâmetros } \\
\text { como: Lente objetiva, que varia entre } 0,4 \mathrm{X} \text {, } \\
4 \mathrm{X}, 20 \mathrm{X}, 40 \mathrm{X} \text { (lentes óticas); binning, ou agru- } \\
\text { pamento dos pixels do detector - valores de } \\
\text { binning > }>\text {, por exemplo } 2 \text {, e } 4 \text {, implicam } \\
\text { perda de resolução, mas se converte em me- } \\
\text { nor tempo de exposição. }\end{array}$ \\
\hline Verificação & $\begin{array}{l}\text { O software verifica os valores dos parâmetros } \\
\text { e estabiliza o sistema. }\end{array}$ \\
\hline Execução & $\begin{array}{l}\text { A amostra é exposta aos raios X e o detector } \\
\text { captura a informação da amostra. }\end{array}$ \\
\hline
\end{tabular}




\subsection{1}

\section{Parâmetros de Aquisição das Imagens}

O software Scout and Scan Control System solicita a determinação de parâmetros que influenciarão na qualidade das imagens capturadas. Esses parâmetros e as respectivas condições utilizadas estão apresentadas na tabela 3.6 .

Tabela 3.6: Parâmetros de aquisição.

\begin{tabular}{lc} 
Parâmetros & Condições \\
\hline Magnificação óptica & $0,4 \mathrm{X}$ \\
$\mathrm{N}^{\circ}$ de projeções & 1601 \\
Tensão $(\mathrm{kV})$ & 140 \\
Tempo de exposição $(\mathrm{s})$ & variável \\
Resolução $(\mu \mathrm{m})$ & 29,5 \\
Binning & 2 \\
Filtro & HE2
\end{tabular}

Tabela 3.7: Parâmetro tempo de exposição(s) .

\begin{tabular}{lcc} 
& Antes & Depois \\
\hline CP 1 & 0,4 & 0,4 \\
CP 2 & 0,8 & 1,0 \\
CP 3 & 1,0 & 0,8 \\
CP 4 & 0,8 & - \\
CP 5 & 0,7 & 1,0 \\
CP 6 & 4,5 & - \\
CP 7 & 0,6 & 0,6 \\
CP 8 & 0,4 & 0,4 \\
CP 9 & 0,6 & 0,6 \\
CP 10 & 0,6 & -
\end{tabular}


Um fator importante a ser levado em consideração é o tempo total de exposição do corpo de prova. Com os parâmetros escolhidos, varredura de cada corpo de prova levou cerca de $5 \mathrm{~h}$, o que tornou a pesquisa viável. Porém, o tamanho de pixel $(29,5 \mu \mathrm{m})$ é relativamente grande, quando comparado com a pesquisa de $\mathrm{Lu}$ et al. (19) que utilizou $1 \mu \mathrm{m}$ e $4 \mu \mathrm{m}$. Isso significa, que detalhes mais finos não serão identificados. Todavia, essa resolução foi suficiente para a análise esperada na pesquisa em questão.

\section{4 .2}

\section{Reconstrução das Imagens}

Após a rotação completa do corpo de prova, um volume representativo desse é reconstruído a partir do conjunto de imagens de projeção. O software que reconstrói as imagens formando o volume é o Reconstructor Scout and Scan Control System. Devido à altura do corpo de prova, foi necessário dividir em três volumes que, posteriormente, foram combinados no software Manual Stitcher Scout and Scan.

Dois são os parâmetros relevantes que o software Scout and Scan Control System Reconstructor pede para obter uma melhor imagem, o Beam Hardening e o Center Shift. Esses parâmetros e seus respectivos valores utilizados, antes e depois da realização do ensaio, estão descritos na tabela 3.8

Tabela 3.8: Parâmetros da Reconstrução das Imagens.

Center Shift

\begin{tabular}{lcclc}
\hline & Antes & Depois & Antes & Depois \\
\hline CP 1 & $-12,0$ & $-12,0$ & 0,14 & 0,14 \\
CP 2 & $-11,0$ & $-9,0$ & 0,14 & 0,14 \\
CP 3 & $-11,0$ & $-11,0$ & 0,14 & 0,14 \\
CP 4 & $-11,0$ & - & 0,14 & - \\
CP 5 & 0,4 & 0,0 & 0,09 & 0,09 \\
CP 6 & 0,5 & - & 0,05 & - \\
CP 7 & $-0,2$ & $-0,2$ & 0,14 & 0,14 \\
CP 8 & $-11,4$ & $-11,4$ & 0,14 & 0,14 \\
CP 9 & $-0,2$ & $-0,2$ & 0,14 & 0,14 \\
CP 10 & $-0,2$ & - & 0,14 & -
\end{tabular}




\section{5 Processamento e Análise Digital das Imagens}

As etapas para processamento e análise das imagens obtidas do tomógrafo foram, basicamente, a aplicação de um filtro para redução de ruídos, o alinhamento das imagens de antes e depois do ensaio, visualização qualitativa em 3D, segmentação da parte sólida (pasta de cimento) e vazios (poros e trincas), obtenção dos dados quantitativos.

\subsection{1}

\section{Pré-processamento e Processamento Digital das Imagens}

Devido ao efeito de cone do tomógrafo a imagem na parte superior e inferior do corpo de prova ficam escuras, como a figura 3.9 apresenta. Essas partes devem ser eliminadas, pois se confundiriam com os tons de vazios. Por isso, o volume total considerado fica menor do que o corpo de prova realmente é.
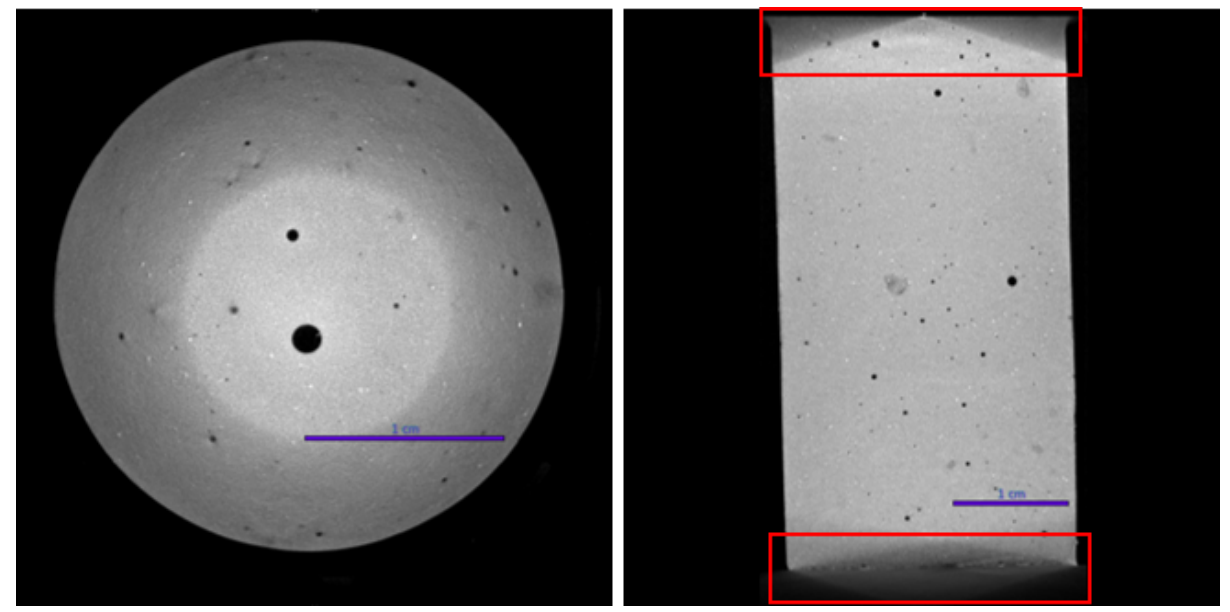

Figura 3.9: Imagens do corpo de prova antes da eliminação das partes inferior e superior.

A redução de ruído de alta frequência espacial foi realizada com o filtro "Non-local Means", implementado no software Fiji. Foi utilizado o valor de Sigma $=5$. Na figura 3.10 é possível observar o efeito do filtro. 
Ainda no software Fiji, é necessário fazer a rotação de uma das imagens do corpo de prova (antes ou depois do ensaio). Isso porque o CP pode não ter sido tomografado exatamente na mesma posição, e na etapa de alinhamento é necessário que as imagens estejam aproximadamente na mesma posição para que possam ser comparadas. Para isso, escolheu-se uma camada semelhante de antes e depois do ensaio e então foi aplicado o comando "Rotate"do Fiji em uma delas, deixando-as aproximadamente alinhadas.
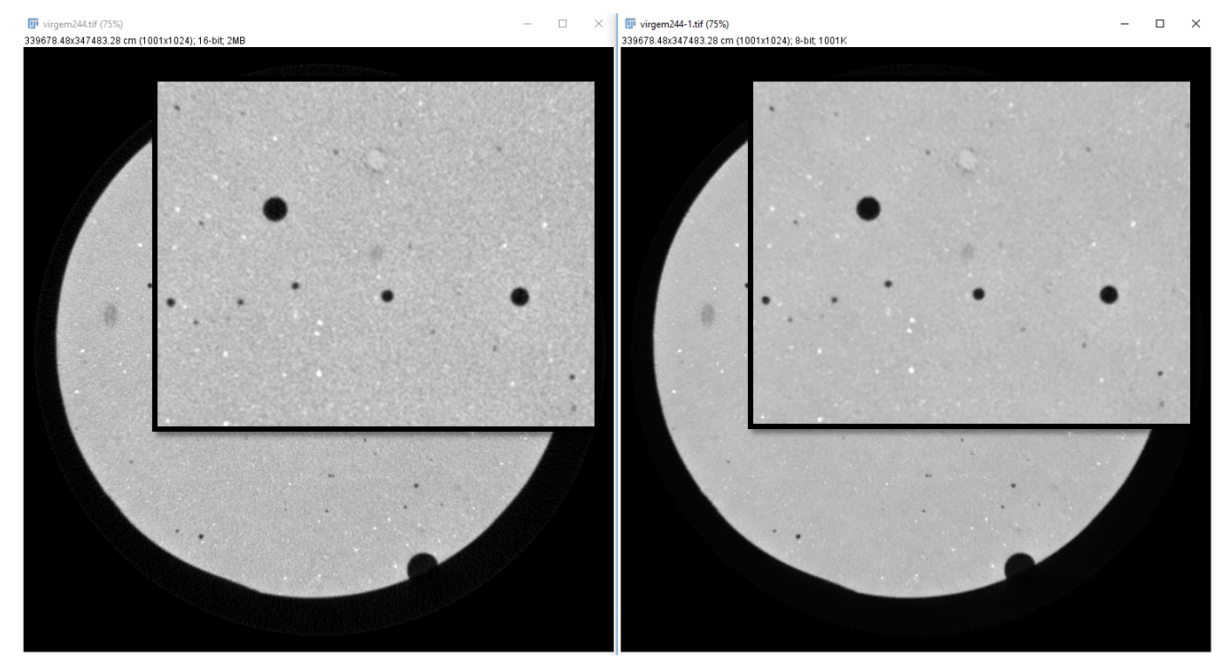

Figura 3.10: Imagens antes e depois da aplicação do filtro Non-local Mean no software Fiji.

Após as etapas no Fiji, foi utilizado o software DataViewer para o alinhamento 3D das imagens de antes e depois de cada ensaio. Para o alinhamento são necessários dois conjuntos de dados: um volume de imagem inicial (Reference) e um volume de imagem de destino (Target). Durante o registro, a imagem destino é transformada para o sistema de coordenadas da imagem inicial, que permanece estacionária. A figura 3.11 mostra a caixa de opções com os parâmetros utilizados.

A figura 3.12 apresenta três projeções das imagens de antes e depois dos ensaios sobreposta antes do alinhamento, e abaixo após o alinhamento no DataViewer. Nas imagens antes do alinhamento é possível ver a borda em branco ou preto, mostrando que apenas um objeto está naquela posição. O que não acontece nas imagens após o alinhamento, nas quais as imagens de antes e depois dos ensaios estão totalmente sobrepostas. 


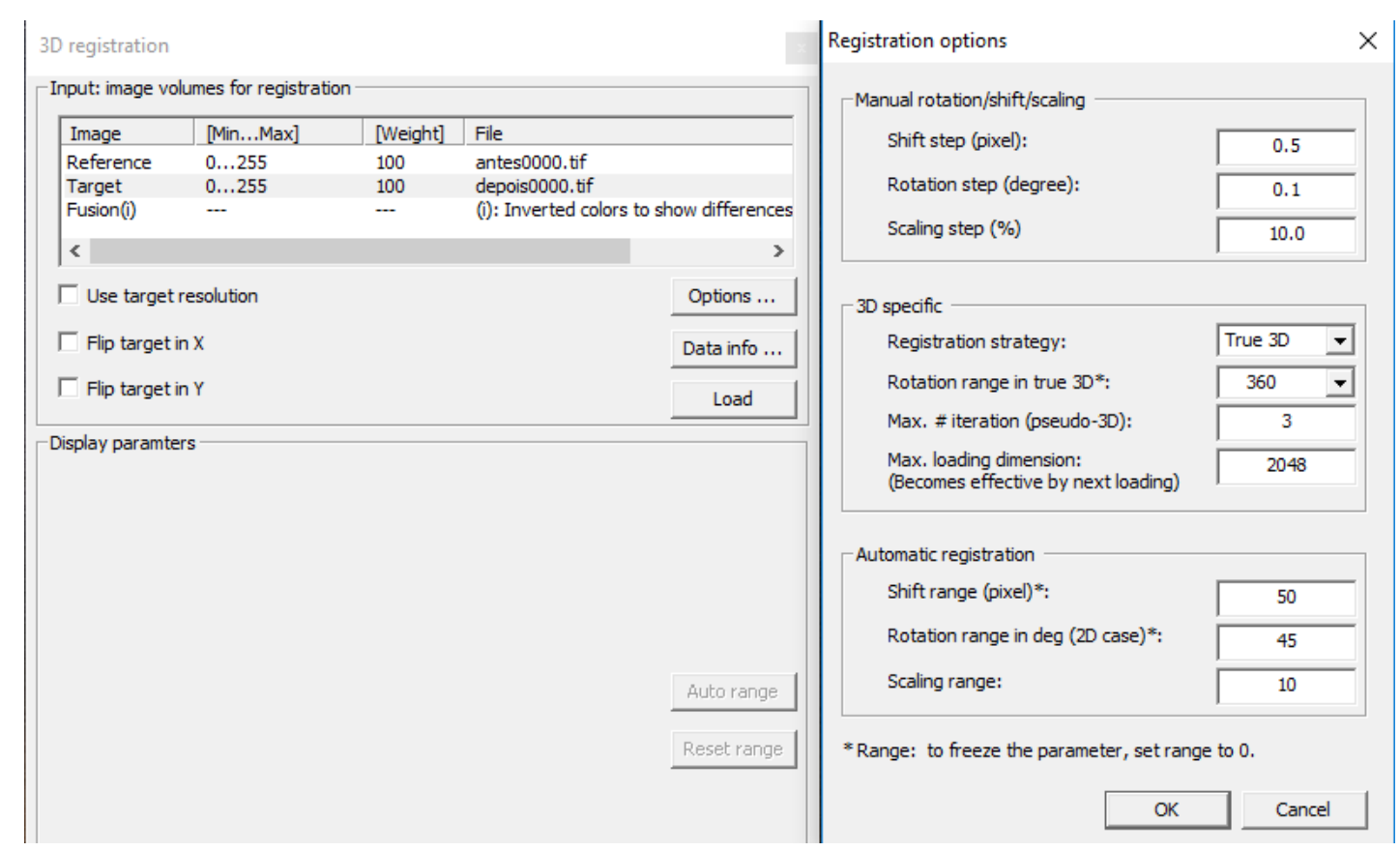

Figura 3.11: Parâmetros DataViewer.
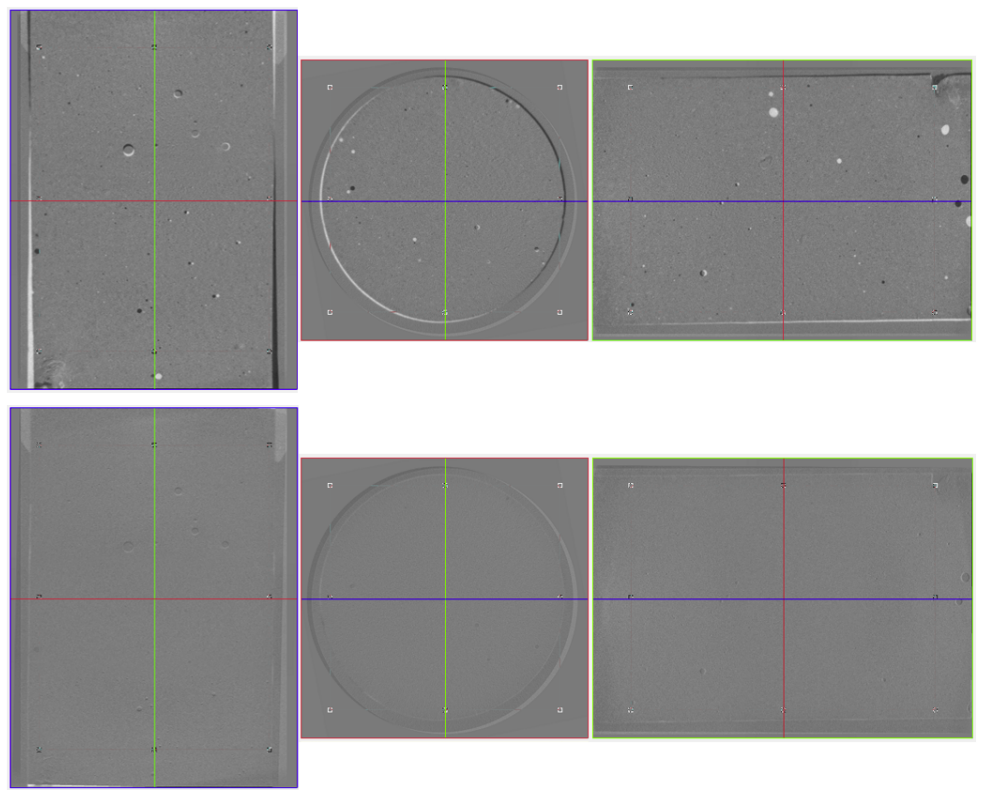

Figura 3.12: Imagens sobrepostas antes e depois do alinhamento no DataViewer.

Para a segmentação da pasta cimentícia e dos vazios foi utilizado o software Dragonfly V3.0. A segmentação se faz pela escolha de um tom de corte no histograma ("Threshold"). 
A Figura 3.13 mostra a segmentação da pasta cimentícia com o "Threshold"de 140, ou seja, tons acima de 140 são considerados pasta. Como os tons dos pixels do fundo da imagem são semelhantes aos dos vazios, não basta segmentar os vazios, pois isso acarretaria na segmentação do fundo junto. Portanto, é necessário segmentar primeiramente a pasta, em seguida preencher os vazios com o comando "fill inner areas", deixando segmentada toda o corpo de prova, e por fim subtrair a primeira imagem da segunda, deixando apenas os vazios segmentados.

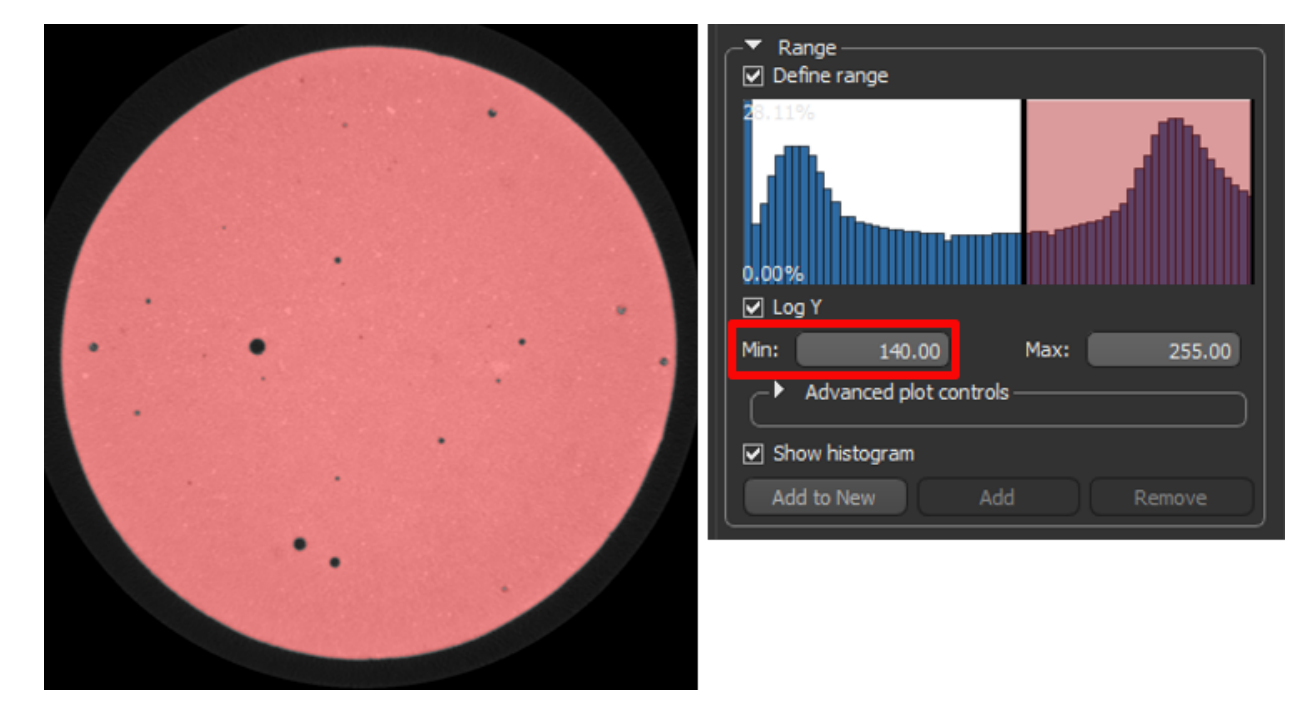

Figura 3.13: Segmentação da pasta cimentícia com o "Threshold"de 140.

Quando a imagem a ser segmentada apresenta apenas a pasta e poros o procedimento descrito anteriormente é suficiente. A dificuldade aparece quando acontece o surgimento de fissuras após os ensaios, uma vez que fissuras sutis (espessura menor que 3 pixels) permanecem com tons claros, dificultando sua discriminação da pasta de cimento. As fissuras nas bordas também são problemas para segmentação, já que se confundem com o fundo. A figura 3.14 mostra as imagens antes e depois do ensaio segmentadas com o mesmo valor do "Threshold". A utilização do mesmo "Threshold"seria o ideal quando são utilizados os mesmos parâmetros de reconstrução. Porém, pelos problemas citados acima, o resultado da segmentação após o ensaio não é satisfatório, uma vez que parte das fissuras não foi segmentada. 

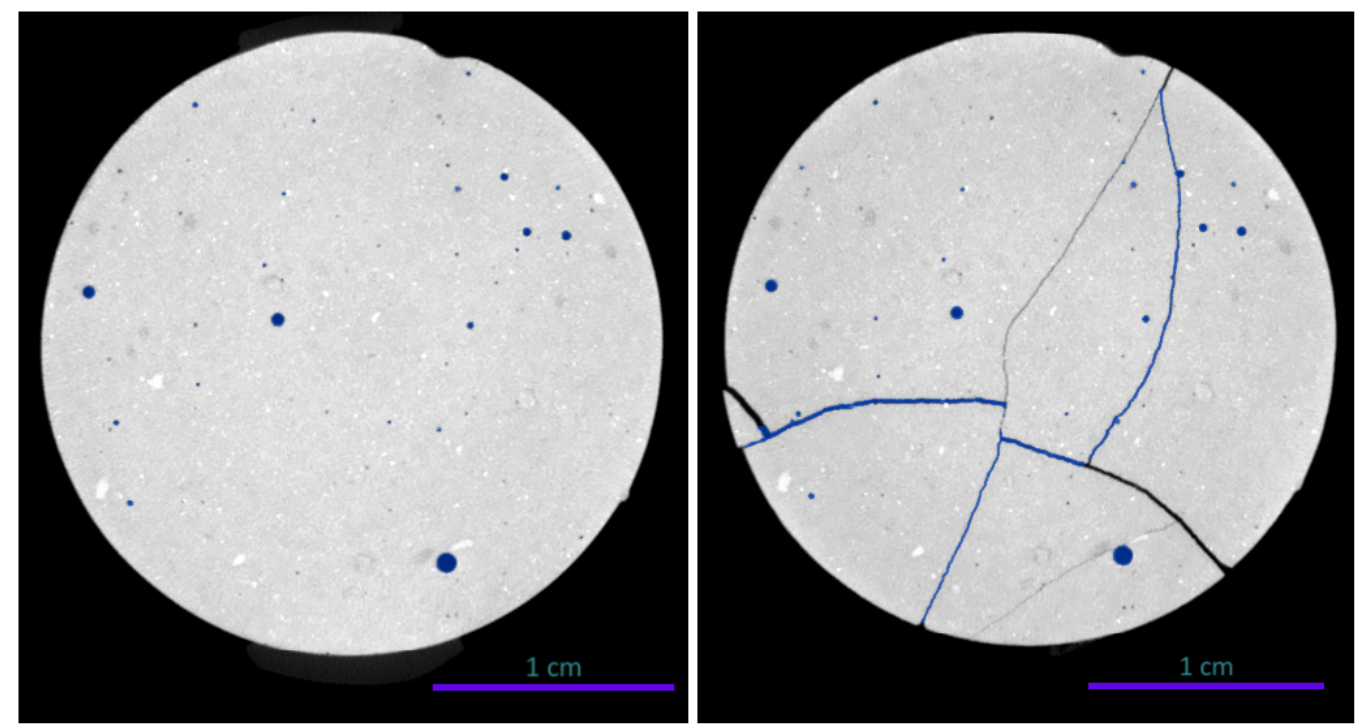

Figura 3.14: Segmentação antes e depois do ensaio com o mesmo valor de corte.

A solução para o problema de seleção da pasta de cimento quando ocorrem fissuras sutis está em aumentar o valor do "Threshold". A figura 3.15 apresenta a seleção da pasta antes do ensaio em um determinado valor de "Threshold", depois do ensaio no mesmo valor e depois do ensaio com um valor maior. Pode-se observar que quando o valor do tom de corte é aumentado, os poros são superdimensionados, mas algumas fissuras passam a ser discriminadas. Ainda assim, fissuras muito sutis não são separadas da pasta. Um limite entre esse superdimensionamento e a discriminação de fissuras deve ser levado em consideração. 

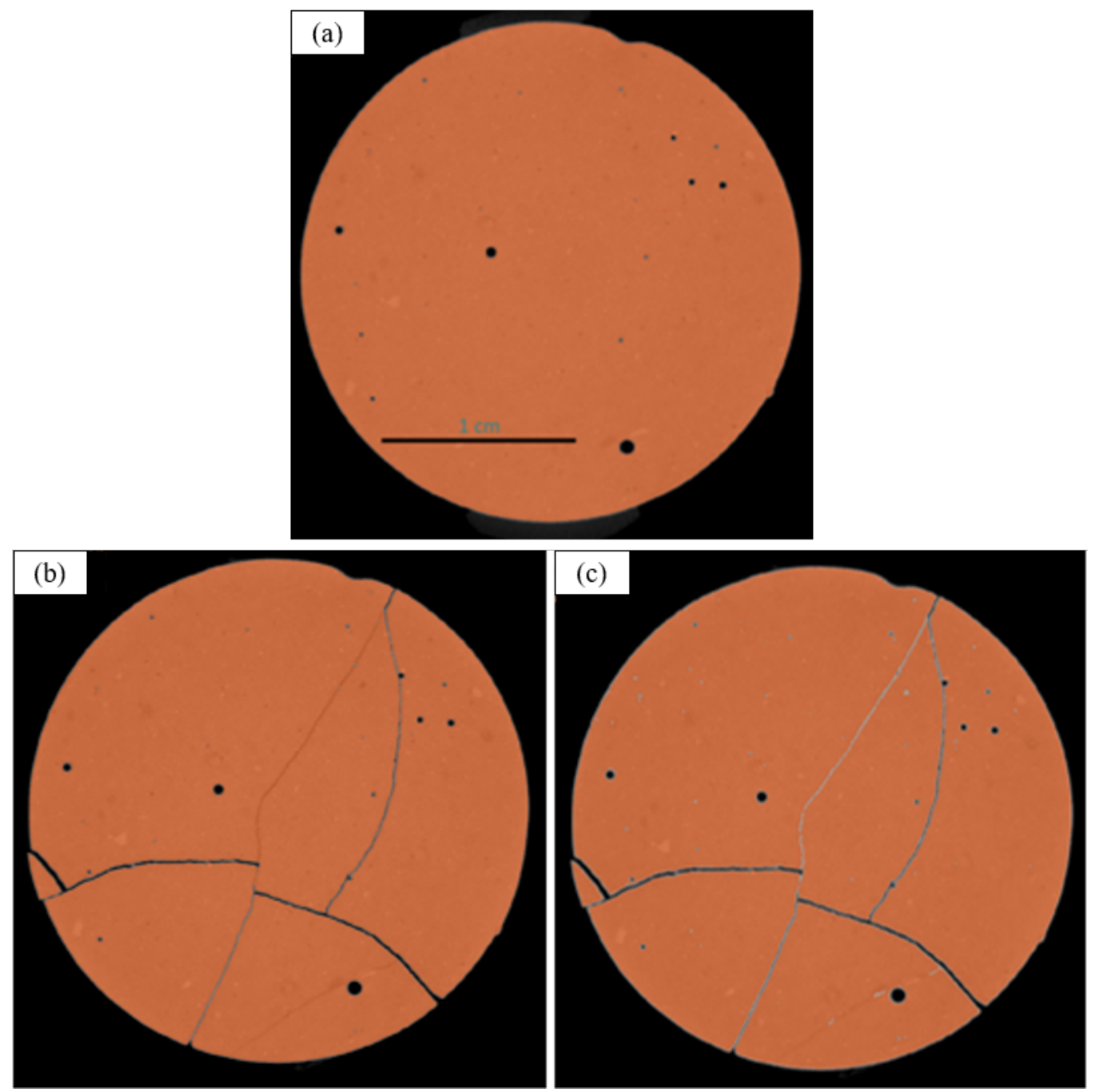

Figura 3.15: Seleção da pasta de cimento: (a) antes do ensaio com o valor de corte de 145; (b) depois do ensaio com o valor de corte de 145; (c) depois do ensaio com o valor de corte de 180 .

Quando o comando "fill inner areas"foi aplicado na imagem (c) da figura 3.15 , as fissuras conectadas com a parte externa não foram preenchidas, como mostra a imagem (a) da figura 3.16. Para o preenchimento dessas foi utilizado o comando "close", que pode ser definido como junção de dois outros comandos do Dragonfly V3.0: o "dilate", que expande a região de interesse, e o "erode", que encolhe a regiao de interesse. Utilizando o "dilate"seguido do "erode", o "close" dilata a fissura não segmentada até quando o algorítimo identifica uma forma semelhante ao elemento estruturante, que seria a borda da imagem. Dessa maneira é segmentado todo o corpo de prova, como mostra a imagem (b) da figura 3.16 . 

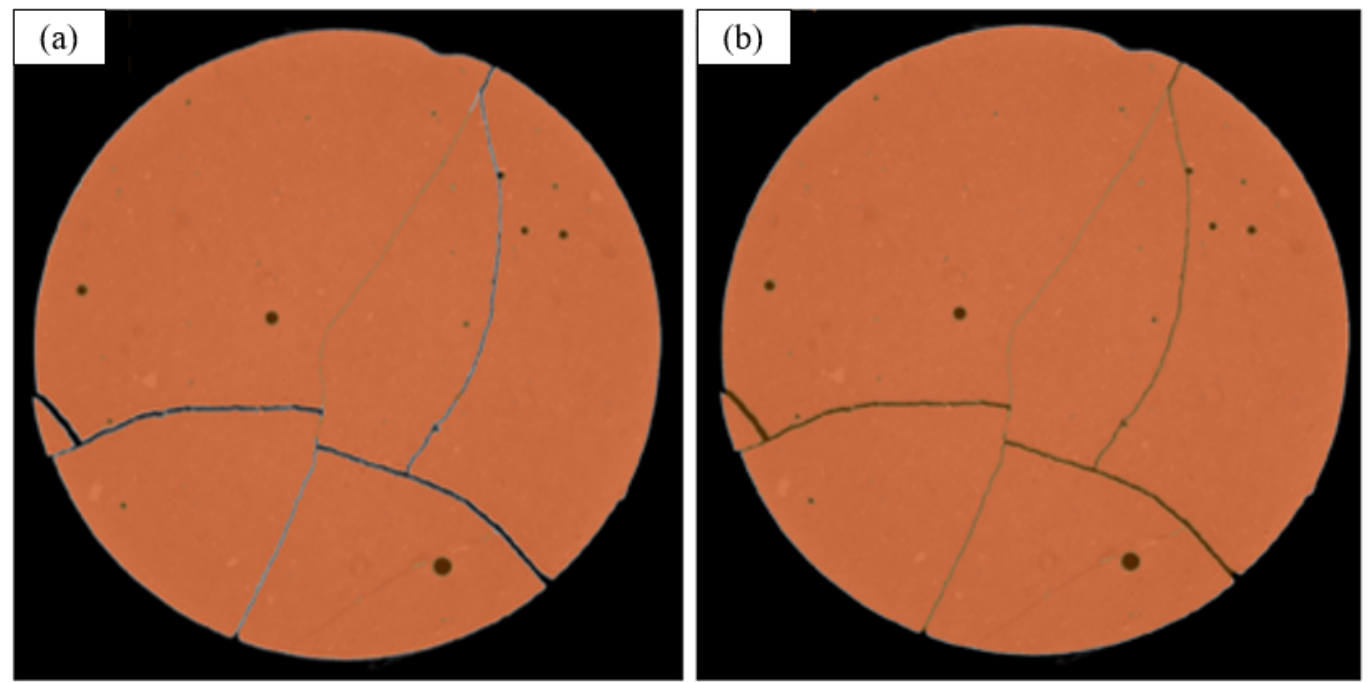

Figura 3.16: Seleção da pasta de cimento e vazios: (a) aplicação do comando "fill inner areas"; (b) aplicação do comando "fill inner areas"e "close".

Enfim, subtraindo a figura 3.15 (c) da figura 3.15 (b) foi obtido as fissuras e poros, como desejado. O resultado está na figura 3.17. Como o intuito da pesquisa é de comparar os vazios antes e depois dos ensaios, nos casos em que ocorreu aparecimento de fissura de mareira que o "Threshold"teve que ser aumentado, as imagens antes do ensaio também tiveram seus "Threshold"aumentado, mantendo o mesmo valor para antes e depois do ensaio.

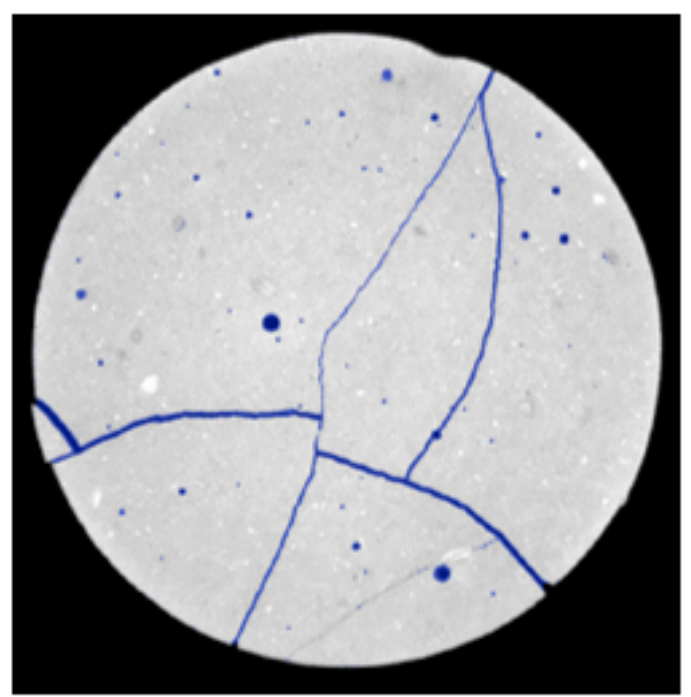

Figura 3.17: Segmentação de poros e fissuras. 


\subsection{2}

\section{Análise Digital das Imagens}

Após o processamento das imagens, no próprio Dragonfly V3.0 extraiu-se tanto informações qualitativas, quanto informações quantitativas. As informações qualitativas referem-se à visualização do aparecimento ou não de defeitos após um determinado ensaio e também das imagens antes e depois de cada ensaio dos poros segmentados sobrepostos, que podem confirmar ou não o crescimento ou aparecimento de poros. A importância da etapa de alinhamento é entendida neste momento, pois quando as imagens de antes e depois são sobrepostas, pode ser analisada a diferença de vazios (aparecimento ou crescimento de poros ou fissuras).

As informações quantitativas são dadas também pelo software Dragonfly V3.0, apresentando o volume e esfericidade das regiões de interesse. O volume pode ser de toda a parte segmentada (vazios), mostrando a porosidade do material, ou também de algum vazio separado que seja de interesse a análise. A esfericidade diz sobre a forma do poro, que é a medida de quão próxima a forma do objeto se aproxima de uma esfera. É definida por uma equação que relaciona o volume do poro com sua área de superfície, de maneira que quando for uma esfera o resultado é 1 . Com o intuito de apresentar a variabilidade de poros encontrados nesta pesquisa, a figura 3.18 mostra a esfericidade dada pelo Dragonfly V3.0 de alguns exemplos, com seus respectivos volumes. O objetivo dos dados quantitativos é relacionar o tamanho e formato do poro com a propiciedade de formação de fissura.

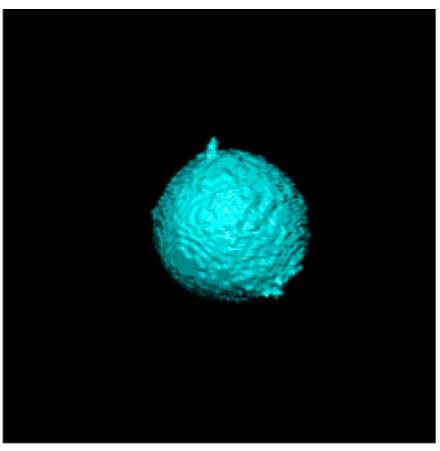

ESFERICIDADE: 0,64 VOLUME: $1,61 \mathrm{~mm}^{3}$

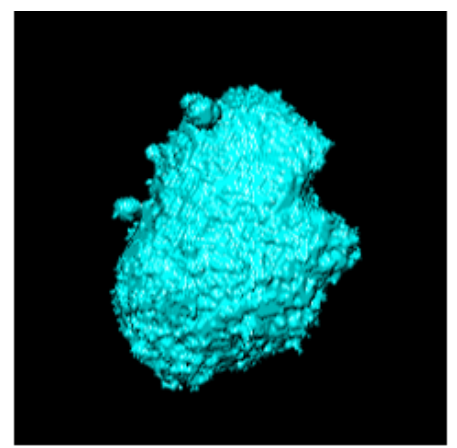

ESFERICIDADE: 0,43 VOLUME: $3,54 \mathrm{~mm}^{3}$

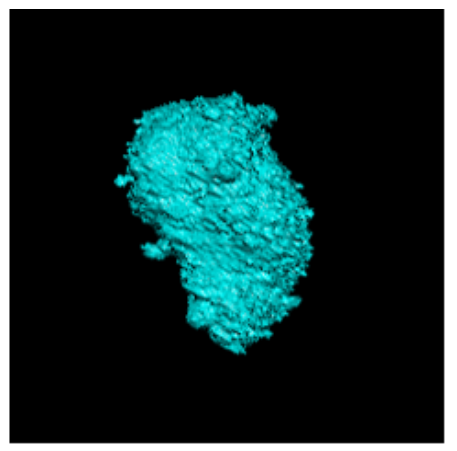

ESFERICIDADE: 0,28 VOLUME: $2,42 \mathrm{~mm}^{3}$

Figura 3.18: Poros com os dados de esfericidade e volume. 


\section{4 \\ Resultados e Discussões}

\section{1}

\section{Ensaio de Carregamento Cíclico}

\subsection{1}

\section{Ensaio de Compressão em Corpos de Prova com Diferentes Idades}

Os resultados dos ensaios de compressão em diferentes idades estão mostradas na tabela 4.1, assim como suas respectivas médias e desvios padrões.

Tabela 4.1: Resultados de tensão de ruptura (MPa) dos ensaios de compressão em corpos de prova diferentes idades.

\begin{tabular}{lccc} 
& 30 dias & 49 dias & 107 dias \\
\hline & 46,52 & 51,59 & 59,66 \\
& 35,19 & 50,86 & 43,36 \\
& 32,39 & 43,00 & 48,33 \\
& & 51,21 & 57,45 \\
Média $(\bar{X})$ & 38,03 & 49,17 & 52,20 \\
Desvio Padrão (dp) & 7,48 & 4,12 & 7,67
\end{tabular}

Esse resultado levou à decisão de utilizar como base da tensão máxima e mínima no ensaio de carregamento cíclico a média da tensão de ruptura $\left(\sigma_{r}\right)$ de corpos de prova da mesma leva. Isso porque o aumento da idade resultou em um aumento na resistência, apesar de apresentar desvios padrões altos. Além disso, é provável que os corpos de prova da mesma leva sofram menos influência de possíveis alterações na moldagem dos corpos de prova. 


\subsection{2}

\section{Ensaio de Compressão na máquina RTR-1500 Rapid Triaxial Rock}

O gráfico da figura 4.1 mostra o resultado do ensaio de compressão realizado na máquina RTR-1500 Rapid Triaxial Rock de dois corpos de prova aos 49 dias de idade (CP A e CP B). Nos gráficos foram traçadas as respectivas retas tangentes. No CP A a tensão de ruptura foi de 29,09 MPa e a partir de aproximadamente $6 \mathrm{MPa}\left(20,6 \%\right.$ da $\left.\sigma_{r}\right)$ observa-se que a inclinação da curva começa a mudar, o que pode estar associado ao aparecimento de defeitos. Já no CP B a tensão de ruptura foi de 24,04 MPa e alteração da curva começa a ser percebida em aproximadamente $4 \mathrm{MPa}\left(16,7 \%\right.$ da $\left.\sigma_{r}\right)$.
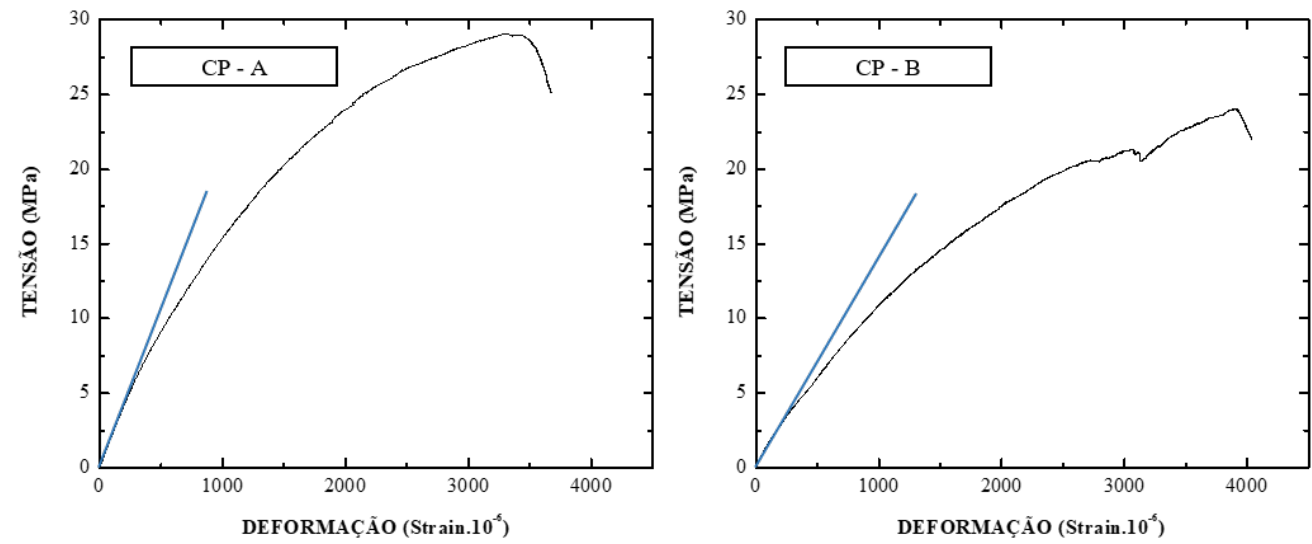

Figura 4.1: Curva Tensão x Deformação dos CP A e B e as respectivas retas tangente à zona elástica.

As tensões de rupturas nesses CP foram muito abaixo do valor encontrado nos ensaios de compressão em corpos de prova com diferentes idades para 49 dias (tabela 4.1), que apresentaram valor médio de 49,17 MPa. A explicação para isso é que, primeiramente, quanto maior o volume do corpo de prova maior a probabilidade de se encontrar defeitos, motivo pelo qual existe uma alta variação no resultado de tensão de ruptura apresentado pelos materiais cerâmicos. Outra justificativa é que o ensaio na máquina RTR-1500 Rapid Triaxial Rock é feito de forma muito mais lenta, 0,005 mm/min, enquanto os outros ensaios são executados a $0,5 \mathrm{~mm} / \mathrm{min}$. Isso acarreta um acúmulo de defeitos durante o ensaio, o que leva o corpo de prova a romper em uma menor tensão de ruptura. Esse é o motivo também da curva tensão x deformação apresentar a real perda de rigidez do material. 
A figura 4.2 mostra a diferença dos gráficos tensão x deformação obtidos nessas situações. O primeiro gráfico é do ensaio na máquina de compressão Material Test System (MTS) 810 de um corpo de prova de 25,4 milímetros de diâmetro e 50,8 milímetros de altura aos 49 dias de idade, que resultou em uma tensão de ruptura de 50,86 MPa. Observa-se um aumento brusco na deformação em aproximadamente 15 e $35 \mathrm{MPa}$, mas a inclinação pouco muda durante o ensaio, quando comparada com o segundo gráfico. O segundo gráfico é da máquina RTR-1500 Rapid Triaxial Rock de um CP de 50 milímetros de diâmetro e 100 milímetros de altura testada aos 49 dias de idade que resultou em uma tensão de ruptura de 29,09 MPa.
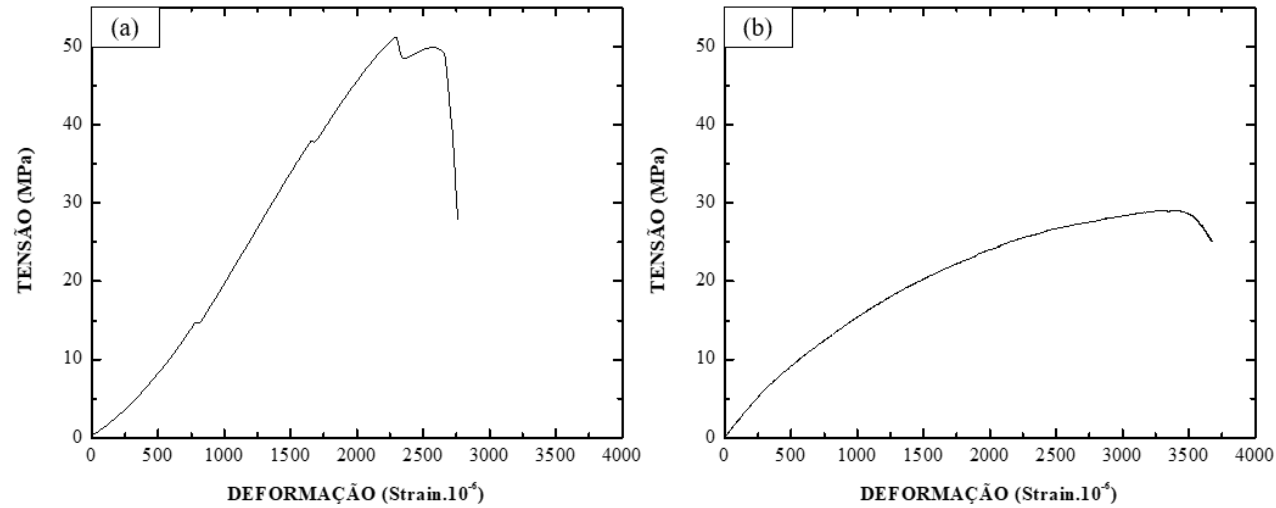

Figura 4.2: Comparação de curvas Tensão x Deformação de ensaios realizados: (a) na máquina Material Test System (MTS) 810 e; (b) na máquina RTR-1500 Rapid Triaxial Rock.

Os ajustes lineares da curva de até 30\% (I) da tensão de ruptura, de 30\% até $50 \%$ (II), de $50 \%$ até $70 \%$ (III) e de $70 \%$ até $90 \%$ (IV) dos dois corpos de prova estão apresentados na figura 4.3. A tabela 4.2 mostra a inclinação da zona elástica (módulo de elasticidade do material) e as inclinações indicadas na figura 4.3. Já para até $30 \%$ da tensão de ruptura a inclinação diminui, mostrando que tensões baixas, como as de 30\%, são suficientes para causar danos no material em questão. E a medida que a tensão aumenta a inclinação diminui cada vez mais, como esperado.

A diferença na $\sigma_{r}$ e no módulo de elasticidade nos CP A e B é justificada pela provável variação de defeitos iniciais presentes em cada corpo de prova, contudo, os dois ensaios comprovaram que baixas tensões são capazes de provocar danos na pasta de cimento classe G. 

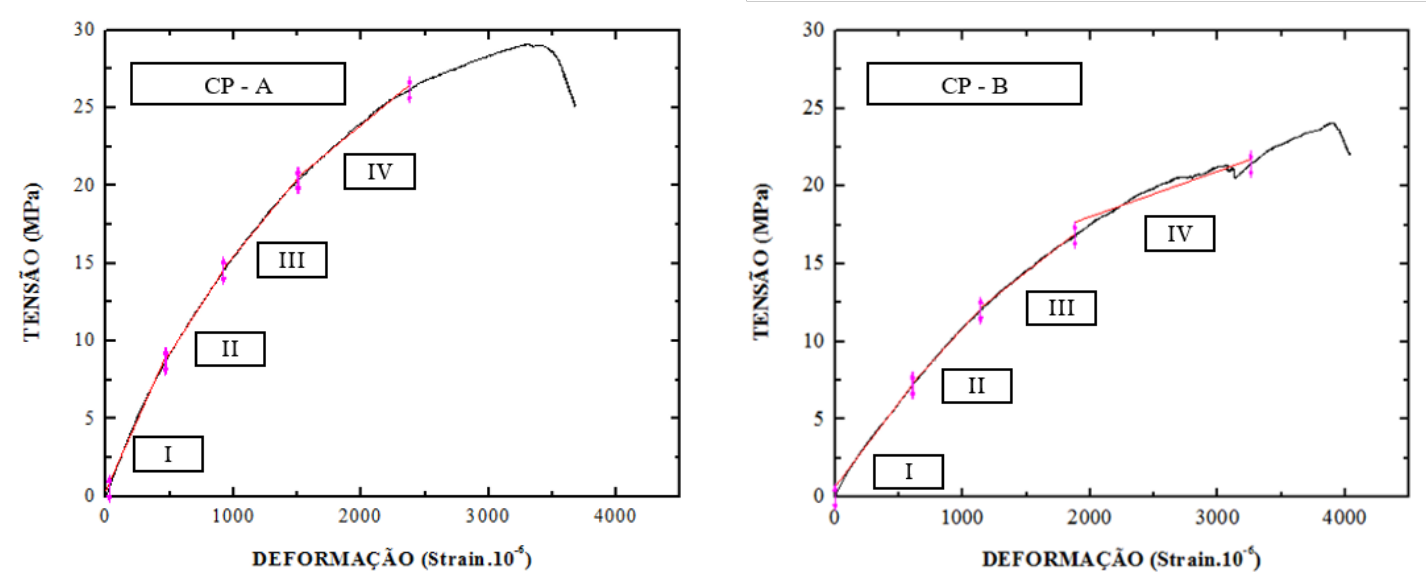

Figura 4.3: Ajuste linear das curvas Tensão x Deformação dos corpos de prova A e B.

Tabela 4.2: Inclinações (GPa) das curvas Tensão x Deformação dos corpos de prova A e B.

\begin{tabular}{crr} 
& CP A & CP B \\
\hline Zona Elástica & 20,20 & 12,25 \\
I & 18,39 & 10,82 \\
II & 12,75 & 9,00 \\
III & 9,97 & 6,43 \\
IV & 6,76 & 2,89
\end{tabular}

\subsection{3}

Análise de dano, microestrutura e correlação com propriedades mecânicas

\subsubsection{1}

\section{CP 1 - 500.000 ciclos a $30 \%$ da tensão de ruptura}

A tabela 4.3 apresenta os resultados do ensaio de compressão de três corpos de provas da mesma leva dos CP 1 e 2. Os ensaios de compressão desses corpos de prova e o ensaio cíclico do CP 1 foram realizados com 32 dias de idade. 
Tabela 4.3: Tensões de ruptura (MPa) dos corpos de prova de referência para os CP 1 e 2.

\begin{tabular}{lc} 
& $\sigma_{r}(\mathbf{M P a})$ \\
\hline & 55,44 \\
& 54,04 \\
& 39,71 \\
Média $(\bar{X})$ & 49,73 \\
Desvio Padrão (dp) & 8,71
\end{tabular}

A partir da média $(\bar{X})$, tem-se que a $\sigma_{m a ́ x}=14,92$ e $\sigma_{m i n}=2,98$. A figura 4.4 apresenta a imagem 2D de uma seção antes do ensaio de 500.000 ciclos e a mesma seção após o ensaio com o aparecimento de uma pequena fissura. Essa apresentou uma espessura aproximada de 2 pixels, o que representa aproximadamente $60 \mu \mathrm{m}$. Lembrando que defeitos menores que 1 pixel não podem ser observados, portanto, se ocorreu aparecimento de fissuras menores que $30 \mu \mathrm{m}$, essas não são detectadas. O comprimento da fissura foi de aproximadamente $3,25 \mathrm{~mm}$.
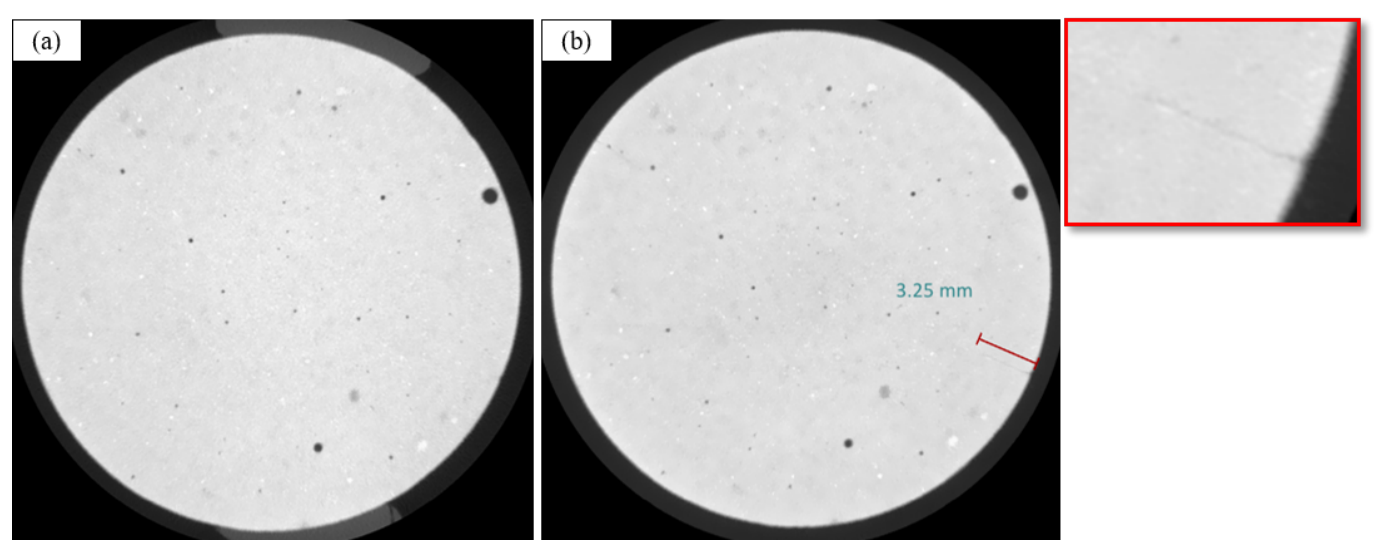

Figura 4.4: Seção do corpo de prova: (a) antes do ensaio cíclico de 500.000 ciclos a 30\% da tensão de ruptura; (b) depois do ensaio com detalhe em zoom.

A figura 4.5 apresenta as imagens 3D da tomografia segmentadas com o valor do "threshold" de 150. Esse valor não é suficiente para segmentar a fissura da figura 4.4. O "threshold" suficiente para a segmentação da fissura acarretaria segmentar partes do CP que não são vazios, pois o tom da fissura é parecido com o tom da pasta de cimento. A figura 4.5 (a) mostra os poros antes do ensaio distribuídos de acordo com a faixa de cor de volume apresentada, vermelho para poros pequenos até o verde para o poro de $3,84 \mathrm{~mm}^{3}$. 
Já a figura 4.5 (b) apresenta os poros após o ensaio, com o mesmo poro em verde com $3,91 \mathrm{~mm}^{3}$, esse aumento é pequeno e pode ter sido causado pelo fato de ser um poro que está na parte superior do corpo de prova, onde foi realizado um "crop". A última imagem (c) é sobreposição de (a) e (b), no qual os poros estão alinhados e não é percebido aumento nos poros, que pode ser comprovado pelos dados quantitativos fornecidos pelo Dragonfly V3.0 (tabela 4.6). Houve, inclusive, um pequeno decréscimo no volume dos poros, que provavelmente se deve por fontes potenciais de incertezas durante a microCT.
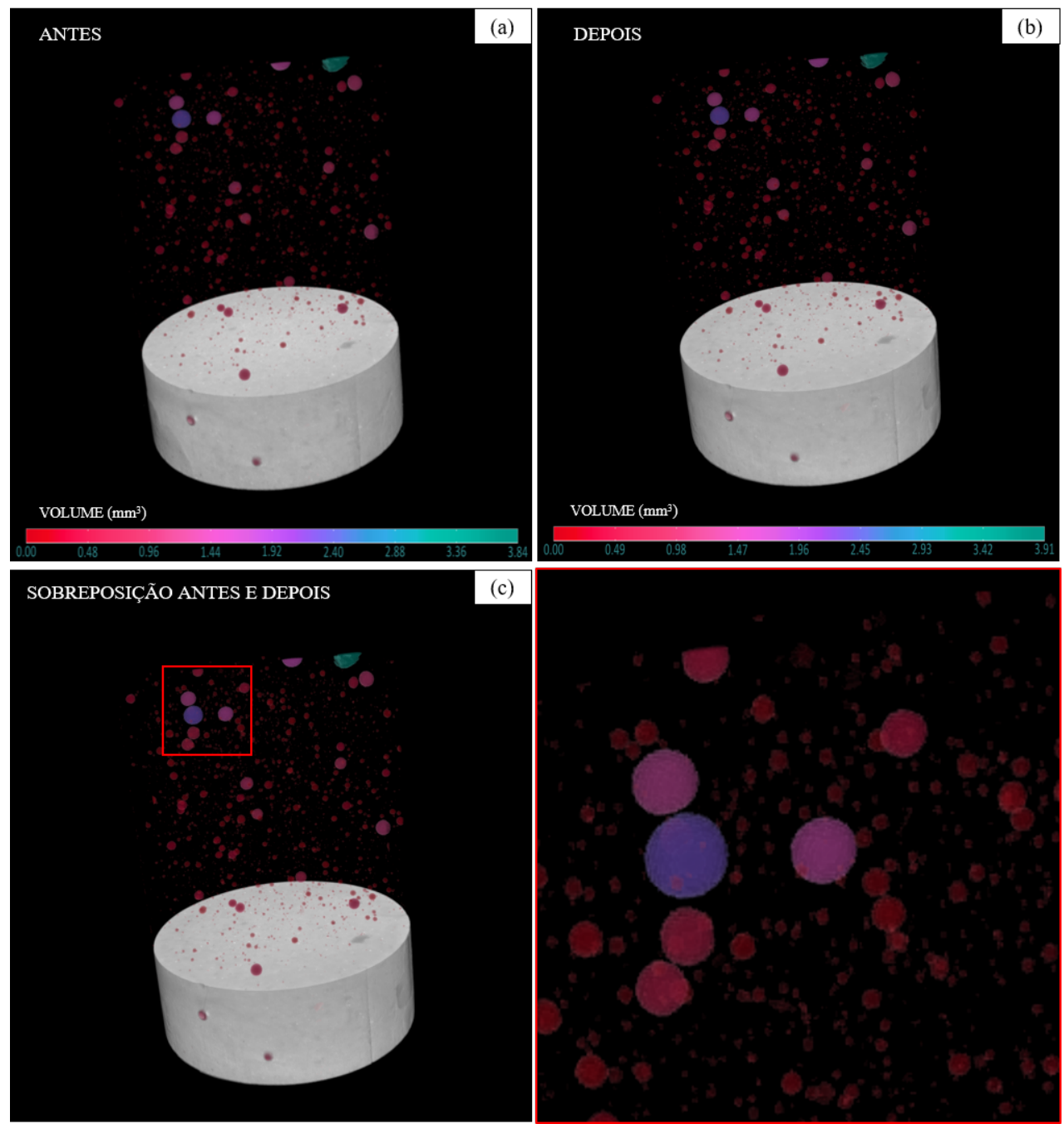

Figura 4.5: Poros em 3D: (a) antes do ensaio de 500.000 ciclos a 30\% da tensão de ruptura; (b) depois do ensaio; (c) sobreposição de (a) e (b). 
Essa diferença causada durante a microCT leva à variação no volume de todos os poros, por isso, calcular o volume médio de poros (volume total dos poros dividido pela quantidade de poros), confirmaria que o aumento ou diminuição do volume foi causada por esse efeito. Deve-se levar em consideração que, quando ocorre essa variação na tomografia, poros pequenos são segmentados ou deixam de ser segmentados, para um mesmo "threshold". Por isso, poros pequenos devem ser excluídos da segmentação, e o valor arbitrário escolhido para poros pequenos foi os poros de até 9 voxels $\left(2,3 \times 10^{-4} \mathrm{~mm}^{3}\right)$.

A tabela 4.4 mostra a quantidade de poros e o volume total desses poros antes e depois do ensaio sem eliminar poros considerados pequenos. Já a tabela 4.5 mostra esses resultados quando os poros de até 9 voxels são excluídos e os volumes médios de poros. Percebece-se que ocorre uma diminuição brusca no númeno de poros antes do ensaio, e uma diminuição não tão grande para depois do ensaio, enquanto o volume de poros pouco é afetado. Analisando as imagens segmentadas, observou-se que existia uma grande população de poros na borda do corpo de prova antes do ensaio, o que não aparecia na imagems pós ensaio. Isso pode ter ocorrido por algum efeito ocorrido na borda do corpo de prova durante a tomografia. Quando muitos desses pequenos poros são elimindaos, o volume médio de poros tende a ser similar (tabela 4.5), mostrando que não houve alteração nos poros com o ensaio.

Tabela 4.4: Número e volume de poros antes e depois do ensaio de 500.000 ciclos a $30 \%$.

\begin{tabular}{lrr} 
& Antes & Depois \\
\hline Número de Poros & 14.054 & 6.122 \\
Volume de Poros $\left(\mathrm{mm}^{3}\right)$ & 54,8 & 53,4
\end{tabular}

Tabela 4.5: Número e volume de poros antes e depois do ensaio de 500.000 ciclos a $30 \%$ eliminando poros de até 9 voxels.

\begin{tabular}{lrr} 
& Antes & Depois \\
\hline Número de Poros & 4.043 & 3.424 \\
Volume de Poros $\left(\mathrm{mm}^{3}\right)$ & 54,3 & 53,2 \\
Volume Médio $\left(\mathrm{mm}^{3}\right)$ & 0,013 & 0,016
\end{tabular}


Plessis et al. (25) realizaram uma pesquisa na qual variaram a resolução de imagens de um concreto obtidas por microCT. Eles tiveram como resultado que para resoluções de 100,60, 40, 20, 10 e $5 \mu$ as porosidades médias foram de $2,4 \%, 2,3 \%, 2,0 \%, 2,0 \%$, e 2,4\%. Isso significa que o aumento da resolução não tem influência significativa na porosidade do material, provavelmente porque poros pequenos tem pouca influência na porosidade total. Condizendo com a diminuição da porosidade pouco expressiva quando poros de 9 voxels são eliminados da tabela 4.4 para a tabela 4.5. A porosidade na pesquisa de Plessis et al. (24) foi maior que nesta, que pode ser explicado por esta ser uma pasta de cimento e aquela um concreto.

Enfim, o volume total do corpo de prova considerado na análise, o volume de poros segmentado e a fração volumétrica de poros (porosidade do material) estão apresentados na tabela 4.6.

Tabela 4.6: Porosidade antes e depois do ensaio de 500.000 ciclos a $30 \%$.

\begin{tabular}{lrr} 
& Antes & Depois \\
\hline Volume Total $\left(\mathrm{mm}^{3}\right)$ & 18.111 & 18.074 \\
Volume de Poros $\left(\mathrm{mm}^{3}\right)$ & 54 & 53 \\
Fração de Poros $(\%)$ & 0,30 & 0,29
\end{tabular}

Sobre a esfericidade dos poros, na figura 4.6 percebe-se que a maioria dos poros está com esfericidade por volta de 0,65 , como mostra o tom de azul da faixa de cor de esfericidade antes e depois do ensaio. Esses poros são consideravelmente esféricos, quando comparados com os típicos encontrados nesta pesquisa.

A curva de histerese gerada dos dados obtidos no ensaio está na figura 4.7, com as curvas de 10 ciclos e 500.000 ciclos apresentadas. O gráfico mostra que a deformação aumentou, mas não houve um aumento na inclinação. Ou seja, o material não perdeu rigidez com o ensaio. 


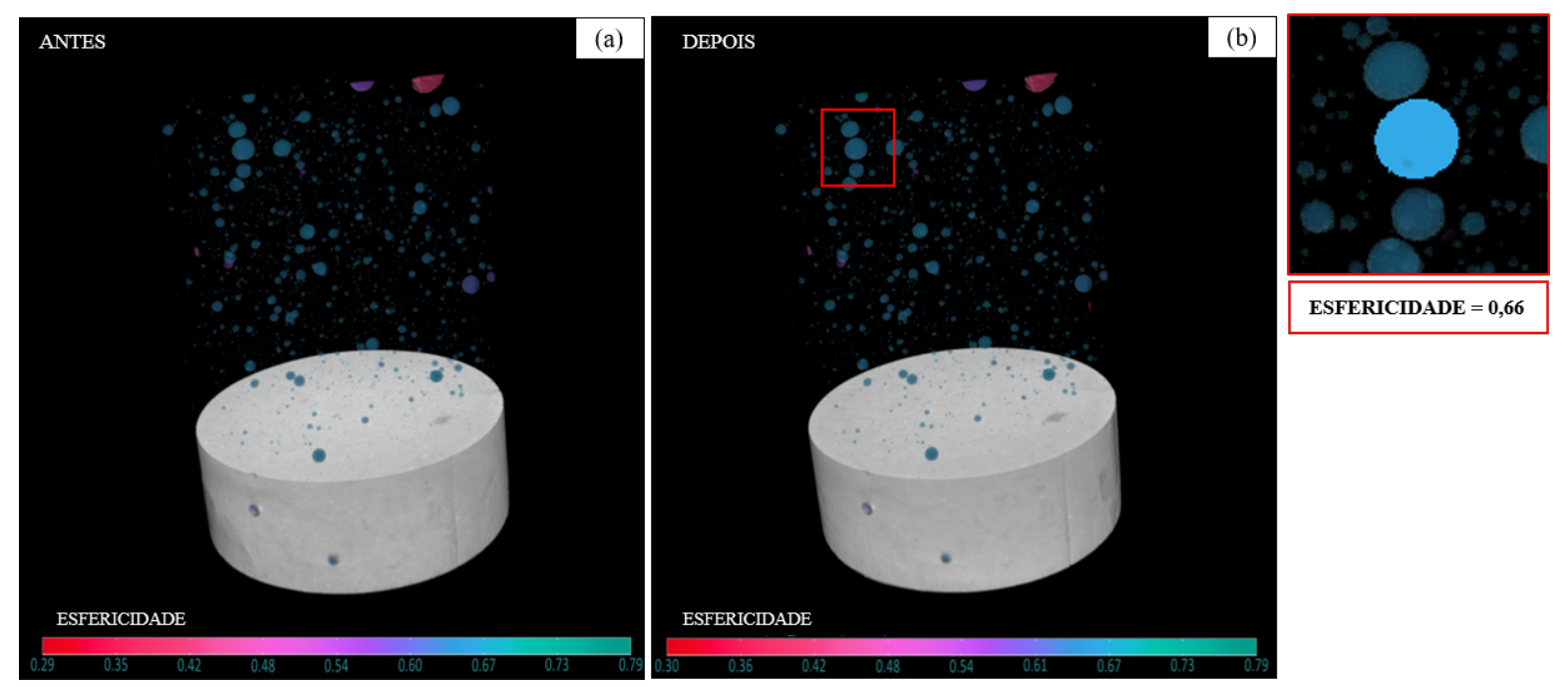

Figura 4.6: Esfericidade dos Poros em 3D: (a) antes do ensaio de 500.000 ciclos a $30 \%$ da tensão de ruptura; (b) depois do ensaio.

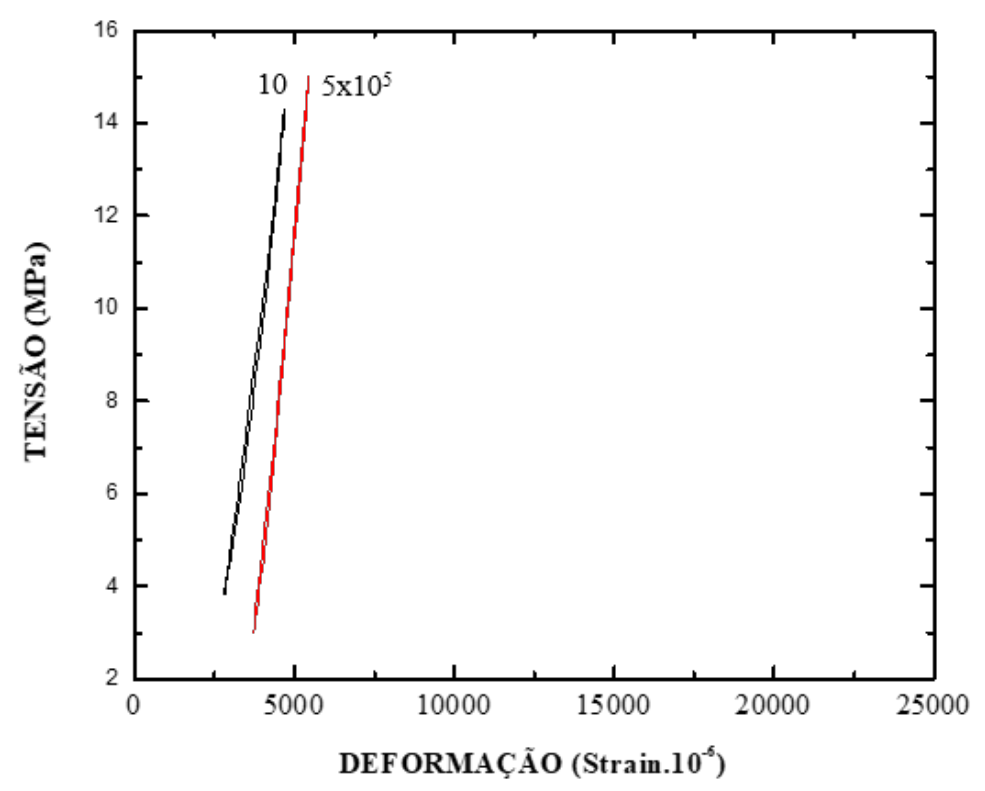

Figura 4.7: Curva de histerese do ensaio cíclico de 500.000 ciclos a $30 \%$ da tensão de ruptura.

Após a segunda microCT o corpo de prova 1 foi submetido a um ensaio estático de compressão, no qual obteve-se $F_{r}=31,68 \mathrm{kN}$. Com isso concluise que a carga máxima utilizada no ensaio cíclico foi menor que $30 \%$ e que provavelmente os 500.000 ciclos pouco influenciaram na sua resistência. 


\subsubsection{2}

\section{CP 2 - $\mathbf{1 . 0 0 0 . 0 0 0}$ ciclos a $30 \%$ da tensão de ruptura}

O CP 2 é da mesma leva do CP 1, portanto, para $30 \%$ os valores de $\sigma_{m a ́ x}$ e $\sigma_{m i n}$ foram os mesmos $\left(\sigma_{m a ́ x}=14,92\right.$ e $\left.\sigma_{m i n}=2,98\right)$. O ensaio cíclico desta foi realizado com 60 dias de idade. Foi observado o aparecimento de uma pequena fissura após o ensaio, que atravessa praticamente todo o corpo de prova. Essa fissura parte de um defeito inicial do corpo de prova, local propício para a sua propagação. A figura 4.8 (a) apresenta uma seção antes do ensaio, destacando o defeito inicial e a (b) mostra a fissura formada a partir desse defeito. A fissura apresentou uma espessura aproximada de 2 pixels, o que representa aproximadamente $60 \mu \mathrm{m}$ e seu comprimento variou a longo do corpo de prova, na seção apresentada está com 2,90 mm.
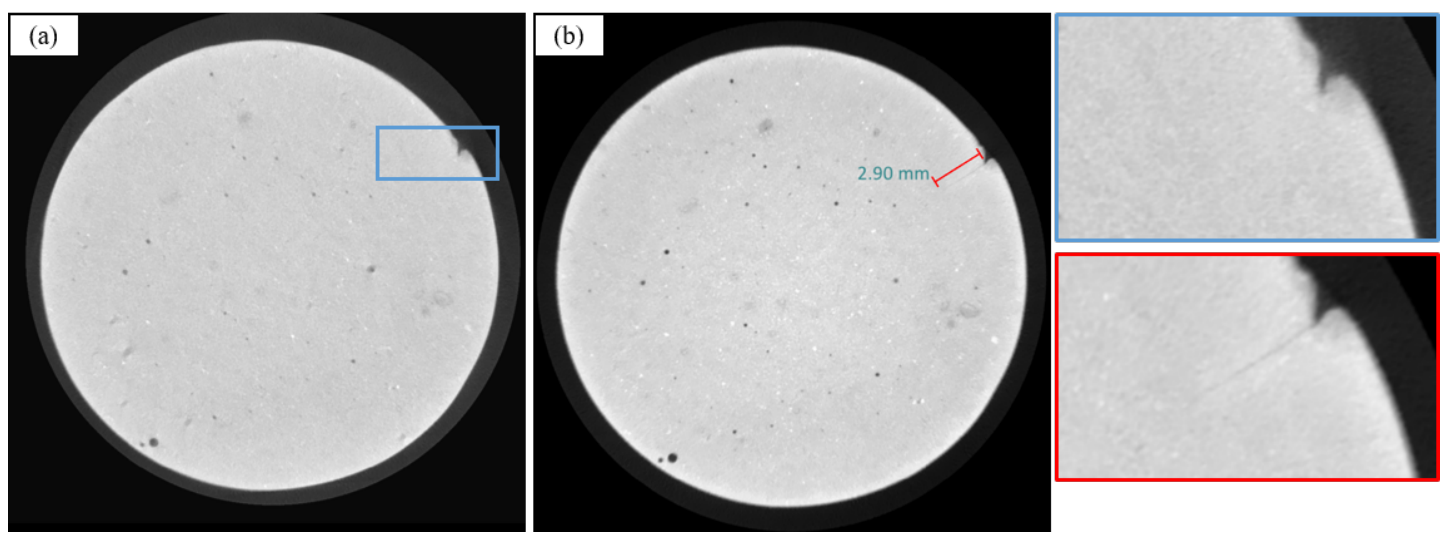

Figura 4.8: Seção do corpo de prova: (a) antes do ensaio cíclico de 1.000.000 ciclos a 30\% da tensão de ruptura; (b) depois do ensaio.

A segmentação dos poros foi realizada com o valor do "threshold" de 140, valor não suficiente para segmentação da fissura. As imagens em 3D dessa segmentação, com os poros distribuídos de acordo com uma faixa de volume estão na figura 4.9. As imagens da figura 4.9 (a) e (b) mostram que a faixa de volume aumentou de $6,81 \mathrm{~mm}^{3}$ para $6,96 \mathrm{~mm}^{3}$. Aumento praticamente desprezível, que provavelmente se deve por fontes potenciais de incertezas durante a microCT. 

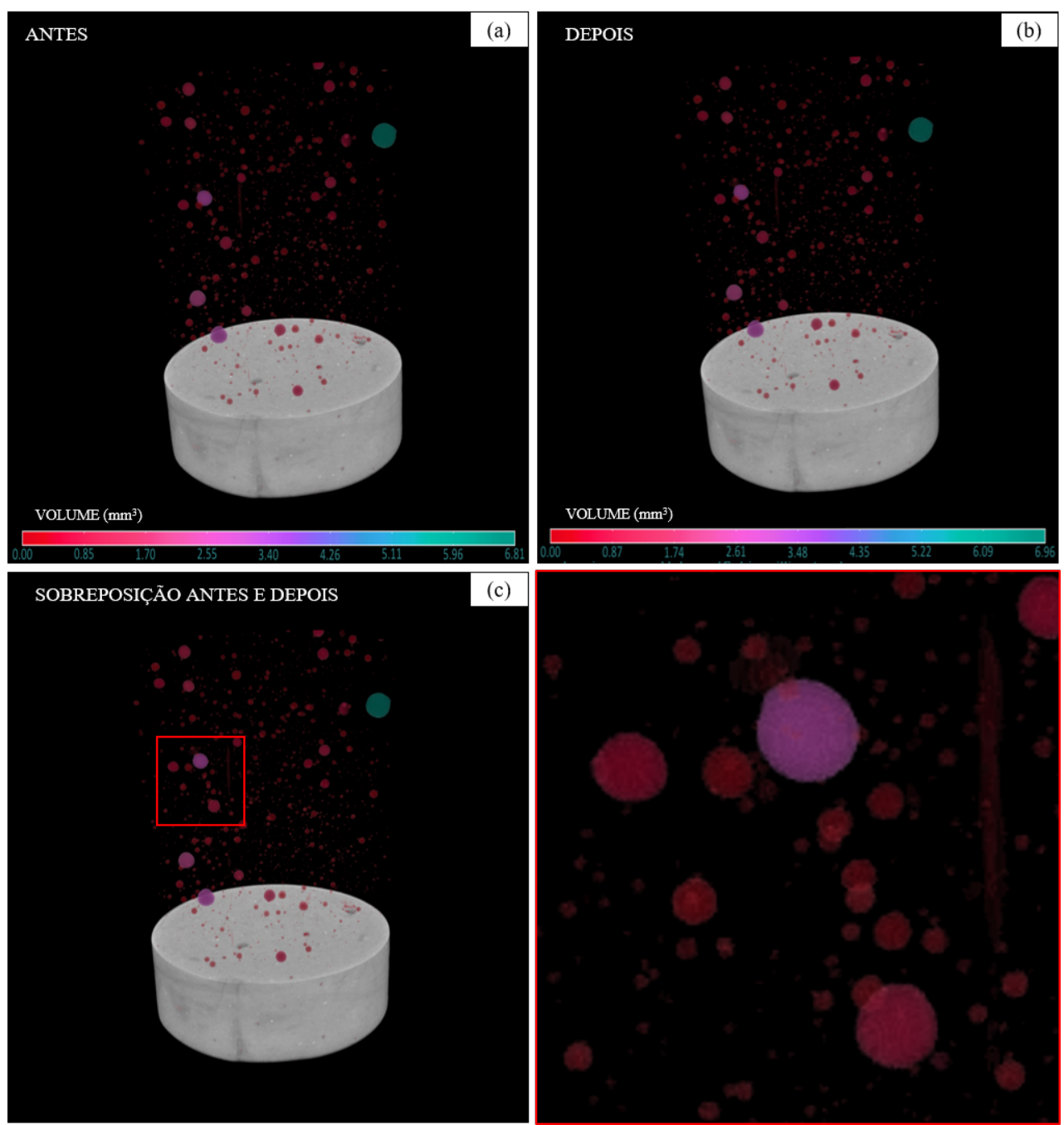

Figura 4.9: Poros em 3D: (a) antes do ensaio de 1.000.000 ciclos a $30 \%$ da tensão de ruptura; (b) depois do ensaio; (c) sobreposição de (a) e (b).

Para confirmação disso, a avaliação de volume médio de poros feita para o CP 1 também foi feita para o CP 2. Na tabela 4.7 apresenta o número de poros e o volume de poros já com os 9 voxels excluídos. O volume médio de poros apresentou uma variação maior que do CP 1, porém quando se elimina poros ainda maiores do que 9 voxels, essa variação tende a diminuir, mostrando que este volume médio está sendo afetado por quantidade de objetos pequenos que possivelmente não sejam poros. A consideração de poros pequenos é bastante arbitrária, mas o fato que o aumento do maior poro (percebido pela faixa de volume) e que o número de poros aumentou releva que a tomografia após o ensaio segmentou regiões maiores para um mesmo "threshold". Na imagem de sobreposição de antes e depois do ensaio da figura 4.9 (c) não é visível a variação nos poros, provando qualitativamente que não houve alteração nos poros. 
Tabela 4.7: Resultado quantitativo do ensaio de 1.000.000 ciclos a 30\%.

\begin{tabular}{lrr} 
& Antes & Depois \\
\hline Volume total $\left(\mathrm{mm}^{3}\right)$ & 20.682 & 20.563 \\
Volume de Poros $\left(\mathrm{mm}^{3}\right)$ & 54,4 & 62,9 \\
Fração de poros $(\%)$ & 0,26 & 0,31 \\
Número de Poros & 2.448 & 3.960 \\
Volume Médio $\left(\mathrm{mm}^{3}\right)$ & 0,022 & 0,016
\end{tabular}

Ainda sobre os dados obtidos do Dragonfly V3.0 apresentados na tabela 4.7, observa-se que a porosidade dos CP 1 e 2 também são similares. Essa similaridade era esperada, uma vez que são CP de uma mesma leva. O comportamento dos dois corpos de prova também foi similar: aparecimento de pequena fissura após submetidos ao carregamento cíclico a 30\% da tensão de ruptura.

A esfericidade dos poros está na figura $4.10 \mathrm{com}$ sua respectiva faixa de cor. A faixa de cor não variou, por essa razão apenas a imagem após o ensaio está apresentada. Os poros estão com esfericidade sem grandes variações em torno de 0,65, como no CP 1.

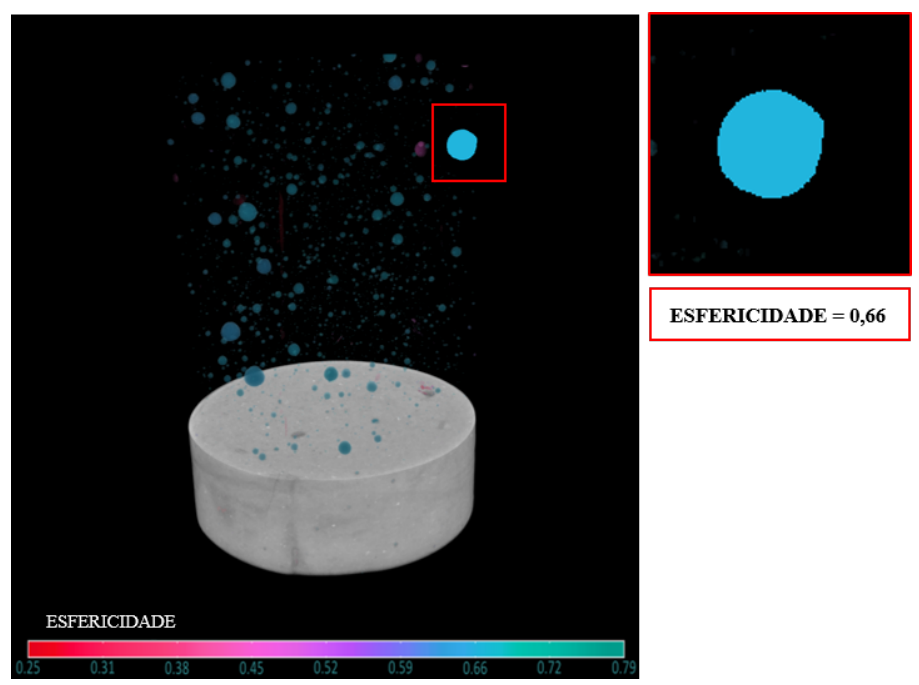

Figura 4.10: Esfericidade dos Poros em 3D depois do ensaio de 1.000 .000 ciclos a $30 \%$ da tensão de ruptura. 
A curva de histerese (figura 4.11), assim como no CP 1, mostra que a deformação aumentou e que a inclinação não alterou com o incremento de ciclos. A rigidez do material não diminuiu após 1.000 .000 ciclos a 30\%. De uma maneira geral, os resultados obtidos dos CP 1 e 2 confirmam que uma tensão de $30 \%$ causou pequenos danos microestruturais, mas não suficientes para afetar as propriedades mecânicas da pasta de cimento classe G.

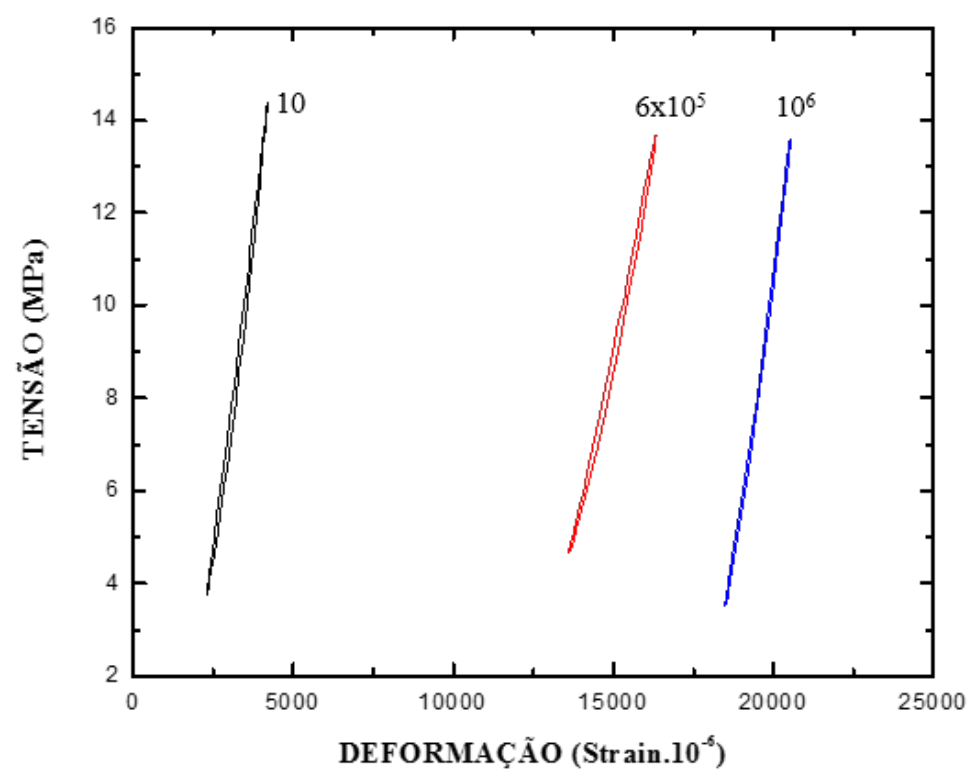

Figura 4.11: Curva de histerese do ensaio cíclico de 1.000 .000 ciclos a $30 \%$.

\subsubsection{3}

\section{CP 3 - 100.000 ciclos a $\mathbf{5 0 \%}$ da tensão de ruptura}

A tabela 4.8 apresenta os resultados do ensaio de compressão de três corpos de provas da mesma leva dos CP 3 e 4 . Os ensaios de compressão e o ensaio cíclico do CP 3 foram realizados com 30 dias de idade. A partir da média $(\bar{X})$, tem-se que a $\sigma_{m a ́ x}=24,73$ e $\sigma_{m i n}=4,95$ para o ensaio de carregamento cíclico.

As imagens da figura 3.14 foram obtidas das tomografias realizadas antes e depois do ensaio de 100.000 ciclos a $50 \%$ e apresenta a imagem 2D de uma seção antes do ensaio e a mesma seção após o ensaio com o aparecimento de fissuras. 
Tabela 4.8: Tensões de ruptura (MPa) dos corpos de prova de referência para os CP 3 e 4.

\begin{tabular}{lc} 
& $\sigma_{r}(\mathbf{M P a})$ \\
\hline & 50,42 \\
& 46,48 \\
& 51,43 \\
Média $(\bar{X})$ & 49,44 \\
Desvio Padrão $(\mathrm{dp})$ & 2,61
\end{tabular}

A princípio, o valor do "threshold" utilizado para a segmentação foi de 145. Porém, com as dificuldades encontradas na segmentação do pós ensaio, o "threshold" foi aumentado para 180. O superdimensionamento na segmentação foi feito também para as imagens antes do ensaio, uma vez que o objetivo era de comparar as imagens. As imagens 3D dos poros e fissura segmentados de antes e depois do ensaio estão apresentadas na figura 4.12, com suas respectivas faixas de cores de volume. A maioria dos poros antes do ensaio (figura 4.12 (a)) possui até $0,7 \mathrm{~mm}^{3}$ (faixa vermelha) e alguns outros maiores de até $5,64 \mathrm{~mm}^{3}$ (poro verde). A figura 4.12 (b) mostra o aparecimento da fissura (verde), que é dada como um objeto único de $610,36 \mathrm{~mm}^{3}$. Na imagem segmentada após o ensaio a fissura pode ser facilmente separada dos poros devido à sua diferença de volume, as imagens da figura 4.12 (c) e (d) mostram essa separação. Os poros aparecem com uma faixa de cor com volume de até $6,23 \mathrm{~mm}^{3}$, esse aumento pode ser justificado pela mesma razão dos CP 1 e 2 . A fissura que surgiu durante o ensaio apresenta poros conectados a ela. Os poros mais expressivos que se conectaram a essa fissura estão destacados na figura 4.12 (a), que na imagem dos poros após o ensaio não são mais encontrados (figura 4.12 (c)). 

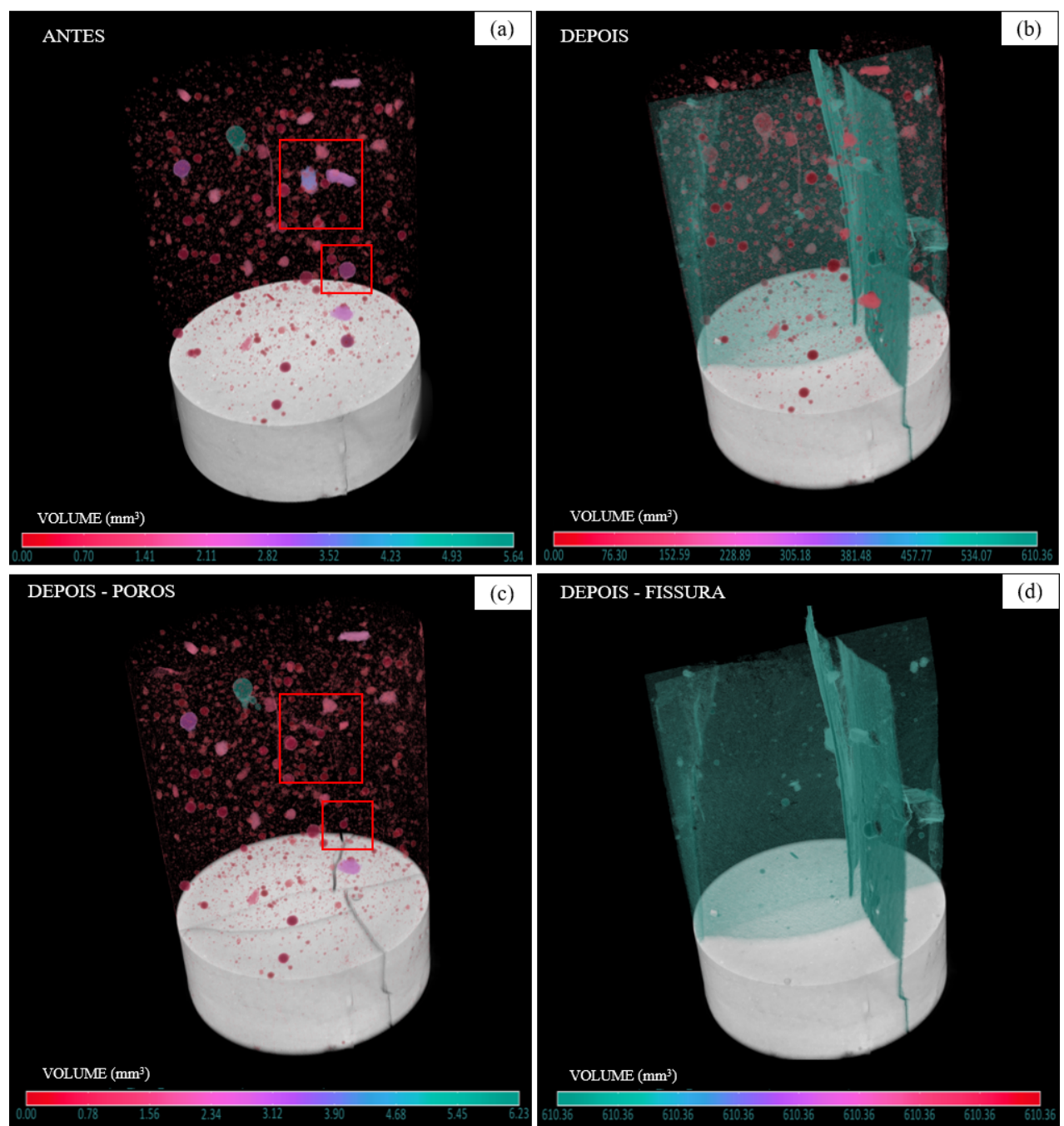

Figura 4.12: (a) Poros em 3D antes do ensaio de 100.000 ciclos a 50\% da tensão de ruptura; (b) Poros e fissura em 3D depois do ensaio; (c) Poros em 3D depois do ensaio; (d) Fissura em 3D depois do ensaio.

O volume total do corpo de prova considerado e o volume e fração de poros de antes e depois do ensaio está na tabela 4.9, assim como o volume e fração da fissura que surgiu após o ensaio. O volume de poros praticamente não alterou antes e depois do ensaio, mesmo que alguns desses poros tenham se conectados com a fissura, a diferença não é significativa para mostrar que houve alteração na porosidade. O cálculo do volume médio de poro foi feito e, mesmo excluindo o volume de até 9 voxels, o valor do volume de poro médio ficou muito pequeno, isso porque o aumento de "threshold" levou a seleção de muitos objetos que possivelmente não eram poros. O aumento do "threshold" também levou a uma porosidade inicial $(0,72 \%)$ muito maior que dos CP 1 e 2 (por volta de $0,30 \%$ ). 
Tabela 4.9: Resultado quantitativo do ensaio de 100.000 ciclos a $50 \%$.

\begin{tabular}{lrr} 
& Antes & Depois \\
\hline Volume total $\left(\mathrm{mm}^{3}\right)$ & 18.947 & 19.216 \\
Volume de poros $\left(\mathrm{mm}^{3}\right)$ & 137 & 138 \\
Fração de poros $(\%)$ & 0,72 & 0,72 \\
Volume da fissura $\left(\mathrm{mm}^{3}\right)$ & - & 610 \\
Fração da fissuras $(\%)$ & - & 3,18 \\
Número de Poros & 17.790 & 31.891 \\
Volume Média $\left(\mathrm{mm}^{3}\right)$ & 0,007 & 0,004
\end{tabular}

Também é observado na tabela 4.9 que a diferença no número de poros de antes e depois do ensaio foi consideravelmente alta. Esse resultado, junto com os do CP 1 e 2, nos leva a concluir que quanto maior a deformação no corpo de prova maior as variações causadas durante a microCT. Isso faz bastante sentido, uma vez que a deformação no CP mudaria a absorção de raio-x durante a tomografia, e as imagens geradas de antes e depois apresentariam histogramas diferentes. Os histogramas dessas estão na figura 4.13 com a segmentação da pasta em vermelho, e realmente apresentam uma pequena variação, no qual a segmentação da pasta apresenta maior quantidade de voxels antes do ensaio. Ou seja, segmenta-se mais voxels de poros após o ensaio, condizendo com o número de poros depois do ensaio ser muito maior. Talvez, nessas situações, o ideal seria definir tons de cortes diferentes. Mas de qualquer maneira, a variação do volume médio de poros não afirma variação nos poros do material.

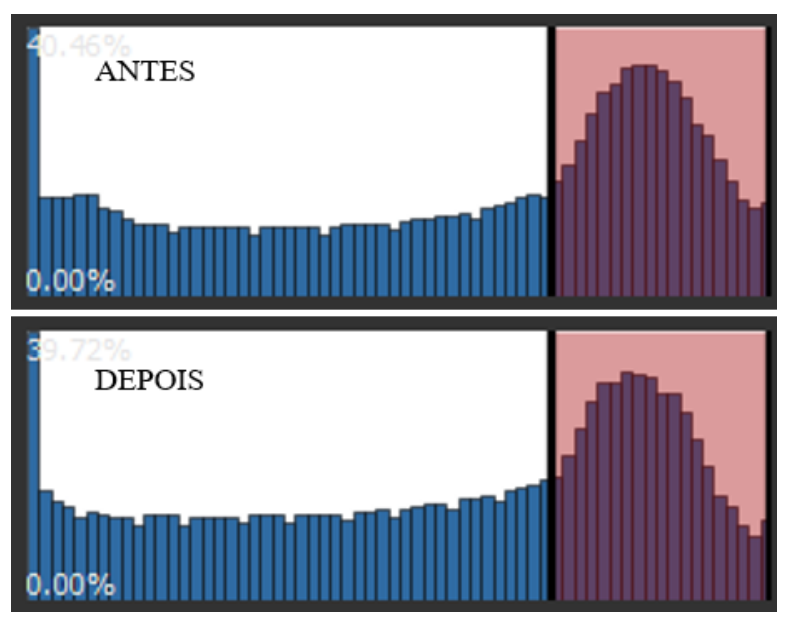

Figura 4.13: Histograma dos tons das imagens de antes e depois do ensaio de 100.000 ciclos a $50 \%$ da tensão de ruptura. 
A esfericidade dos poros antes (figura 4.14 (a)) apresenta uma variação maior quando comparada com os CP 1 e 2, com alguns poros em azul com esfericidade por volta de 0,60, mas outros menos esféricos com as cores entre roxo e rosa. Depois do ensaio (figura 4.14 (b)), a fissura aparece como a menor esfericidade $(0,04)$, como esperado, mas nos poros não é percebido variação de esfericidade.
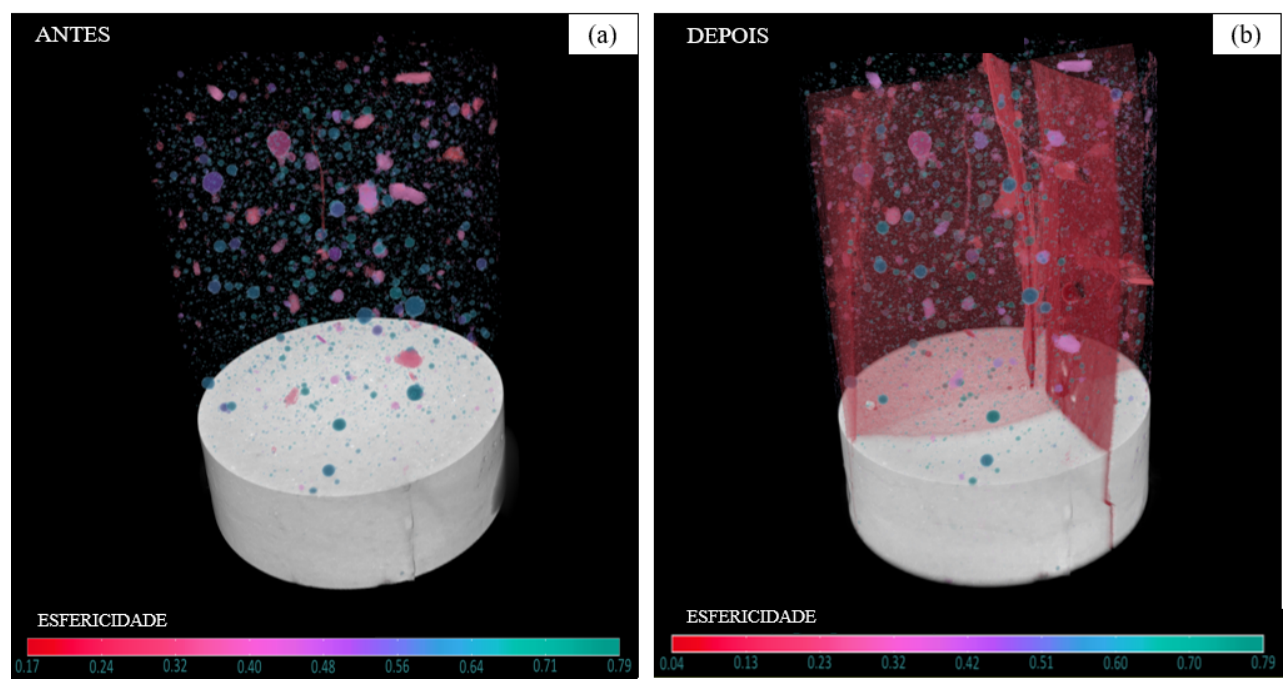

Figura 4.14: Esfericidade dos Poros e Fissura em 3D: (a) antes do ensaio de 100.000 ciclos a $50 \%$ da tensão de ruptura; (b) depois do ensaio.

Os três poros destacados na figura 4.12 (a) foram analisados separadamente e estão apresentados na figura 4.15 com seus respectivos volume e esfericidade. Os três poros apresentam volumes expressivos quando comparados com os outros poros, isso é visto na faixa de cor da figura 4.12 (a) que apresenta um poro de $5,64 \mathrm{~mm}^{3}$, mas a maioria está abaixo de aproximadamente 2,0 $\mathrm{mm}^{3}$. Dois desses poros possuem esfericidade pequena quando comparada com o restante dos poros, de 0,43 e 0,38. Esses dois poros podem ser propícios ao surgimento da fissura, devido ao seu tamanho e formato. 


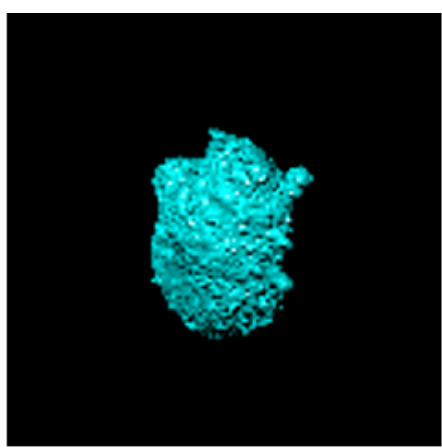

ESFERICIDADE: 0,43 VOLUME: $3,54 \mathrm{~mm}^{3}$

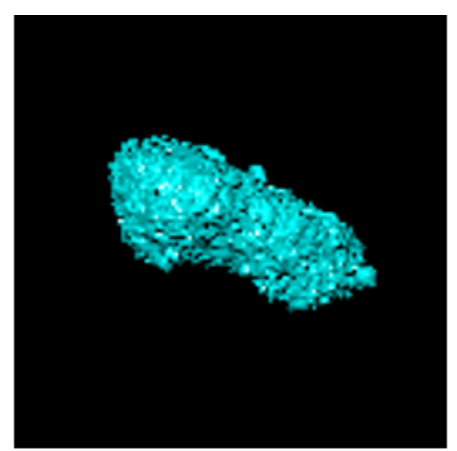

ESFERICIDADE: 0,38 VOLUME: $2,42 \mathrm{~mm}^{3}$

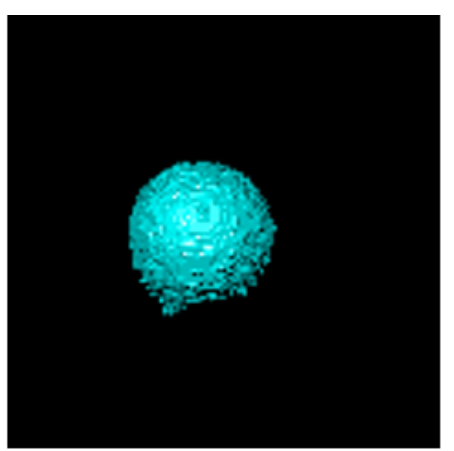

ESFERICIDADE: 0,61 VOLUME: $2,00 \mathrm{~mm}^{3}$

Figura 4.15: Poros que se conectaram a fissura que surgiu no ensaio de 100.000 ciclos a $50 \%$ da tensão de ruptura.

A curva de histerese gerada dos dados obtidos no ensaio está na figura 4.16, com as curvas de 10 ciclos e 100.000 ciclos apresentadas. Essa mostra que a deformação aumentou mas que não ocorreu alteração na inclinação, mostrando que a rigidez do material não alterou após 100.000 ciclos a $50 \%$.

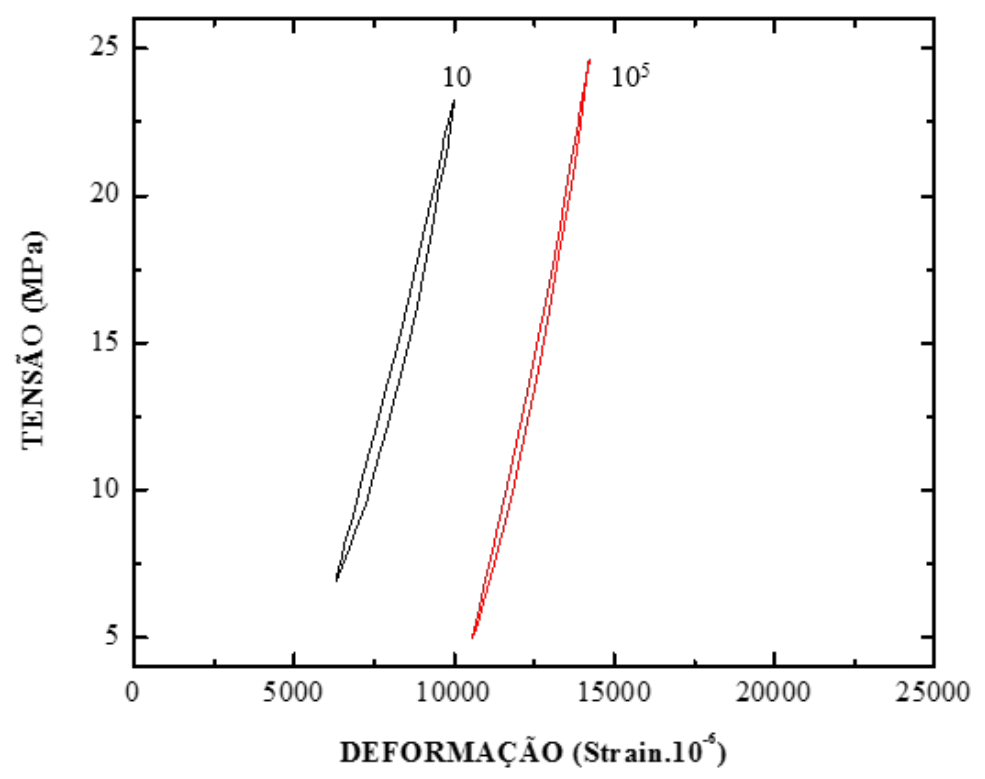

Figura 4.16: Curva de histerese do ensaio cíclico de 100.000 ciclos a $50 \%$. 


\subsubsection{4}

\section{CP 4 - $\mathbf{5 0 0 . 0 0 0}$ ciclos a $\mathbf{5 0 \%}$ da tensão de ruptura}

O corpo de prova 4 é da mesma leva do CP 3, portanto, para $50 \%$ os valores de $\sigma_{m a ́ x}$ e $\sigma_{\text {min }}$ são os mesmos. O ensaio cíclico deste foi realizado com 31 dias. O CP rompeu durante o ensaio no ciclo 861. Sua curva de histerese está mostrada na figura 4.17, com os ciclos 10, 800, 845 e 848 plotadas.

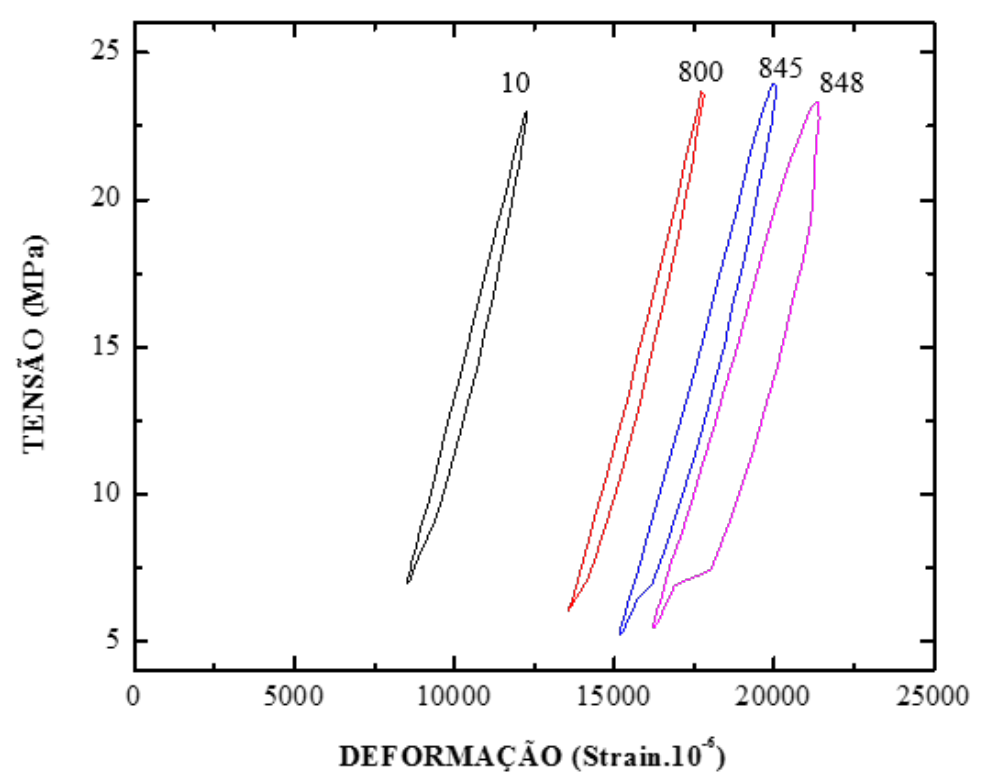

Figura 4.17: Curva de histerese do ensaio cíclico a 50\%.

Esse resultado condiz com os resultados dos ensaios na máquina RTR1500 Rapid Triaxial Rock, no qual para 30\% até 50\% da tensão de ruptura a inclinação da curva apresenta uma queda significativa. O fato do corpo de prova3 não ter rompido e do corpo de prova 4 ter rompido é justificado por não se poder ter certeza da tensão de ruptura do CP ensaiado.

Como o desvio padrão dos resultados das cargas de ruptura dos ensaios de compressão (tabela 4.8) é relativamente pequeno, é possível que por volta de $50 \%$ da tensão de ruptura a pasta de cimento classe G perca significativamente suas propriedades mecânicas. A curva de histerese também mostra que perto da ruptura os ciclos inclinam bruscamente, como é observado do ciclo 845 para o ciclo 848. Esse comportamento é característico de um material extremamente frágil, no qual o crescimento e propagação de defeito acontece de maneira brusca. 


\subsubsection{5}

\section{CP 5 - 100.000 ciclos a $70 \%$ da tensão de ruptura}

A tabela 4.10 apresenta os resultados do ensaio de compressão de quatro corpos de provas da mesma leva do CP 5. Tanto os ensaios de compressão, quanto o ensaio cíclico do CP 5 foram realizados aos 28 dias. A partir da média $(\bar{X})$, tem-se que a $\sigma_{m a ́ x}=24,25$ e $\sigma_{m i n}=4,85$. O corpo de prova não rompeu, como era esperado. Isso pode ser justificado pelo alto desvio padrão, podendo o ensaio ter sido realizado a um valor muito abaixo de $70 \%$.

Tabela 4.10: Tensões de ruptura (MPa) dos corpos de prova de referência para os CP 5.

\begin{tabular}{lc} 
& $\sigma_{r}$ (MPa) \\
\hline & 46,52 \\
& 35,19 \\
& 32,39 \\
& 24,51 \\
& 34,65 \\
Média $(\bar{X})$ & 9,11
\end{tabular}

O corpo de prova já apresentava defeitos na parte inferior, como mostra a primeira imagem 2D da figura 4.18 e imagem de poros e fissuras em 3D da figura 4.19(a), que ocorreu provavelmente durante a moldagem do corpo de prova.
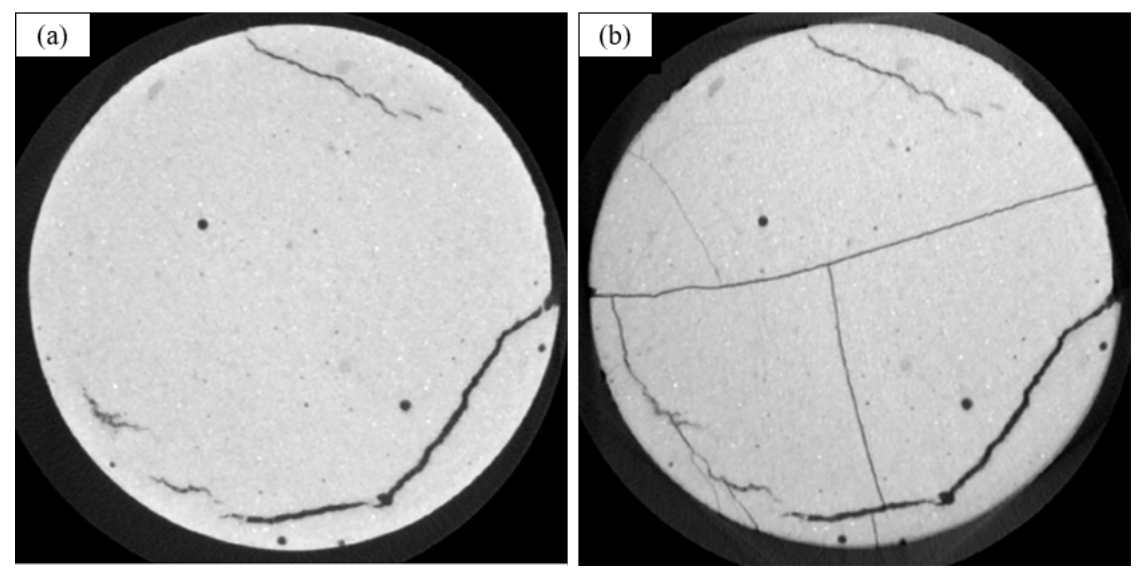

Figura 4.18: Seção do corpo de prova: (a) antes do ensaio cíclico de 100.000 ciclos a $70 \%$ da tensão de ruptura; (b) depois do ensaio. 
A segmentação dos poros e fissuras utilizou um valor do "threshold" de 160 e também o comando "close". Após 100.000 ciclos apareceram novas fissuras e as existentes se propagam, como mostra a segunda imagem 2D da figura 4.18 e a imagem da figura 4.19 (b). Quando comparamos as imagens segmentadas antes e depois do ensaio, percebemos que a fissura antes do ensaio não está conectada, na figura 4.19 (a) uma parte está em verde (um objeto de 51,02 $\mathrm{mm}^{3}$ ) e outra em rosa. Na imagem pós ensaio, essa fissura se conecta a que aparece durante o ensaio, gerando um único objeto de 237,32 $\mathrm{mm}^{3}$ (figura 4.19 $(\mathrm{d}))$.
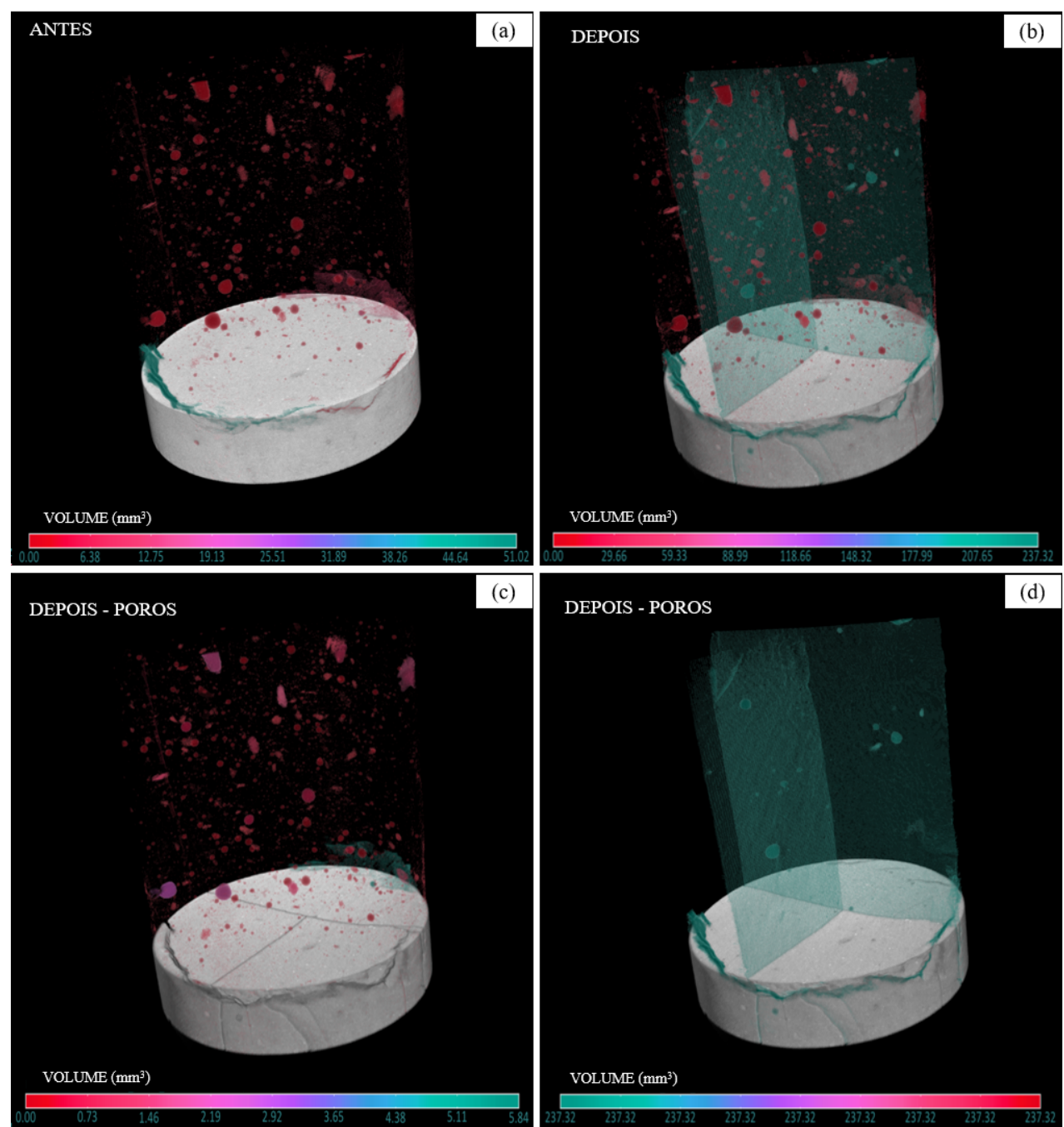

Figura 4.19: (a) Poros e fissura em 3D antes do ensaio de 100.000 ciclos a $70 \%$ da tensão de ruptura; (b) Poros e fissura em 3D depois do ensaio; (c) Poros em 3D depois do ensaio; (d) Fissura em 3D depois do ensaio. 
A tabela 4.11 mostra os resultados quantitativos obtidos do Dragonfly V3.0. A fissura foi separada dos poros nas imagens de antes e depois do ensaio para comparação dos poros. Ocorreu um aumento significativo na fração de poros (de $0,27 \%$ para $0,36 \%$ ). Assim como no corpo de prova 3 , a deformação afetou o histograma da imagem após o ensaio (figura 4.20), o que justifica essa diferença na porosidade. Novamente, não se pode afirmar sobre mudança na estrutura dos poros.

Tabela 4.11: Resultado quantitativo do ensaio de 100.000 ciclos a $70 \%$.

\begin{tabular}{lrr} 
& Antes & Depois \\
\hline Volume total $\left(\mathrm{mm}^{3}\right)$ & 16.627 & 16.554 \\
Volume de Poros $\left(\mathrm{mm}^{3}\right)$ & 45 & 60 \\
Fração de Poros $(\%)$ & 0,27 & 0,36 \\
Volume da fissura $\left(\mathrm{mm}^{3}\right)$ & 64 & 237 \\
Fração da fissura $(\%)$ & 0,38 & 1,43 \\
Número de Poros & 7.076 & 11.871
\end{tabular}

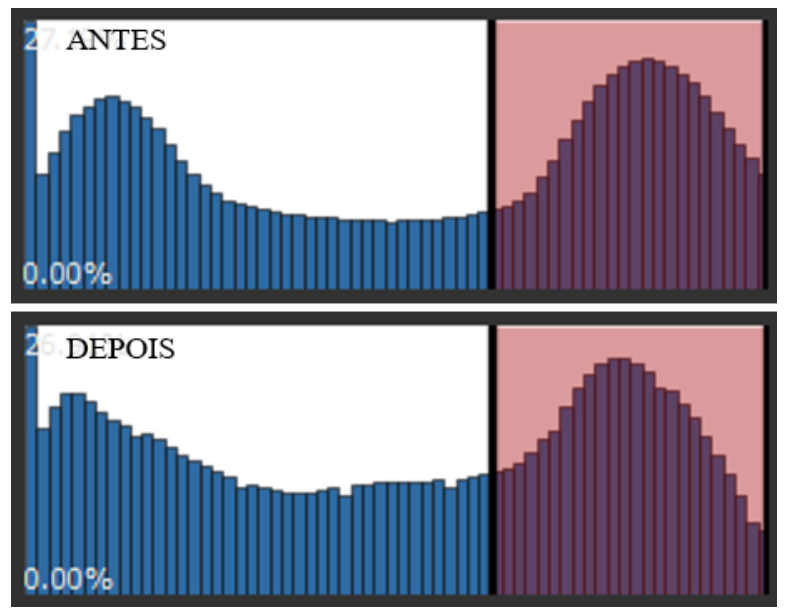

Figura 4.20: Histograma dos tons das imagens de antes e depois do ensaio de 100.000 ciclos a $70 \%$ da tensão de ruptura.

A respeito da esfericidade dos poros, na figura 4.21, pode-se dizer que a maioria dos poros está por volta de 0,65 com alguns poros menos esféricos por volta de 0,40 . Os CP 1 e 2 apresentaram menores variações e o CP 3 uma maior variação na faixa, quando comparados com o corpo de prova em questão. Podemos dizer que a esfericidade inicial está relacionada com a preparação do corpo de prova, já que estamos tratando do mesmo material. 


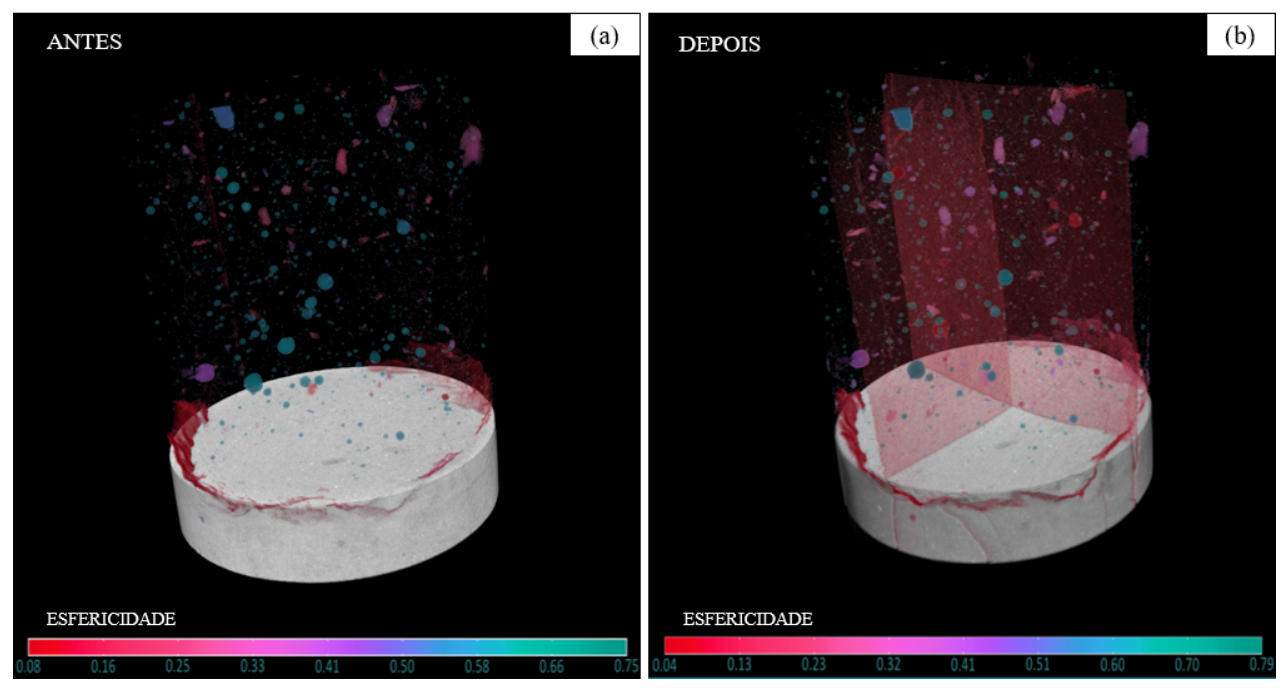

Figura 4.21: Esfericidade dos Poros e Fissura em 3D: (a) antes do ensaio de 100.000 ciclos a $70 \%$ da tensão de ruptura.; (b) depois do ensaio.

A curva de histerese mostra que a deformação aumentou, mas que não ocorreu variação na inclinação, mostrando que a rigidez do material não alterou após o ensaio (figura 4.22).

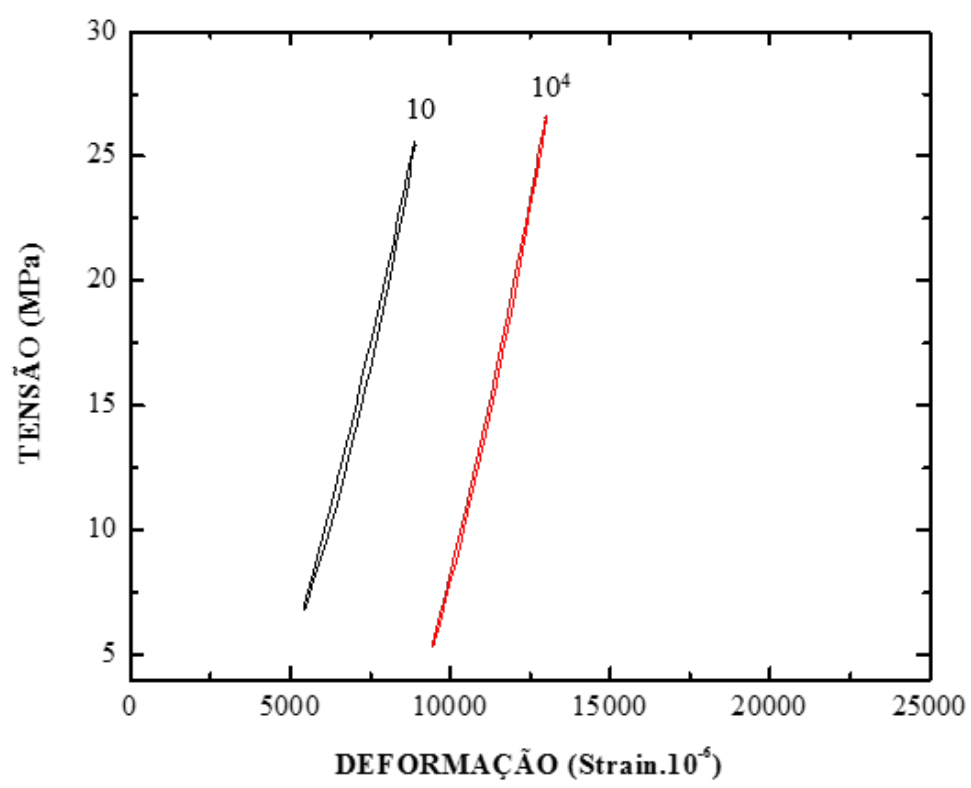

Figura 4.22: Curva de histerese do ensaio cíclico a $70 \%$. 


\subsubsection{6}

\section{CP 6 - $\mathbf{5 0 0 . 0 0 0}$ ciclos a $\mathbf{7 0} \%$ da tensão de ruptura}

A tabela 4.12 apresenta os resultados do ensaio de compressão de três corpos de provas da mesma leva do CP 6. Os ensaios de compressão desses corpos de prova e o ensaio cíclico do CP 6 foram realizados aos 35 dias. A partir da média $(\bar{X})$, tem-se que a $\sigma_{m a ́ x}=33,23$ e $\sigma_{m i n}=6,65$.

Tabela 4.12: Tensões de ruptura (MPa) dos corpos de prova de referência para os CP 6.

\begin{tabular}{lc} 
& $\sigma_{r}$ (MPa) \\
\hline & 45,29 \\
& 47,84 \\
& 47,86 \\
& 48,86 \\
& 47,46 \\
Média $(\bar{X})$ & 1,52 \\
Desvio Padrão (dp)
\end{tabular}

O corpo de prova rompeu durante o ensaio no ciclo 395. Sua curva de histerese está apresentada na figura 4.23, que mostra os ciclos 10, 300, 380 e 382 plotados. Assim como o CP 4, a evolução brusca da inclinação e o aumento do volume do ciclo 380 para o ciclo 382 confirma se tratar de um material extremamente frágil. 


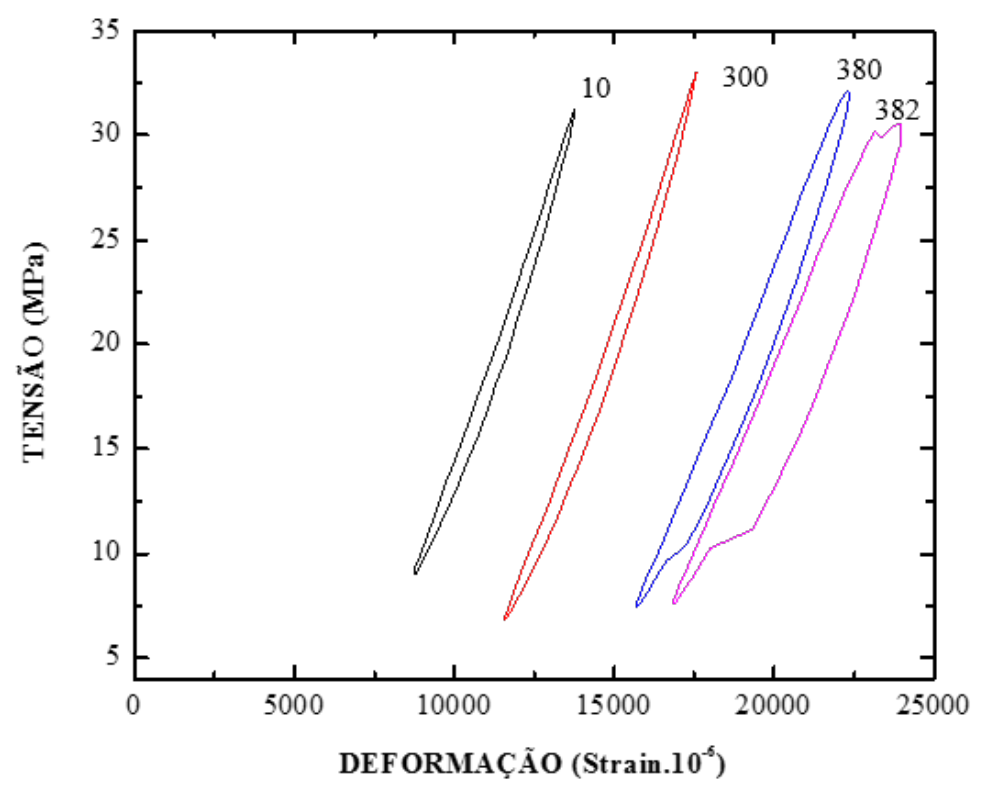

Figura 4.23: Curva de histerese do ensaio cíclico a $70 \%$.

\section{2}

\section{Ensaio de Temperaturas Elevadas}

\subsection{1}

\section{Ensaio de compressão em corpos de prova submetidos a diferentes temperaturas}

Os resultados dos ensaios de compressão nos corpos de prova submetidos anteriormente às temperaturas de $100^{\circ} \mathrm{C}, 200^{\circ} \mathrm{C}, 450^{\circ} \mathrm{C}$ e a do corpo de prova de referência (temperatura ambiente) estão apresentadas na tabela 4.13. Os $\mathrm{CP}$ submetidos a $650^{\circ} \mathrm{C}$ se desfizeram, não possibilitado a realização do ensaio de compressão.

Tabela 4.13: Resultados das tensões de ruptura $\left(\sigma_{r}\right)$ dos ensaios de compressão para diferentes temperaturas.

\begin{tabular}{lrrrr} 
& Ref. & $100^{\circ} \mathbf{C}$ & $200^{\circ} \mathbf{C}$ & $450^{\circ} \mathbf{C}$ \\
\hline & 47,19 & 50,92 & 42,25 & 31,83 \\
& 47,01 & 56,27 & 47,76 & 18,10 \\
& 36,45 & 52,91 & 45,21 & 32,84 \\
Média $(\bar{X})$ & 43,55 & 53,37 & 45,07 & 27,59 \\
Desvio Padrão (dp) & 6,14 & 2,70 & 2,76 & 8,23
\end{tabular}


Os resultados mostraram um aumento na média das tensões de ruptura para os corpos de prova submetidos a $100^{\circ} \mathrm{C}$ e praticamente sem alteração quando submetido a $200^{\circ} \mathrm{C}$. Esse aumento de resistência está relacionado com a umidade do material. Concretos testados sem umidade apresentam resistência 15\% superior devido a um aumento das forças de atração de Van der Walls entre os produtos de hidratação da matriz (5). O gráfico da figura 4.24 apresenta essa variação de $\sigma_{r}$ com o aumento de temperatura e seus respectivos desvios padrões.

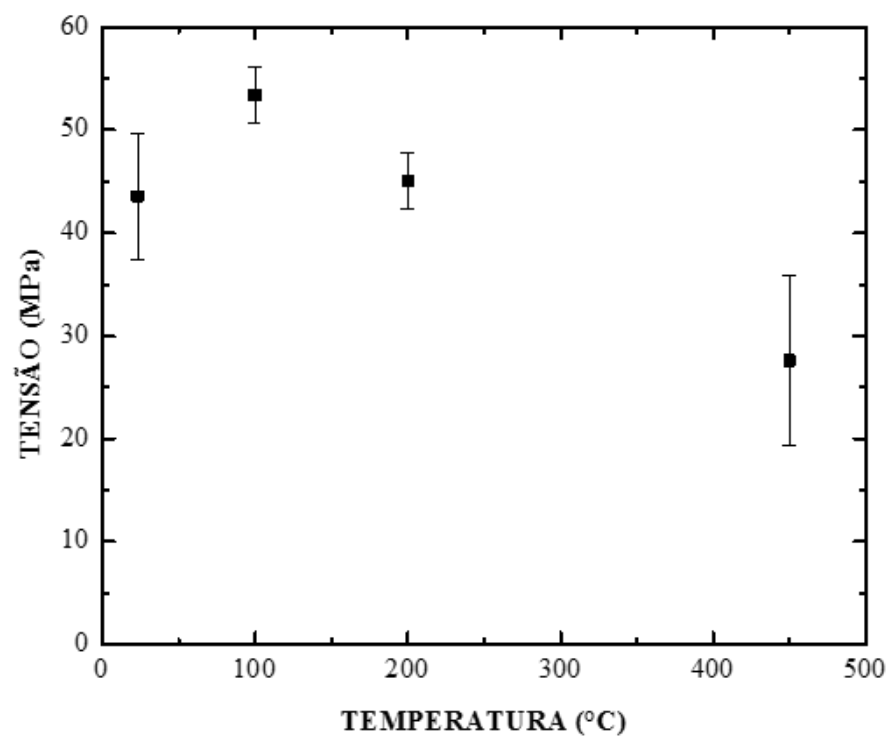

Figura 4.24: Variação de $\sigma_{r}$ com o aumento de temperatura.

Dos ensaios de compressão em corpos de prova submetidos a diferentes temperaturas foram obtidos os gráficos tensão x deformação, que desses podem ser calculadas as inclinações, ou seja, o módulo de elasticidade do material. A figura 4.25 mostra esses gráficos e a tabela 4.14 apresenta os módulos de elasticidade para cada temperatura. 

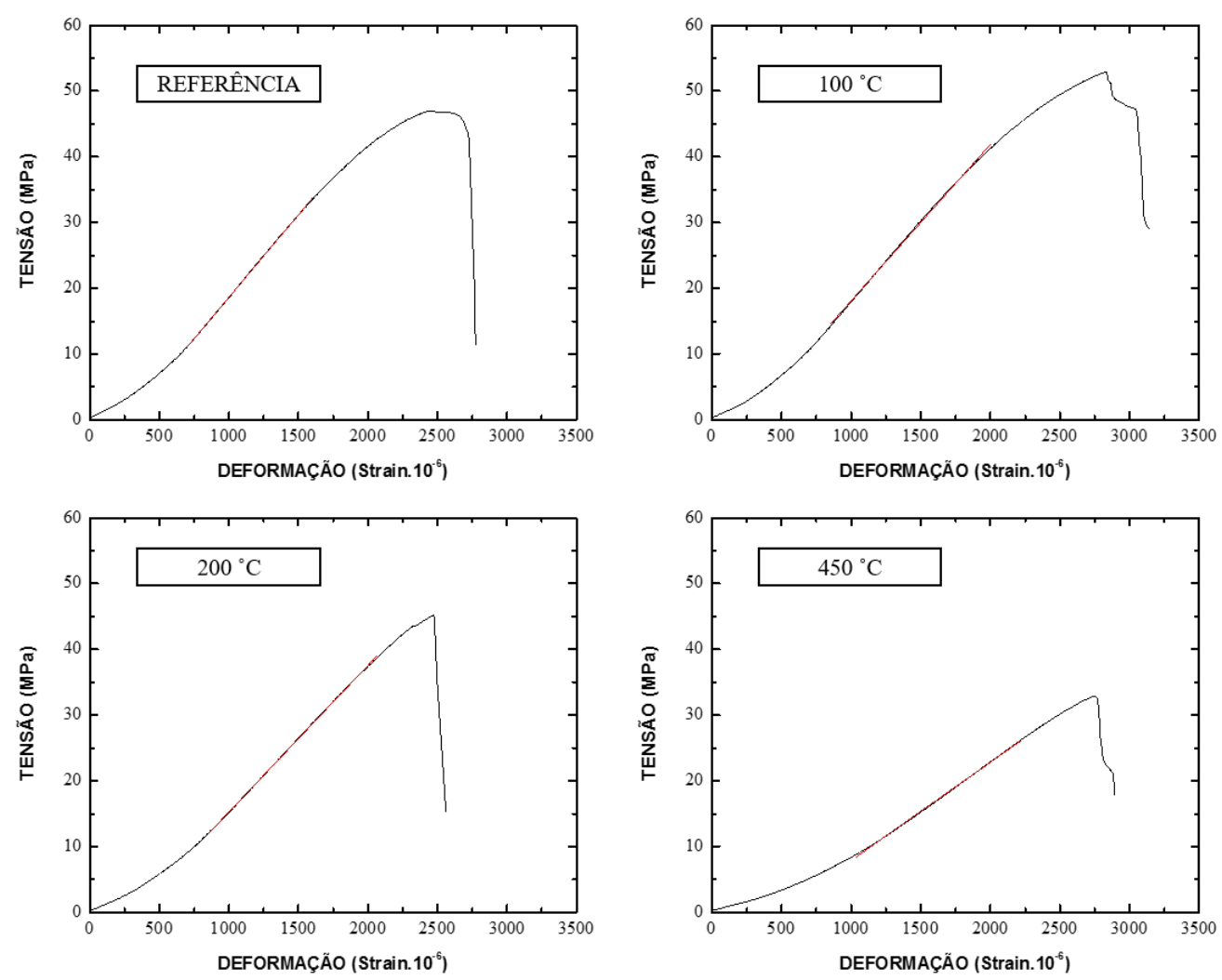

Figura 4.25: Curva Tensão x Deformação com o aumento de temperatura.

Tabela 4.14: Módulo de elasticidade (GPa) com o aumento da temperatura.

Inclinação (GPa)

\begin{tabular}{cc}
\hline Referência & 25,1 \\
$100^{\circ} \mathrm{C}$ & 23,8 \\
$200^{\circ} \mathrm{C}$ & 22,3 \\
$450^{\circ} \mathrm{C}$ & 14,9
\end{tabular}

A inclinação reduziu pouco até $200^{\circ} \mathrm{C}$, mostrando que até essa temperatura a rigidez do material pouco é afetada. Assim, espera-se que apareçam poucos defeitos nos corpos de prova submetidos a essas temperaturas. Já para $450^{\circ} \mathrm{C}$ a rigidez do material é afetada significativamente, no qual provavelmente apareçam muitos defeitos. 


\subsection{2}

DRX

A figura 4.26 mostra o resultado do ensaio de DRX realizados nos mesmos CPs do item 4.2.1, no qual o $\mathrm{Ca}(\mathrm{OH})_{2}$ quase não teve alteração até a curva de $450^{\circ} \mathrm{C}$. Em $450^{\circ} \mathrm{C}$ ocorreu um pequeno decaimento nos picos quando comparado com as temperaturas inferiores, mas não o quanto esperado de acordo com o TG realizado na pesquisa de Zhu et al. (3) (2.7) que indica que a desidroxilação do $\mathrm{Ca}(\mathrm{OH})_{2}$ ocorre a $440^{\circ} \mathrm{C}$.

Isso é explicado pelo fato de que durante o ensaio o interior do $\mathrm{CP}$ pode não chegar a $450^{\circ} \mathrm{C}$, mas chegou a temperatura suficiente para início da desidroxilação do $\mathrm{Ca}(\mathrm{OH})_{2}$, uma vez que os picos de $\mathrm{Ca}(\mathrm{OH})_{2}$ estão um pouco menores. O fato é que a diminuição da rigidez do material a $450^{\circ} \mathrm{C}$ (tabela 4.14) e os possíveis danos formados não estão relacionados com a desidroxilação do $\mathrm{Ca}(\mathrm{OH})_{2}$ e sim com as tensões de origem térmicas causadas por variação na temperatura.

Em $650^{\circ} \mathrm{C}$ os picos de $\mathrm{Ca}(\mathrm{OH})_{2}$ diminuem drasticamente. Também é percebido, condizendo com o ensaio de DRX realizado na pesquisa de Zhu et al. (3) (2.8), que a etringita não aparece mais a $200^{\circ} \mathrm{C}$.

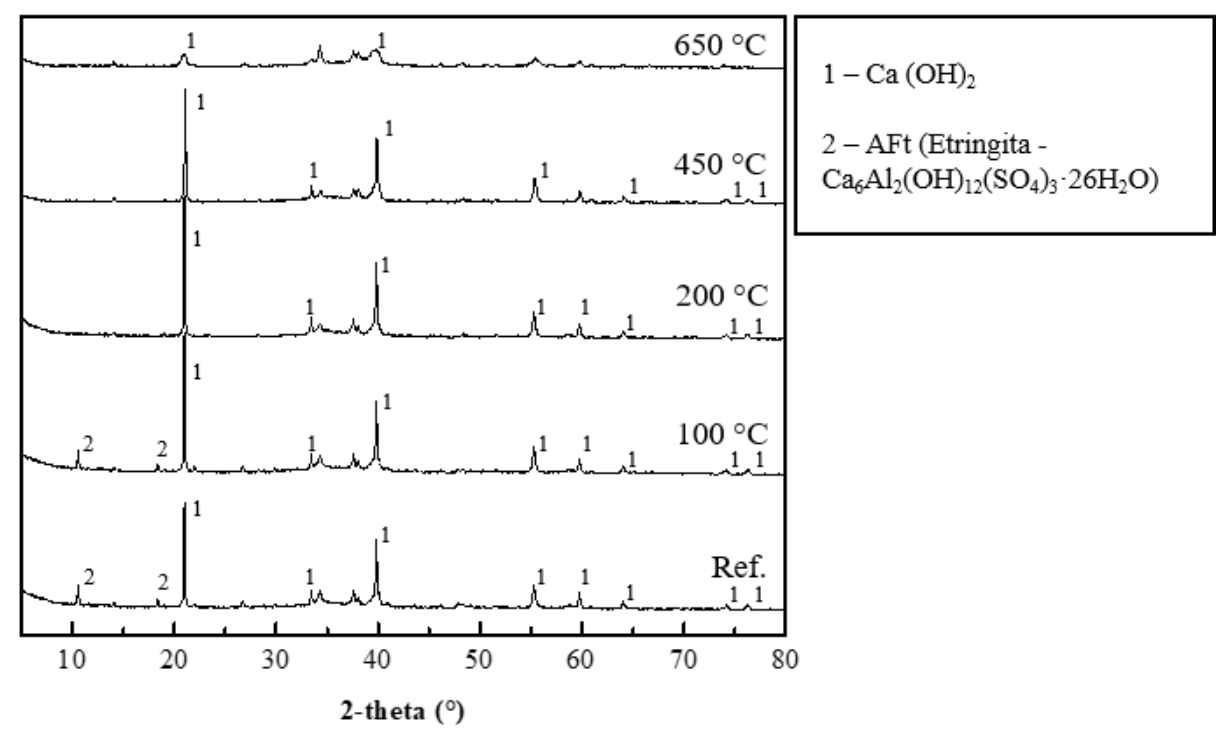

Figura 4.26: Resultado do ensaio de DRX. 


\subsection{3}

DSC e TGA

O resultado da análise térmica está na figura 4.27. A análise térmica diferencial (DSC), curva em vermelho, mostra dois picos em aproximadamente $100^{\circ} \mathrm{C}$ e $440^{\circ} \mathrm{C}$, indicando que nessas temperaturas ocorreram reações endotérmicas, atribuídas a evaporação da água fisicamente adsorvida e a desidroxilação da portlandita, respectivamente. A análise termogravimétrica (TGA), curva em preto, mostra que nessas duas temperaturas ocorreram uma perda de massa significativa, confirmando os eventos de evaporação da água fisicamente adsorvida em torno de $100^{\circ} \mathrm{C}$ e a desidroxilação da portlandita a aproximadamente $440^{\circ} \mathrm{C}$.

Os ensaios de DSC e TGA estão de acordo com os ensaio térmicos de Zhu et al. (3) (2.7) e confirmaram a hipótese de que no ensaio de DRX o interior do corpo de prova não chegou a $440^{\circ} \mathrm{C}$, uma vez que é nessa temperatura que ocorre a desidroxilação do $\mathrm{Ca}(\mathrm{OH})_{2}$. Também é observado um decaimento da massa em $650^{\circ} \mathrm{C}$, que está relacionado com a decomposição do $\mathrm{CaCO}_{3}$.

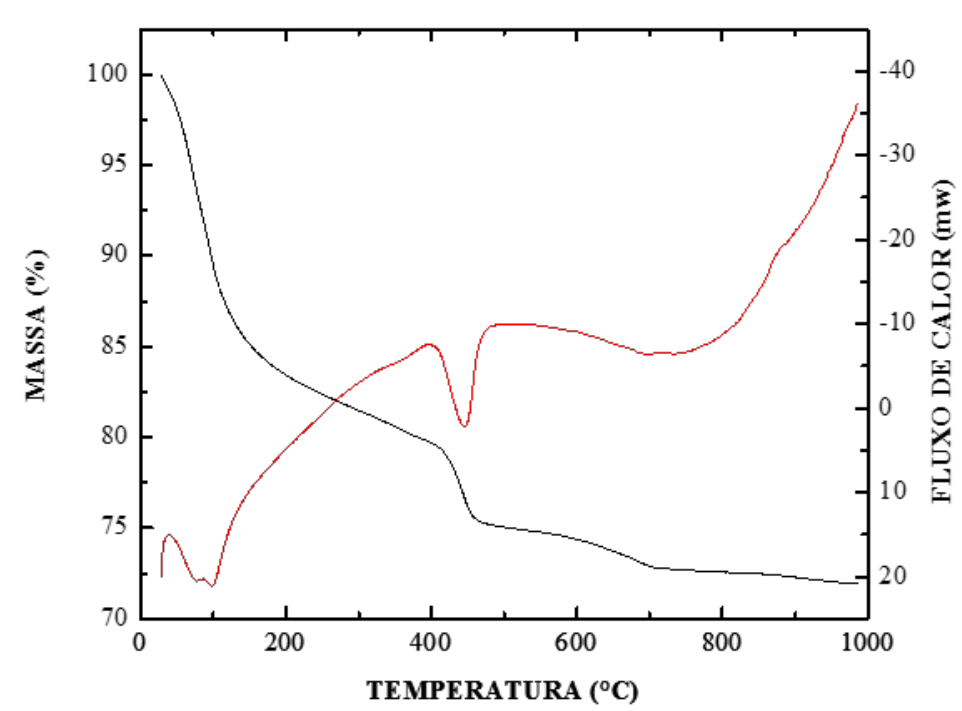

Figura 4.27: Resultado das análises térmicas. 


\subsection{4}

Análise de dano, microestrutura e correlação com propriedades mecânicas

\subsubsection{1}

CP $7-100^{\circ} \mathbf{C}$

O corpo de prova submetido a $100^{\circ} \mathrm{C}$ apresentou o aparecimento de fissuras de espessura aproximada de 2 pixels na superfície do corpo de prova (figura 4.28) com poucas adentrando nessa (figura 4.29).
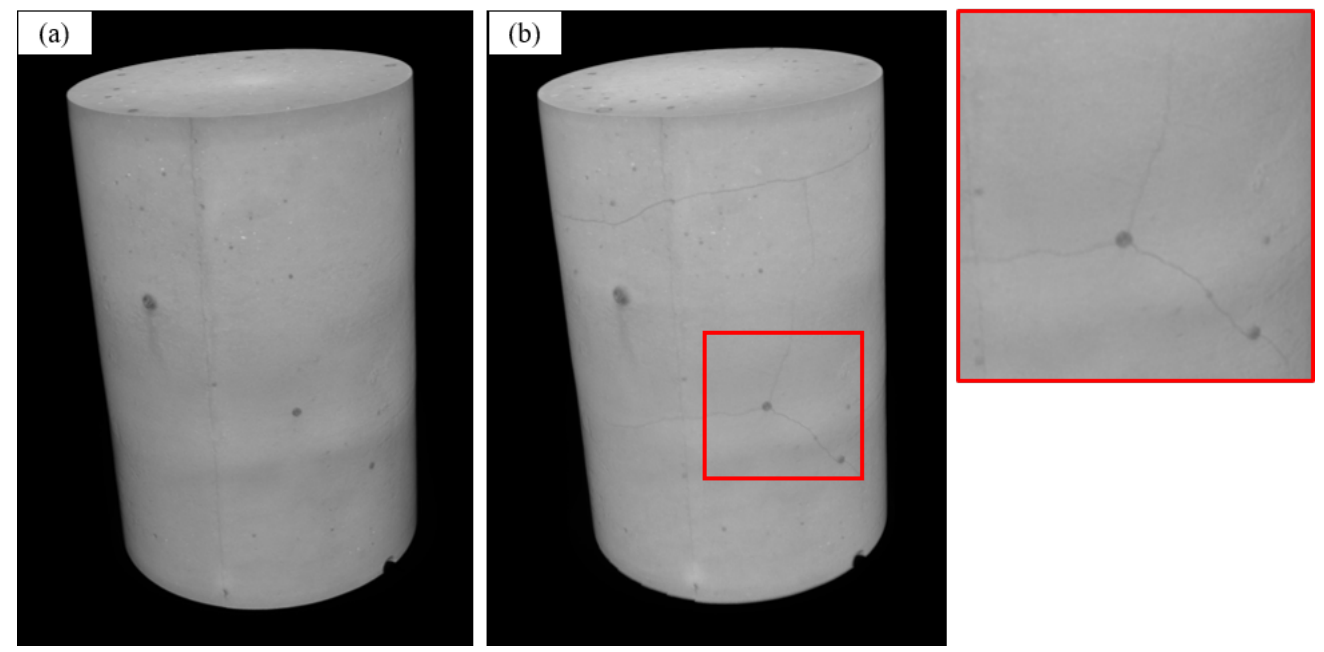

Figura 4.28: Superfície do corpo de prova: (a) antes do ensaio de temperatura elevada de $100^{\circ} \mathrm{C}$; (b) depois do ensaio.
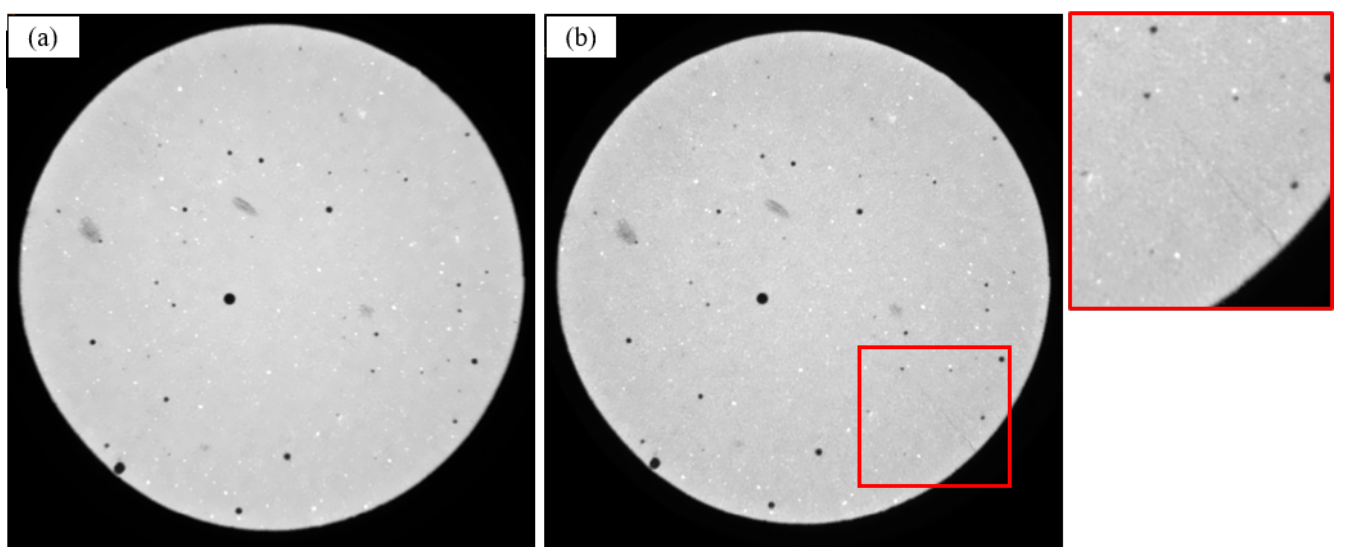

Figura 4.29: Seção do corpo de prova: (a) antes do ensaio de temperatura elevada de $100^{\circ} \mathrm{C}$; (b) depois do ensaio. 
Para a segmentação dos poros foi utilizado o "threshold"de 150 e o resultado em 3D está na figura 4.30, que mostra os poros antes e depois sobrepostos. A faixa de cor de volume não variou para antes e depois do ensaio, apresentando poros de até $2,01 \mathrm{~mm}^{3}$, mas com a maioria dos poros por volta de $0,25 \mathrm{~mm}^{3}$.
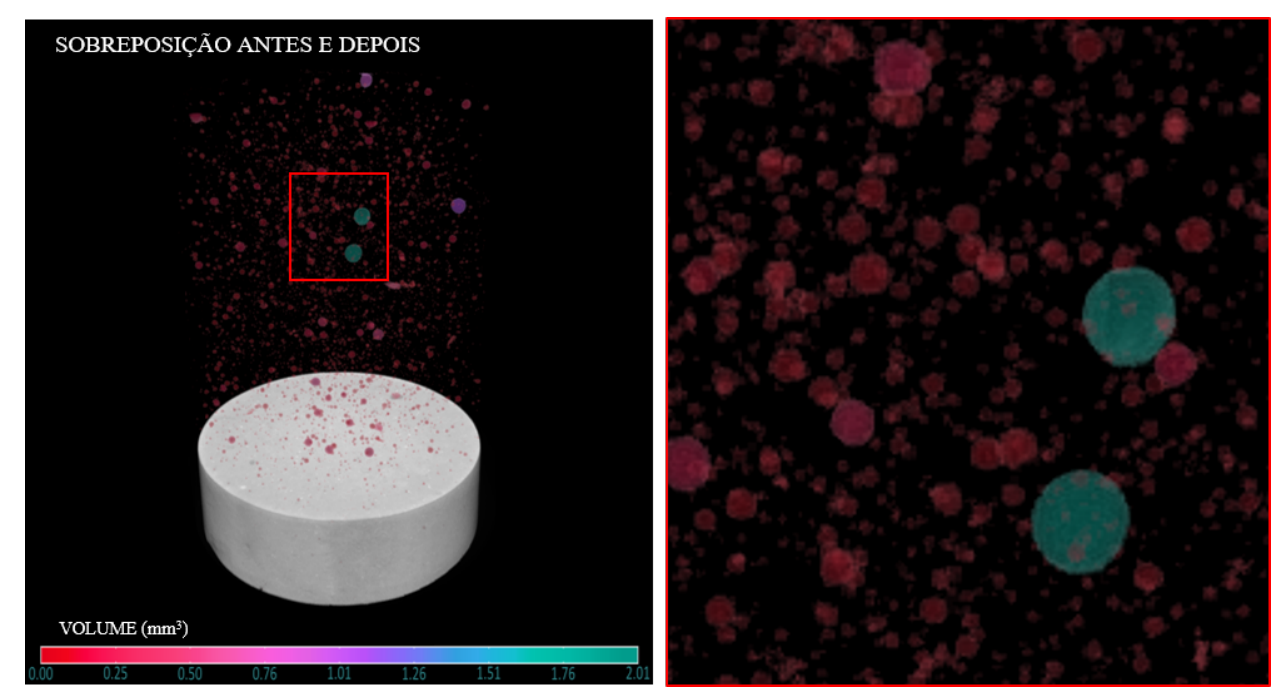

Figura 4.30: Sobreposição dos poros em 3D de antes e depois do ensaio de temperatura elevada de $100^{\circ} \mathrm{C}$.

Os dados quantitativos gerados pelo Dragonfly estão apresentados na tabela 4.15. O volume dos poros não alterou para antes e depois do ensaio e a quantidade de poros também não teve alteração expressiva, após eliminar poros de até 9 voxels. Isso acarretou em um volume médio de poro praticamente igual, mostrando que não houve alteração na estrutura dos poros.

Tabela 4.15: Resultado quantitativo do corpo de prova submetido a $100^{\circ} \mathrm{C}$.

\begin{tabular}{lrr} 
& Antes & Depois \\
\hline Volume total $\left(\mathrm{mm}^{3}\right)$ & 20.146 & 20.045 \\
Volume de Poros $\left(\mathrm{mm}^{3}\right)$ & 55 & 55 \\
Fração de Poros $(\%)$ & 0,28 & 0,28 \\
Número de Poros & 7.649 & 7.370 \\
Volume Médio $\left(\mathrm{mm}^{3}\right)$ & 0,007 & 0,007
\end{tabular}


A esfericidade dos poros está na figura $4.31 \mathrm{com}$ sua respectiva faixa de cor. A faixa de cor não variou, por essa razão apenas a imagem após o ensaio está apresentada. Os poros estão com esfericidade sem grandes variações em torno de 0,65 .

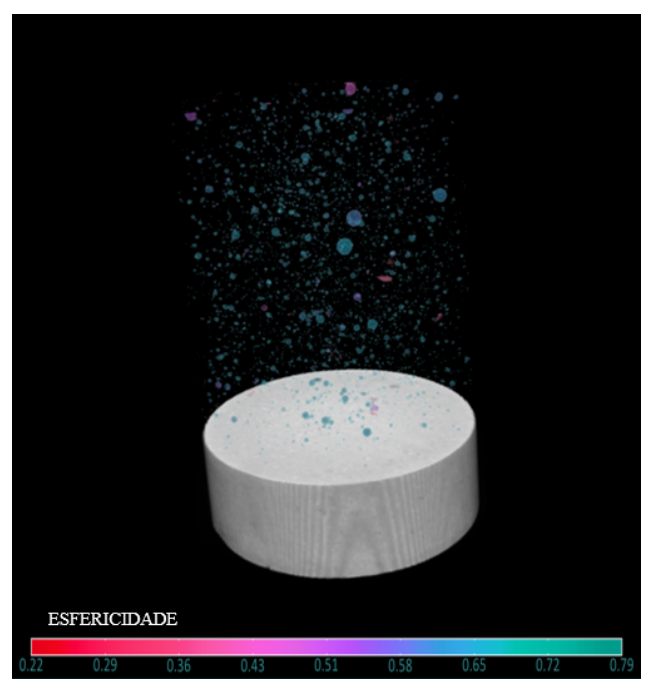

Figura 4.31: Esfericidade dos Poros em 3D depois do ensaio de temperatura elevada de $100^{\circ} \mathrm{C}$.

\subsubsection{2 \\ CP $8-200^{\circ} \mathrm{C}$}

O resultado para o corpo de prova submetido a $200^{\circ} \mathrm{C}$ foi similar ao do $\mathrm{CP}$ submetido a $100^{\circ} \mathrm{C}$. Mostrando que elevar a temperatura até $200^{\circ} \mathrm{C}$ pouco difere quando comparada a elevar a $100^{\circ} \mathrm{C}$. Isso condiz com os resultados de compressão, no qual não houve perda de resistência mecânica até $200^{\circ} \mathrm{C}$. Também confere com os resultados de DSC e TGA que mostram que até $200^{\circ} \mathrm{C}$ ocorre a evaporação da água fisicamente adsorvida, e esse evento não causa influência em suas propriedades mecânica.

As figuras 4.33 e 4.32 mostram o aparecimento de fissuras de aproximadamente 2 pixel de espessuras na superfície do corpo de prova. As fissuras são menos perceptível quando comparadas com o CP 7, mostrando que ocorreu menor quantidade e tamanho de fissuras, apesar da temperatura ser mais alta. 

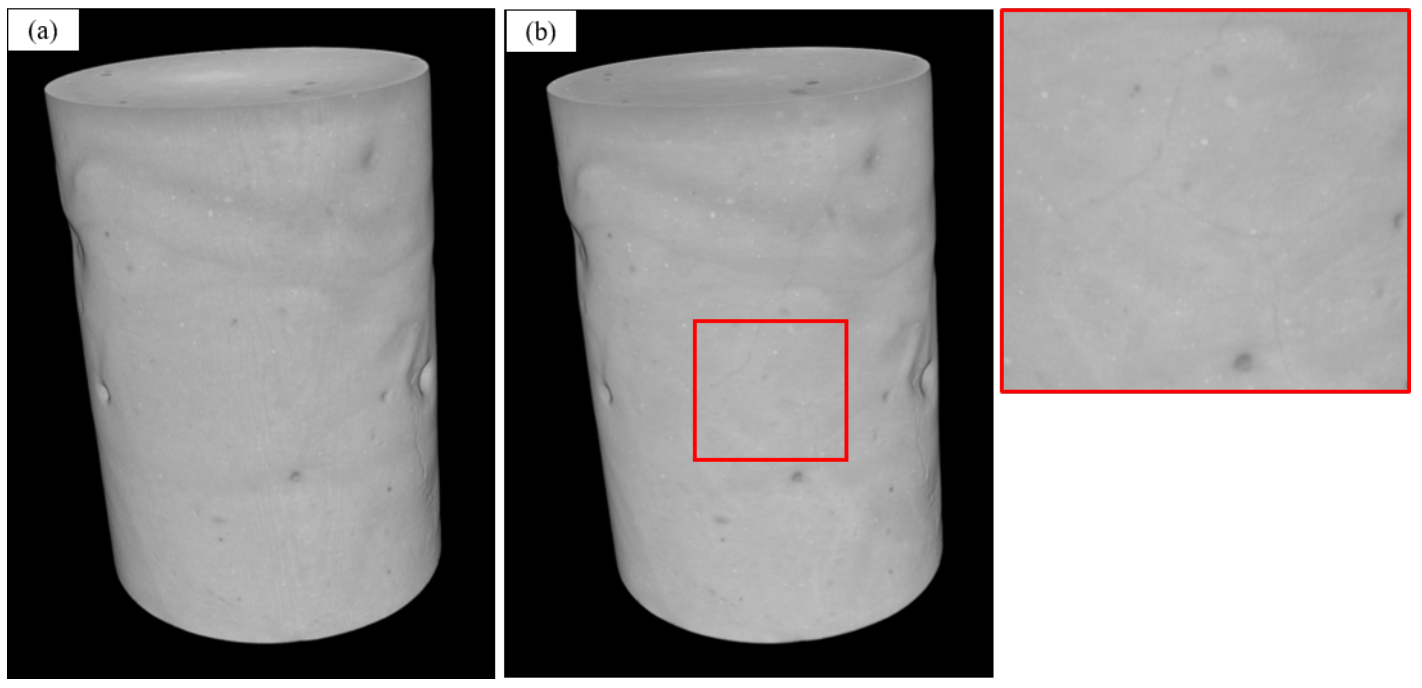

Figura 4.32: Superfície do corpo de prova: (a) antes do ensaio de temperatura elevada de $200^{\circ} \mathrm{C}$; (b) depois do ensaio.
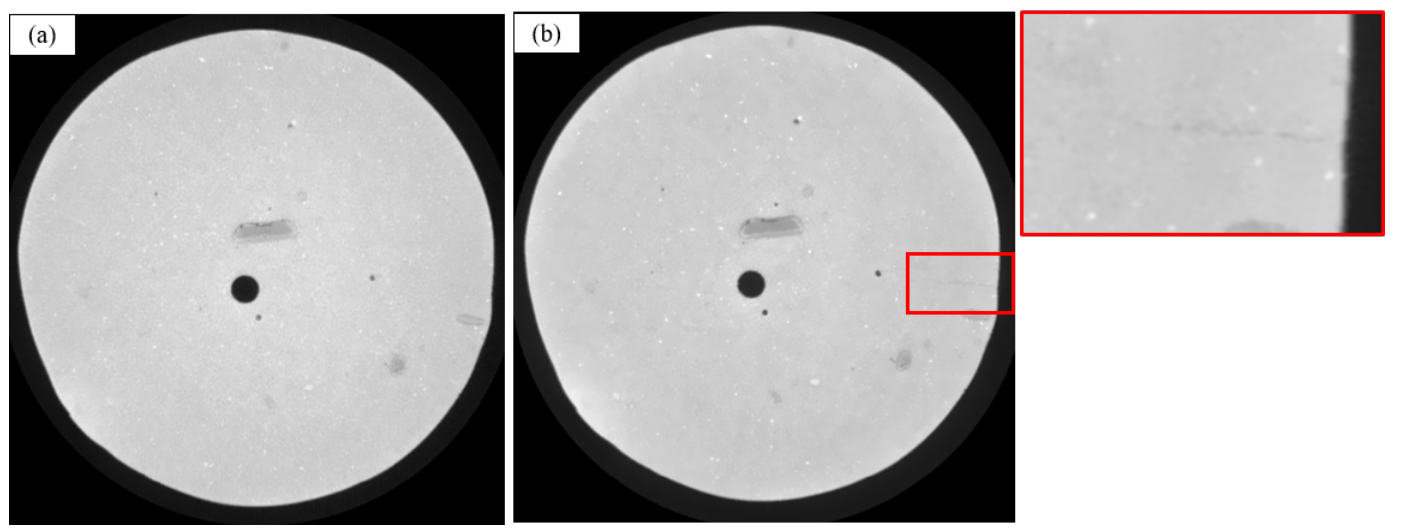

Figura 4.33: Seção do corpo de prova: (a) antes do ensaio de temperatura elevada de $200^{\circ} \mathrm{C}$; (b) depois do ensaio.

A segmentação foi feita em um "threshod"de 150, resultando na imagem 3D da figura 4.34 que apresenta a sobreposição dos poros antes e depois do ensaio. A faixa de cor de volume não alterou para antes e depois do ensaio, apresentando poros de até $6,44 \mathrm{~mm}^{3}$, mas com a maioria dos poros por volta de $0,9 \mathrm{~mm}^{3}$. Aparentemente o CP 8 apresenta menor quantidade de poros com volumes maiores, quando comparado com o corpo de prova 7 . 


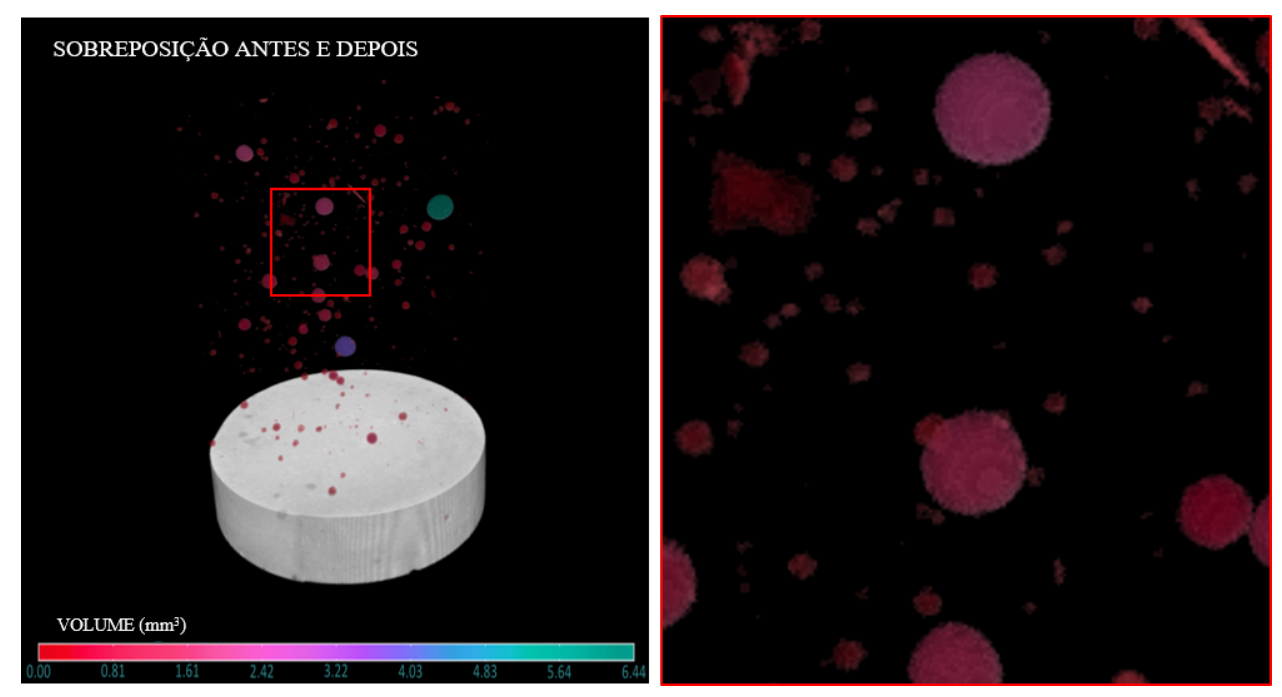

Figura 4.34: Sobreposição dos poros em 3D de antes e depois do ensaio de temperatura elevada de $200^{\circ} \mathrm{C}$.

A tabela 4.16 com os dados quantitativos obtidos do Dragonfly confirma o que é visto na figura 4.34. Apesar da porosidade ser similar para o CP 7 $(0,28 \%)$ e o CP $8(0,24 \%)$, o CP 8 apresenta menor quantidade de poros de volumes maiores. Isso é comprovado pelo volume médio de poros, que o CP 8 apresenta uma ordem de grandeza maior que a do CP 7. Essa diferença pode ter influenciado no fato de no CP 8 se ter observado menos fissuramento apesar de ter sido submetido a uma temperatura maior. Porém, seria necessário novos experimentos para afirmar essa analogia.

Tabela 4.16: Resultado quantitativo do corpo de prova submetido a $200^{\circ} \mathrm{C}$.

\begin{tabular}{lrr} 
& Antes & Depois \\
\hline Volume total $\left(\mathrm{mm}^{3}\right)$ & 19.077 & 18.938 \\
Volume de Poros $\left(\mathrm{mm}^{3}\right)$ & 46 & 46 \\
Fração de Poros $(\%)$ & 0,24 & 0,24 \\
Número de Poros & 592 & 612 \\
Volume Médio $\left(\mathrm{mm}^{3}\right)$ & 0,078 & 0,075
\end{tabular}

A esfericidade dos poros apresentados na figura 4.35 mostra que os poros estão mais esféricos do que os poros do $\mathrm{CP} 7$, com a maioria dos poros em torno de 0,75 . Isso também pode ter afetado no aparecimento de menos fissuras do CP 8 quando comparado com o CP 7. Novamente, novos estudos devem ser feito para afirmação disso. Uma constatação de todos os corpos de prova analisados foi de que os poros maiores tendem a ter maior esfericidade. Por isso, como o CP 8 apresentou maior volume médio de poro, a esfericidades desses foram maiores. 


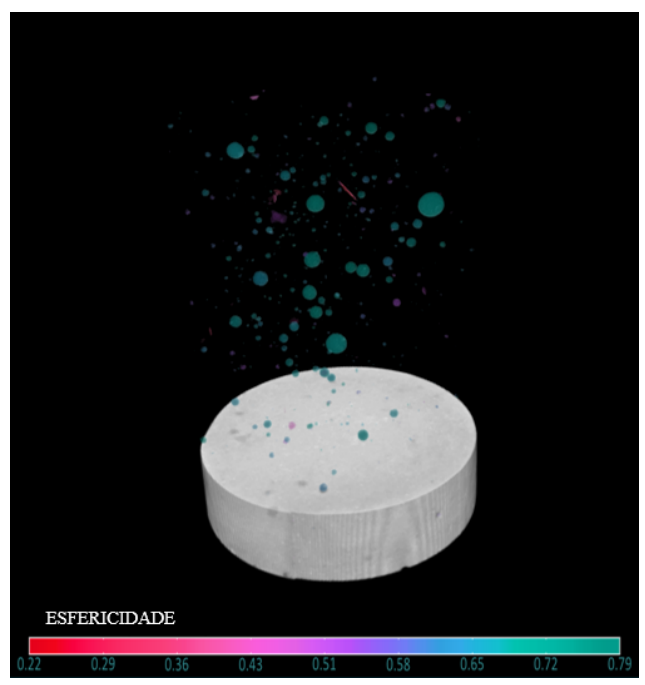

Figura 4.35: Esfericidade dos Poros em 3D depois do ensaio de temperatura elevada de $200^{\circ} \mathrm{C}$.

\subsubsection{3}

\section{CP $9-450^{\circ} \mathbf{C}$}

O corpo de prova submetido a $450^{\circ} \mathrm{C}$ apresentou fissuramento por todo o corpo de prova. Em sua superfície as fissuras são bastante visíveis, como mostra a figura 4.36 .
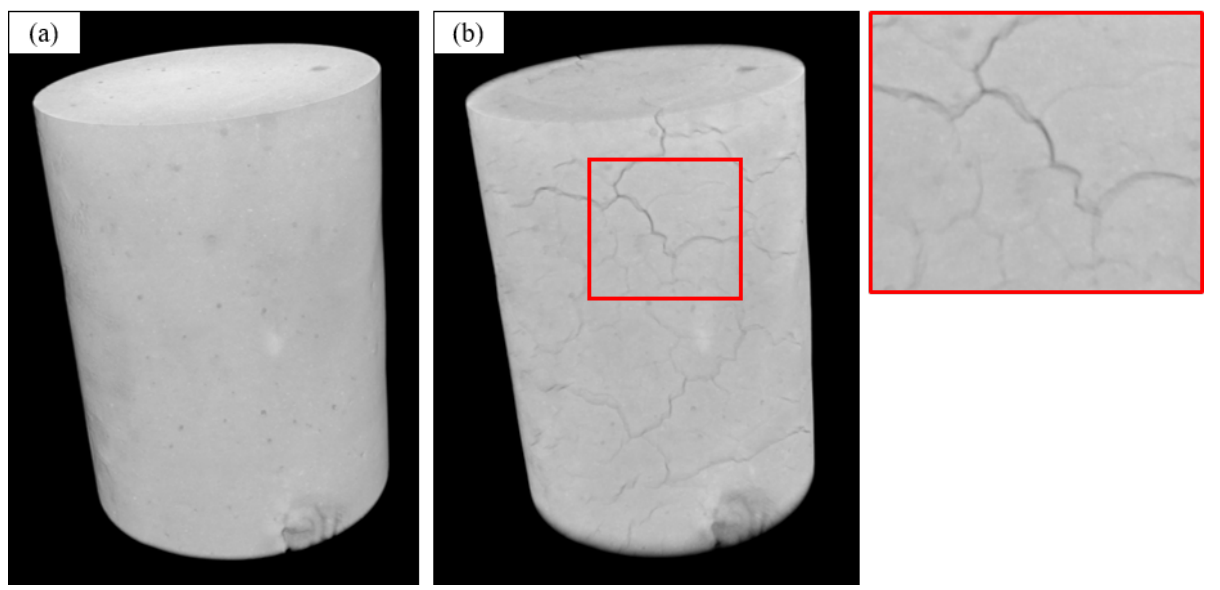

Figura 4.36: Superfície do corpo de prova: (a) antes do ensaio de temperatura elevada de $450^{\circ} \mathrm{C}$; (b) depois do ensaio. 
A segmentação de poros e fissuras das imagens do corpo de prova após ser submetida á $450^{\circ} \mathrm{C}$ teve que ser superdimensionada e utilizar o comando "close", como explicado nos procedimentos. Como o objetivo foi de comparar as imagem antes e depois, as imagens de antes também foram superdimensionadas, e para as duas o "threshod"utilizado foi de 190. O resultado da segmentação está na figura 4.37.
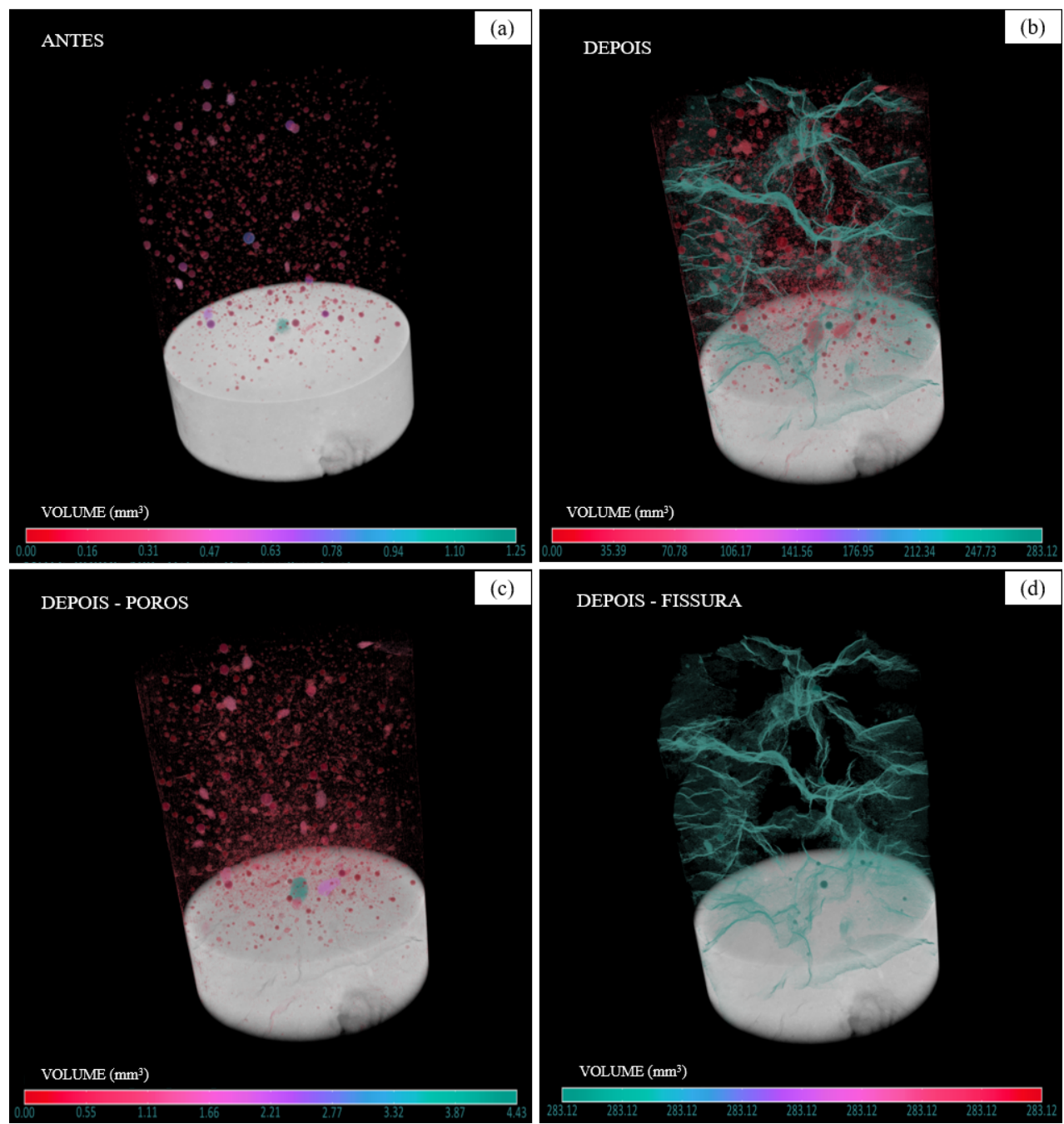

Figura 4.37: (a) Poros em 3D antes do ensaio de temperatura elevada de $450^{\circ} \mathrm{C}$; (b) Poros e fissura em 3D depois do ensaio; (c) Poros em 3D depois do ensaio; (d) Fissura em 3D depois do ensaio.

A figura 4.37 (a) mostra os poros antes do ensaio separados por cores de acordo com a faixa de volume, no qual o maior poro apresenta $1,25 \mathrm{~mm}^{3} \mathrm{e}$ a maioria deles está em torno de $0,20 \mathrm{~mm}^{3}$. A faixa de volume se assemelha mais com o CP 7 do que com o CP 8, mostrando tendência a poros menores. Já a figura 4.37 (b) apresenta os poros e a fissura após o ensaio. 
A fissura é apresentada como um único objeto de $283,12 \mathrm{~mm}^{3}$ e os poros estão variando até $4,43 \mathrm{~mm}^{3}$, como mostrado em (c) e (d) também na figura 4.37. Mais uma vez, como justificado para os corpos de prova 3 e 5,o histograma das imagens mudou provavelmente devido á deformação do CP (figura 4.38). Assim, apesar do aumento da faixa de volume na imagens (a) e (c) da figura 4.37 , isso não garante que aconteceu um aumento dos poros.
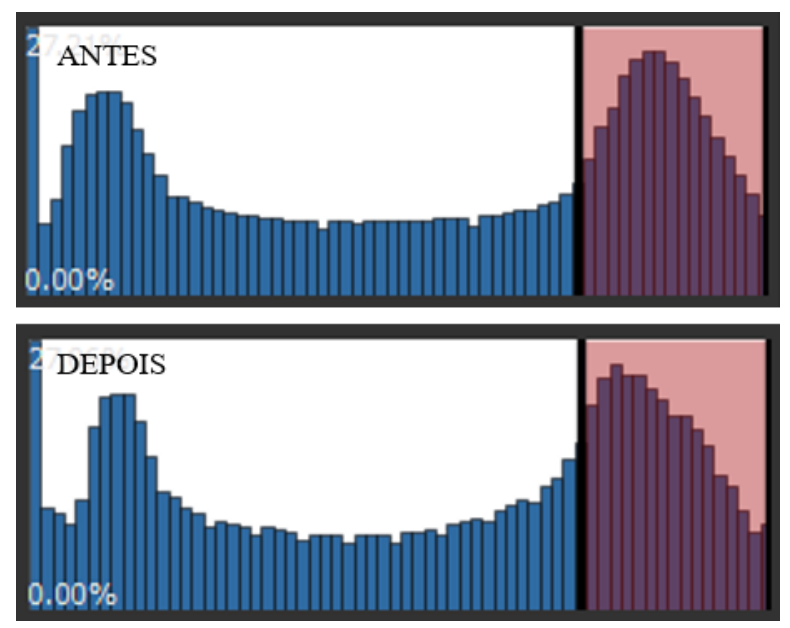

Figura 4.38: Histograma dos tons das imagens de antes e depois do ensaio de temperatura elevada de $450^{\circ} \mathrm{C}$.

Os dados quantitativos estão na tabela 4.17, com os volumes, frações e números de poros após eliminação de 9 voxels. A porosidade inicial está maior que nos CP 7 e 8 devido ao superdimensionamento do valor do "threshod". O aumento do número e volume de poros após o ensaio é devido à mudança no histograma, não podendo se afirmar que houve alteração na estrutura dos poros com o ensaio.

Tabela 4.17: Resultado quantitativo do corpo de prova submetido a $450^{\circ} \mathrm{C}$.

\begin{tabular}{lrr} 
& Antes & Depois \\
\hline Volume total $\left(\mathrm{mm}^{3}\right)$ & 17.911 & 17.303 \\
Volume de Poros $\left(\mathrm{mm}^{3}\right)$ & 67 & 191 \\
Fração de Poros $(\%)$ & 0,37 & 1,10 \\
Volume da fissura $\left(\mathrm{mm}^{3}\right)$ & - & 283 \\
Fração da fissura $(\%)$ & - & 1,64 \\
Número de Poros & 8.760 & 105.306
\end{tabular}


4.2.4.4

CP $10-650^{\circ} \mathrm{C}$

Quando a pasta de cimento classe $\mathrm{G}$ é submetida a $650^{\circ} \mathrm{C}$ por uma hora essa se desfaz completamente, como mostra a foto da figura 4.39. Por isso, a tomografia após o ensaio não foi possível ser realizada, assim como o ensaio de compressão citado anteriormente. Isso significa que com fissuramento causada por tensões térmicas quando submetido a $650^{\circ} \mathrm{C}$ e a degradação do $\mathrm{CaCO}_{3}$, comprovado pelos ensaios térmicos que ocorre a aproximadamente $650^{\circ} \mathrm{C}$, o material perde completamente suas propriedades mecânicas.

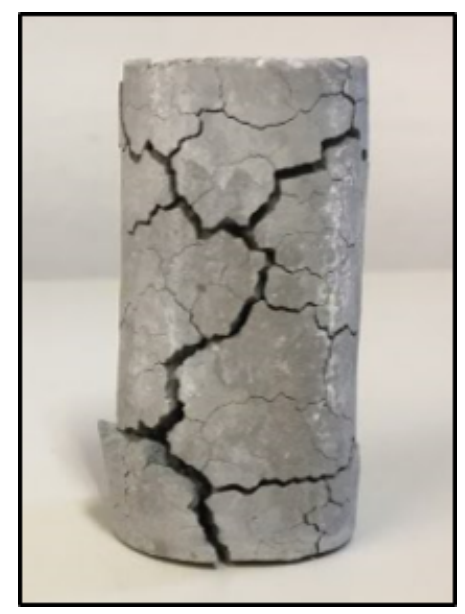

Figura 4.39: Corpo de prova após ser submetido a $650^{\circ} \mathrm{C}$. 


\section{5}

\section{Conclusões}

A rotina computacional desenvolvida foi bastante promissora para avaliar poros e fissuras em materiais cimentícios, em 3D, e esta metodologia pode ser aplicada a outros materiais com defeitos similares. A técnica da microCT foi eficiente para visualização de fissuras que surgiram nos corpos de provas durante os ensaios, sendo analisados qualitativa e quantitativamente. A porosidade inicial dos corpos de prova também foi medida de maneira efetiva. Porém, a técnica não foi sensível para identificar o crescimento ou não de poros durante o ensaio. A princípio, a ideia do valor médio de poro eliminaria a influência de fontes potenciais de incertezas durante a microCT. Porém, essas incertezas acarretaram em seleção ou não de poros pequenos e a influência de muitos poros pequenos mascara esse resultado de valor médio. A determinação de um valor arbitrário para excluir poros pequenos não trouxe resultados precisos, mas o fato foi que quanto mais poros pequenos eram eliminados, mais os valores médios de poros se aproximavam. Para corpos de prova que se deformaram durante o ensaio essa ideia foi ainda menos eficaz, uma vez que as imagens de antes e depois do ensaio passaram a apresentar histogramas um pouco diferentes.

Em relação aos ensaios realizados, conclui-se que para carregamento cíclico a pasta de cimento classe $G$ apresenta uma alta variação de comportamento quando submetida a esforços cíclicos, que está relacionada com a variação na estrutura interna. Portanto, cuidados na moldagem da estrutura e utilização de aditivos que diminuam a porosidade são alternativas para que a estrutura apresente menos defeitos iniciais e respondam positivamente quanto a esse tipo esforço. De qualquer forma, pode-se afirmar que esse material não se mantém estável com carregamento cíclico acima de $50 \%$ da $\sigma_{r}$. Já nos ensaios de temperaturas elevadas pode-se visualizar fissuras de origem térmica sendo formadas em pequena quantidade para temperaturas de $100^{\circ} \mathrm{C}$ e $200^{\circ} \mathrm{C}$ e em grande quantidade para temperatura de $450^{\circ} \mathrm{C}$. A desidroxilação do $\mathrm{Ca}(\mathrm{OH})_{2}$ e a degradação do $\mathrm{CaCO}_{3}$ causaram alta deterioração no material quando submetido a $650^{\circ} \mathrm{C}$. 


\section{6}

\section{Sugestão para Trabalhos Futuros}

Este trabalho mostrou que o carregamento cíclico de $30 \%$ da $\sigma_{r}$ é capaz de causar danos ao material estudado, porém essa influência ficou limitada a danos de $30 \mu \mathrm{m}$. É possível que uma melhor resolução revelasse maior quantidade de danos e, talvez, pudesse diferenciar danos para 500.000 e 1.000 .000 de ciclos.

Um ensaio de temperatura elevada a uma temperatura que ocorresse a total desidroxilação do $\mathrm{Ca}(\mathrm{OH})_{2}$ poderia mostrar o comportamento das fissuras quando esse evento ocorre, podendo ser comparado com as fissuras do corpo de prova submetido a $450^{\circ} \mathrm{C}$ (temperatura imediatamente antes do acontecimento da desidroxilação do $\left.\mathrm{Ca}(\mathrm{OH})_{2}\right)$.

Para corpos de prova que se deformam após o ensaio a ponto de influenciar significativamente no histograma da imagem, uma rotina de segmentação com variação do "threshold"poderia ser elaborada. Talvez, isso traria resultados positivos para confirmação sobre a alteração ou não da estrutura de poros.

Além disso uma maior representatividade seria desejável para confirmar os resultados deste trabalho, uma vez que foi realizado apenas um corpo de prova para cada sequência de microCT, ensaio, microCT. Isso confirmaria a influência dos defeitos iniciais com o comportamento do material para cada ensaio.

No mais, um trabalho que correlacionasse a porosidade inicial com a resistência à compressão do material cimentício utilizando a mesma rotina computacional desenvolvida seria bastante interessante. Pois diria sobre o comportamento do material a partir de sua porosidade, forma e distribuição dos poros. 


\section{Referências bibliográficas}

[1] PANG, X., DARBE, R., RAVI, K., MEYER, C. Low-cycle fatigue of oil well cements in compression. ACl Materials Journal, V.109 No.2:pp.185-194, 2012.

[2] RAJU, N.K. Comparative study of the fatigue behavior of concrete, mortar, and paste in uniaxial compression. $\mathrm{ACl}$ Journal, V.67 No.6:pp.461-463, 1970.

[3] ZHU, H., WU, Q., ZHANG, C., DENG, F. Thermal stability and structural characterization of class g oil well cement paste exposed to elevated temperature. Journal of Materials in Civil Engineering, V.27 No.11, 2015.

[4] JINGFU, Z., KAI, L., RUIXUE, H., BO, W., JINLONG., Y. Development and change of compressive strength for class $\mathrm{g}$ oil well cement under high temperature. Advanced Materials Research, V.941944:pp.1441-1444, 2014.

[5] MEHTA, P. K., MONTEIRO, P. J. M. Concrete Microstructure, Properties, and Materials. McGraw-Hill, USA, 3 edition, 2006.

[6] HEWLETT, P. Lea's Chemistry of Cement and Concrete. John Wiley\&Sons, England, 4 edition, 1997.

[7] LÉCOlier, E., RivereAu, A., LE SAUÔT, G., AudiBerT-HAYET, A. Durability of hardened portland cement paste used for oilwell cementing. Oil \& Gas Science and Technology, V.62 No.3:pp.335-345, 2007.

[8] FISHER, A. K., BULLEN, F., BEAL, D. The durability of cellulose fibre reinforced concrete pipes in sewage applications. Cement and Concrete Research, V.31 No.4:pp.543-553, 2001.

[9] BINICI, H., DURGUN, M. Y., RIZAOGLU, T., KOLUÇOLAK, M. Investigation of durability properties of concrete pipes incorporating blast furnace slag and ground basaltic pumice as fine aggregates. Scientia Iranica A, V.19 No.3:pp.366-372, 2012. 
[10] ROZIERE E., LOUKILI A., EL HACHEM R., GRONDIN F. Durability of concrete exposed to leaching and external sulphate attacks. Cement and Concrete Research, V.39 No.12:pp.1188-1198, 2009.

[11] MERIDA A., KHARCHI F. Pozzolan concrete durability on sulphate attack. Procedia Engineering, V. 114:pp.832-837, 2015.

[12] SUN, W., ZHANG, Y. M., YAN, H. D., MU, R. Damage and damage resistance of high strength concrete under the action of load and freeze-thaw cycles. Cement and Concrete Research, V.29 No.9:pp.15191523, 1999.

[13] JIANG, L., NIU, D., YUAN, L., FEI, Q. Durability of concrete under sulfate attack exposed to freeze-thaw cycles. Cold Regions Science and Technology, V.405-408:pp.2734-2738, 2013.

[14] ZIJL, G.P.A.G, BOSHOFF, W.P., WAGNER C., SLOWIK, V. A Framework for Durability Design with Strain-hardening Cement -Based Composites. Springer, USA, 2017.

[15] XIAO, J., LI, H., YANG, Z. Fatigue behavior of recycled aggregate concrete under compression and bending cyclic loadings. Construction and Building Materials, V.38:pp.681-688, 2013.

[16] JIANG, F.X., ZHAO, T.J., HAO, M.L. Influence of uniaxial tensile cyclic load on the porosity of high performance concrete. Applied Mechanics and Materials, V.94-96:pp.1500-1504, 2011.

[17] BRAZ, D., LOPES, R.T., MOTTA, L.M.G. Research on fatigue cracking growth parameters in asphaltic mixtures using computed tomography. Nuclear Instruments and Methods in Physics Research B, V.213:pp.498-502, 2004.

[18] KIM, K.Y., YUN, T.S., PARK, K.P. Evaluation of pore structures and cracking in cement paste exposed to elevated temperatures by $\mathrm{x}$ ray computed tomography. Cement and Concrete Research, V.50:pp.3440, 2013.

[19] LU, S., LANDIS, E.N., KEANE, D.T. X-ray microtomographic studies of pore structure and permeability in portland cement concrete. Materials and Structures, V.39:pp.611-620, 2006.

[20] NAIK, N.N., JUPE, A.C., STOCK, S.R., WILKINSON, A.P., LEE, P.L., KURTIS K.E. Sulfate attack monitored by microct and edxrd: 
Influence of cement type, water-to-cement ratio, and aggregate. Cement and Concrete Research, V.36:pp.144-159, 2006.

[21] JUNG, J., HAMACHI, M., OBARA, Y., TANIKURA, I., WATANABE, S. Analysis of damage in specimen under cyclic uniaxial loading test by x-ray ct metho. Rock Mechanics for Global Issues, p. pp.365371,2014

[22] SILVA, C.B.L. Efeito de rochas salinas na hidratação e comportamento mecânico de pastas cimentícias para poços de petróleo. Dissertação de Mestrado, PUC, Rio de Janeiro, 2016.

[23] ABNT/CB-018 CIMENTO, CONCRETO E AGREGADOS. Concreto Procedimento para moldagem e cura de corpos de prova. Associação Brasileira de Normas Técnicas, Rio de Janeiro, 2016.

[24] ZEISS. XRM Flat Panel User's Guide. Carl Zeiss X-ray Microscopy, Pleasanton, USA, 2015.

[25] PlesSIS, A., OLAWUYI, B.J., BOSHOFF, W.P., ROUX, G. Simple and fast porosity analysis of concrete using x-ray computed tomography. Materials and Structures, V.49:pp.553-562, 2016. 